\title{
Epinephrine Responsiveness is Reduced in Livers from Trained Mice
}

\author{
by \\ Hana Aishe Dibe \\ A Thesis \\ presented to \\ The University of Guelph \\ In partial fulfilment of requirements \\ for the degree of \\ Master of Science \\ in \\ Human Health and Nutritional Sciences
}

Guelph, Ontario, Canada

(C) Hana A. Dibe, April 2020 


\begin{abstract}
EPINEPHRINE RESPONSIVENESS IS REDUCED IN LIVERS FROM TRAINED MICE
\end{abstract}

Hana A. Dibe

University of Guelph, 2020
Advisor:

Dr. David C. Wright

The purpose of this thesis was to determine if exercise training could alter the liver's response to epinephrine. We hypothesized that training would reduce the response to an epinephrine challenge in vivo as demonstrated by a blunted rise in blood glucose, an attenuated reduction in glycogen and an abrogated induction of PKA responsive genes. To examine this, male C57BL/6 mice were exercise trained through VWR or remained sedentary for 12 days, then subjected to an intraperitoneal epinephrine or vehicle challenge. Trained mice had a blunted rise in glucose 15 minutes post-epinephrine injection and a decreased reduction in liver glycogen compared to sedentary mice. This was followed by similar changes in protein content/phosphorylation and gene expression for enzymes involved in the $\beta$-adrenergic signalling pathway. Together our data suggest that prior exercise training reduces the liver's response to epinephrine. This could be beneficial in the context of glycogen sparing during exercise. 


\section{ACKNOWLEDGEMENTS}

First and foremost, my sincere thanks to my advisor Dr. David Wright for his support and guidance during my Master's degree. I could not have succeeded without your encouragement and belief in my ability to do research. I am so thankful to have had such a patient, intelligent, and motivating mentor.

To Dr. Lindsay Robinson and Dr. David Dyck thank you for taking the time to be on my examination committee. I really appreciate your feedback and contribution to my thesis as well as your engaging questions during the defence.

To the past and current Wright Lab members, thank you for making the lab an exciting environment to work in every day. It was truly an honour to work alongside such a bright group of individuals. To have you guys around to learn from and answer all of my (mostly mundane) questions was more than I could have asked for. I will continue to strive for your level of dedication and work ethic. I look forward to seeing what future endeavors you all will go on to achieve- I'm confident I'll see you in professorial roles one day!

To my friends in HHNS, thank you for being an open, caring, hilarious, and a supportive group of people to go through graduate school with. Thank you for countering my self-doubt on a daily basis and always making coming into ANNU something to look forward to. I will truly miss my Branion snack breaks, watering-my-plant visits, and our regular departmental gatherings.

I would also like to thank Diana, Andy, and the A-team. I could not have completed my experiments and degree without your attentiveness and assistance.

Lastly, a special thanks to the Dibe family and friends at home for providing me with endless support and love throughout my academic endeavors. Now onto the next! 


\section{TABLE OF CONTENTS}

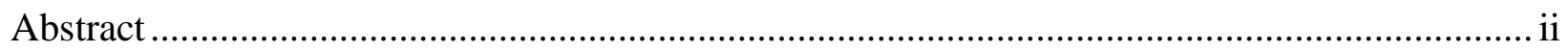

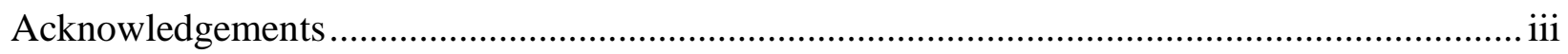

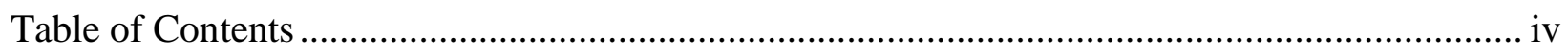

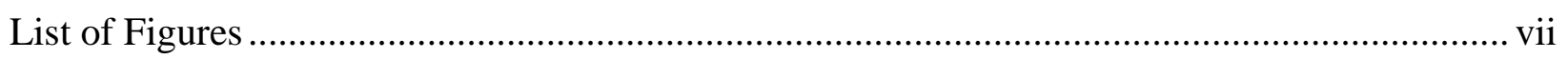

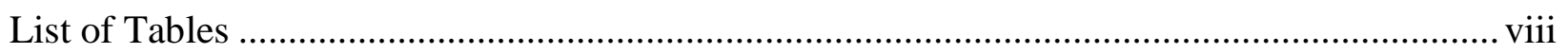

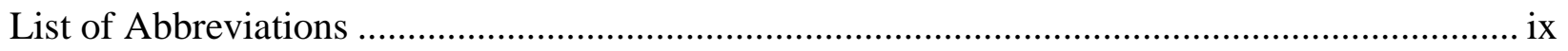

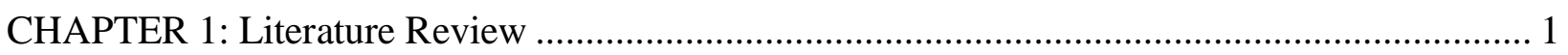

1.1 Catecholamine regulation of fuel mobilization............................................................... 1

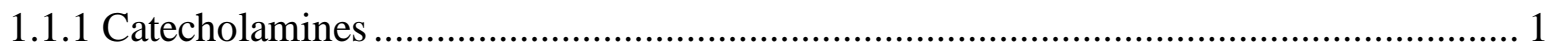

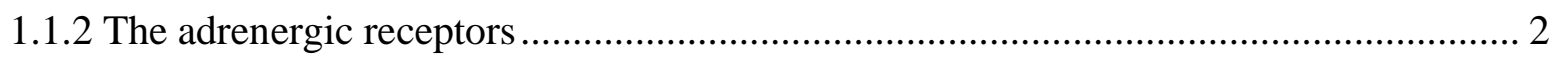

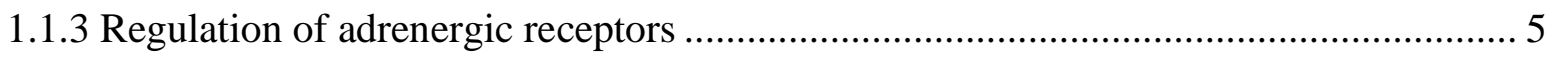

1.1.4 Tissue specific effects of catecholamines ................................................................ 6

1.1.5 Negative regulators of catecholamine signalling ........................................................ 10

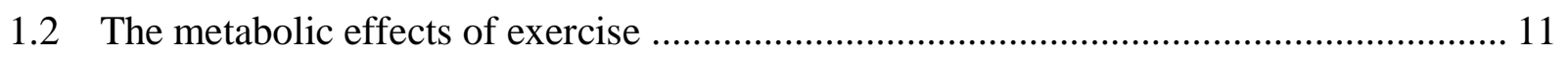

1.2.1 Rodent models of exercise training ............................................................................... 11

1.2.2 Acute effects of exercise ........................................................................................ 12

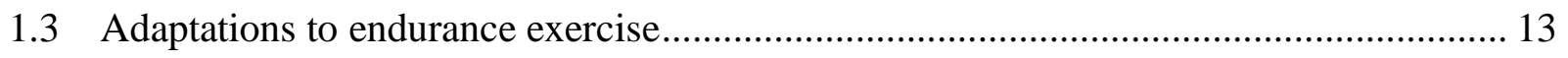

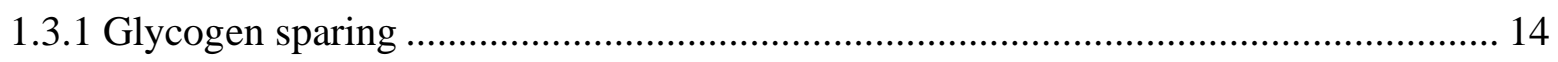

1.3.2 Effects of endurance exercise on skeletal muscle metabolism ................................. 15

1.3.3 Hormonal adaptations to endurance exercise …………………............................. 15

1.3.4 Training induced changes in the adrenergic responsiveness to catecholamines .......... 17

1.3.5 Exercise-mediated regulation of adrenergic receptors ................................................. 19

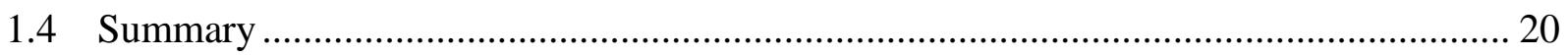

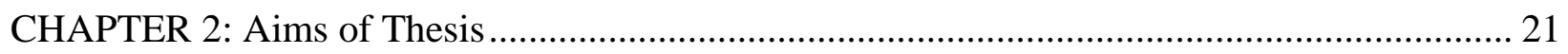

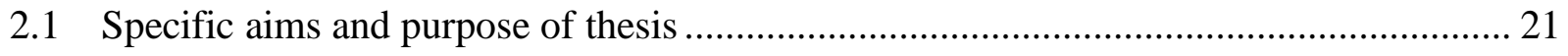

CHAPTER 3: Epinephrine Responsiveness is Reduced in Livers from Trained Mice ................. 22 


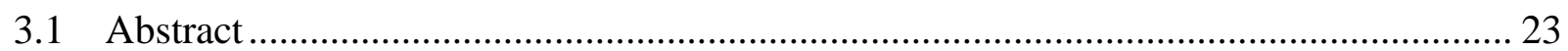

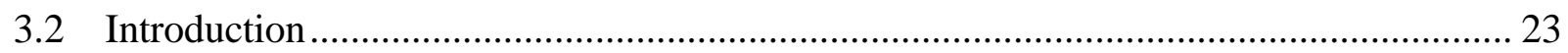

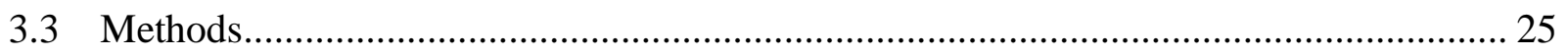

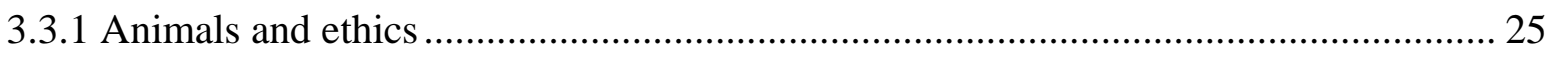

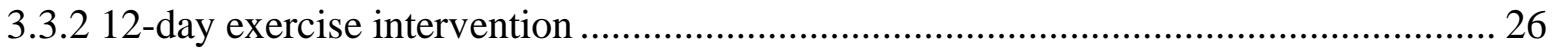

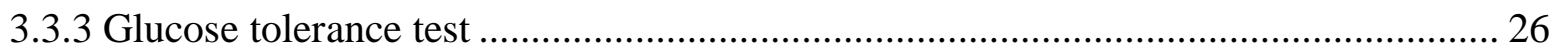

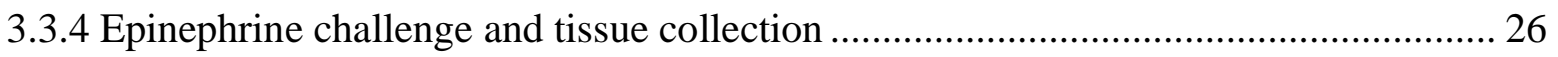

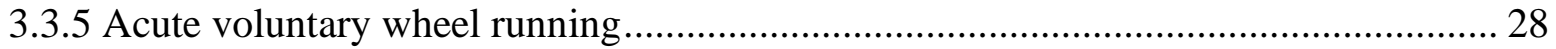

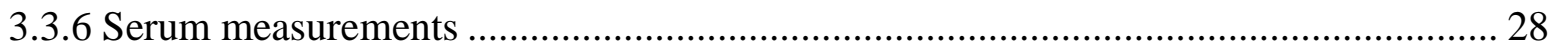

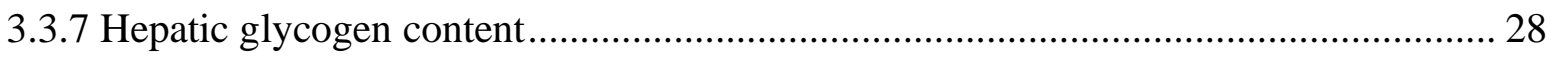

3.3.8 Western blotting ............................................................................................... 29

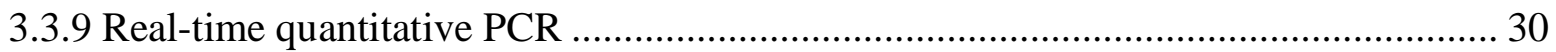

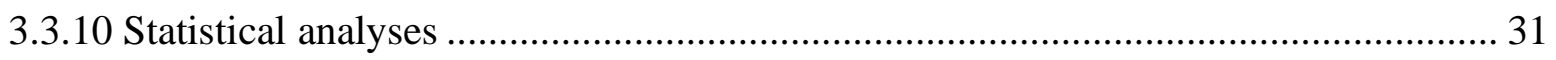

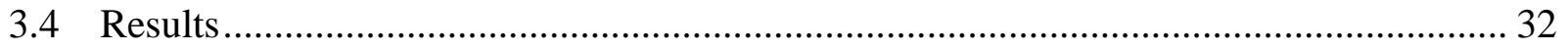

3.4.1 12 days of VWR exercise training attenuates weight gain despite similar food intake32

3.4.2 Exercise training attenuates the increase in blood glucose in response to epinephrine33

3.4.3 Exercise training does not impact the effect of epinephrine on circulating markers of

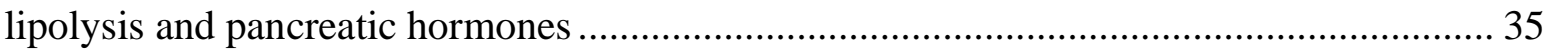

3.4.4 Exercise training reduces epinephrine-induced increases in gluconeogenic gene

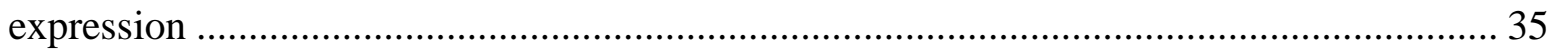

3.4.5 Epinephrine alters mRNA expression of $\alpha$ - and $\beta$ - adrenergic receptors .................... 38

3.4.6 Epinephrine activates PKA and reduces insulin signaling in the liver from both

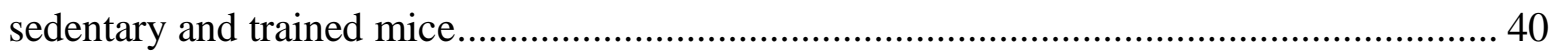

3.4.7 PDE3B and PDE4B in liver are increased with exercise training ............................. 42

3.4.8 Acute VWR does not induce liver epinephrine resistance............................................. 44

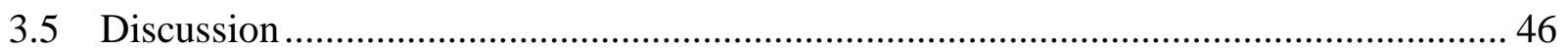

CHAPTER 4: Additional results and extended discussion......................................................... 51

4.1 Treadmill exercise test in sedentary and trained mice ……............................................ 51

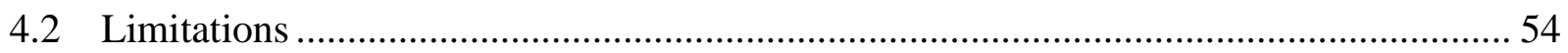




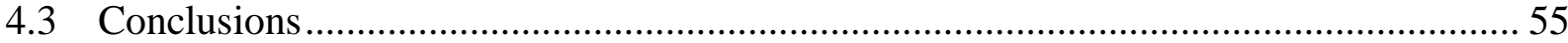




\section{LIST OF FIGURES}

Figure 1.1 Schematic diagram of select adrenergic receptor signalling pathways...................... 4

Figure 3.112 days of voluntary wheel running attenuated weight gain despite similar food intake and increased markers of mitochondrial content in triceps muscles.

Figure 3.2 The acute blood glucose response to an epinephrine injection is blunted by exercise

training

Figure 3.3 Circulating metabolites and glucoregulatory hormones are altered in response to an

acute epinephrine injection. 36

Figure 3.4 Hepatic gene expression and protein content of gluconeogenic markers

Figure 3.5 Epinephrine increases gene expression of adrenergic receptors in the liver.

Figure 3.6 Epinephrine activates PKA and reduces markers of insulin signaling in the livers of SED and TR mice.

Figure 3.7 Changes in cAMP-degrading enzyme phosphodiesterase $3 \mathrm{~B}$ and $4 \mathrm{~B}$ do not account

for altered glucose responses between SED and TR mice.

Figure 3.8 Acute VWR does not change the metabolic response to epinephrine.

Figure 4.1 VWR training does not protect against hepatic glycogen depletion in a 2-hour treadmill exercise test. 


\section{LIST OF TABLES}

Table 1.1 Summary of adrenergic receptor subtypes and functions ........................................ 2

Table 3.1 Blood glucose 15 minutes after epinephrine injection of varying doses ................... 27

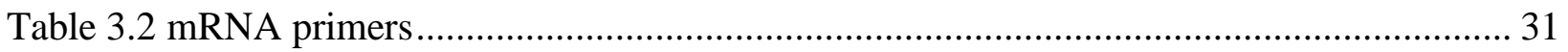




\section{LIST OF ABBREVIATIONS}

$\mathrm{AC}$

adenylyl cyclase

ACC acetyl-CoA carboxylase

AKT protein kinase B

AMPK 5'AMP-activated protein kinase

AMP adenosine monophosphate

ATGL adipose triglyceride lipase

ATP adenosine triphosphate

cAMP 3', 5' -cyclic AMP

CORE-1 ubiquinol-cytochrome $\mathrm{C}$ reductase core protein 1

COXIV cytochrome C oxidase subunit IV

DAG diacylglycerol

EPAC exchange protein directly activated by cAMP

EPI epinephrine

EX exercise

FFA free fatty acids

FOXO1 forkhead box protein $\mathrm{O} 1$

G6Pase glucose-6-phosphatase

GLUT2 glucose transporter isoform 2

GPCR G-protein coupled receptor

GTT glucose tolerance test 


$\begin{array}{ll}\text { HGP } & \text { hepatic glucose production } \\ \text { HKII } & \text { hexokinase II } \\ \text { HSL } & \text { hormone sensitive lipase } \\ \text { IRS 1 } & \text { insulin receptor substrate 1 } \\ \text { IRS 2 } & \text { insulin receptor substrate 2 } \\ \text { IP3 } & \text { inositol triphosphate } \\ \text { MAG } & \text { monoacylglyceride } \\ \text { MAPK } & \text { mitogen-activated protein kinase } \\ \text { MEK } & \text { mitogen-activated protein kinase kinase } \\ \text { MGL } & \text { monoacylglycerol lipase } \\ \text { NEFA } & \text { non-esterified fatty acid } \\ \text { PDE } & \text { phosphodiesterase } \\ \text { PDE3B } & \text { phosphodiesterase 3B } \\ \text { PDE4B } & \text { phosphodiesterase 4B } \\ \text { PEPCK } & \text { phosphoenolpyruvate carboxykinase } \\ \text { PGC-1a } & \text { peroxisome proliferator-activated receptor gamma coactivator 1-alpha } \\ \text { PI3K } & \text { phosphatidylinositol 3-kinase } \\ \text { PIP2 } & \text { phosphatidylinositol 4,5-biphosphate } \\ \text { PIP3 } & \text { phosphatidylinositol 3,4,5-triphosphate } \\ \text { PKA } & \text { protein kinase A } \\ \text { PKC } & \text { protein kinase C } \\ \text { PLC } & \text { phospholipase C } \\ \text { SED } & \text { sedentary } \\ \text { Hol }\end{array}$


SH2 Src-homology 2

SNS sympathetic nervous system

TAG triacylglyceride

CRTC2 CREB-regulated transcriptional coactivator 2

TR trained

VEH vehicle

VLDL very low-density lipoproteins

VWR voluntary wheel running 


\section{CHAPTER 1: Literature Review}

\subsection{Catecholamine regulation of fuel mobilization}

\subsubsection{Catecholamines}

Catecholamines play a major role in modulating the body's physiological response to stress when the sympathetic nervous system (SNS) is activated. They coordinate the adaptive responses to external stressors such as exercise, heat or cold exposure, and hypoxia, as well as psychological stressors such as anxiety, anger, or fear (Chin et al., 1973; Dimsdale \& Moss, 1980; Koh et al., 2007; Ward et al., 1983). The three main catecholamines are dopamine, norepinephrine, and epinephrine, all synthesized from the amino acid tyrosine (Goldstein, 2010). Norepinephrine is produced from post-ganglionic neurons of the SNS and the chromaffin cells of the adrenal medulla, epinephrine is produced from the adrenal medulla, and dopamine is produced in the post-ganglionic neurons of the SNS and in the kidneys (de Leeuw et al., 1978; Goldstein et al., 1983; Marley \& Livett, 1987; Morrison \& Cao, 2000; Silverberg et al., 1978). Norepinephrine and dopamine function as both neurotransmitters and hormones, while epinephrine functions in an endocrine manner. Research has demonstrated that epinephrine is a stronger stimulator of metabolic perturbations than norepinephrine, causing more robust spikes in glucose production (Bearn et al., 1951; Ensinger et al., 2002; Fernqvist-Forbes et al., 1997; McGuinness et al., 1997). The liver clears roughly 75-80\% of catecholamines upon first-pass metabolism, reducing the amount that reaches circulation and peripheral tissues (Sokal \& Sarcione, 1959). Exercise is a potent activator of the SNS's "fight or flight" response, causing increases in the secretion of norepinephrine and epinephrine which help coordinate the quick mobilization of fuel and substrate delivery to working muscles (Kjær et al., 1987). These 
responses include increases in heart rate, adipose tissue lipolysis, liver glucose production, and skeletal muscle glycogen breakdown.

\subsubsection{The adrenergic receptors}

Norepinephrine and epinephrine bind to the ubiquitously expressed adrenergic receptors. Adrenergic receptors are part of the large family of G-protein coupled receptors (GPCR). Activation of GPCR leads to conformational changes that activate their coupled Gproteins through the exchange of GDP for GTP in the alpha subunit (Perez, 2005). G-proteins are heterotrimeric proteins containing an $\alpha, \beta$, and $\gamma$ subunit. The alpha subunit is further classified into four subgroups $\alpha_{\mathrm{s}}, \alpha_{\mathrm{i}}, \alpha_{\mathrm{q}}$, and $\alpha_{\mathrm{o}}$. Active G-proteins modulate the activity of nearby effector molecules such as adenylyl cyclase (AC) or phospholipase C (PLC), which subsequently regulate second messengers involved in various signal transduction pathways. The receptors are expressed in multiple organs in the body, with varying tissue-specificity across subtypes (Table

1) (Yumiko Kawai et al., 1986). The adrenergic receptor family includes two $\alpha\left(\alpha_{1}, \alpha_{2}\right)$ and three $\beta\left(\beta_{1}, \beta_{2}, \beta_{3}\right)$ receptors (Table 1) (Arner et al., 1990; Bylund, 1992; Nantel et al., 1995). The alpha receptors have been further classified through numerous radioligand binding studies and include three $\alpha_{1}\left(\alpha_{1 \mathrm{~A}}, \alpha_{1 \mathrm{~B}}, \alpha_{1 \mathrm{D}}\right)$ and three $\alpha_{2}\left(\alpha_{2 \mathrm{~A}}, \alpha_{2 \mathrm{~B}}, \alpha_{2 \mathrm{C}}\right)$ receptor subtypes.

Table 1.1 Summary of adrenergic receptor subtypes and functions

\begin{tabular}{|l|l|l|}
\hline Receptor & Location & General Function \\
\hline $\boldsymbol{\alpha 1}$ & $\begin{array}{l}\text { Heart } \\
\text { Vascular Smooth Muscle }\end{array}$ & $\begin{array}{l}\text { Increases contractility } \\
\text { Vasoconstriction }\end{array}$ \\
\hline $\boldsymbol{\alpha 2}$ & $\begin{array}{l}\text { Adipose Tissue } \\
\text { Pancreas } \\
\text { Vascular Smooth Muscle }\end{array}$ & $\begin{array}{l}\text { Inhibits lipolysis } \\
\text { Inhibits insulin and stimulates glucagon release } \\
\text { Vasoconstriction }\end{array}$ \\
\hline $\boldsymbol{\beta 1}$ & $\begin{array}{l}\text { Heart } \\
\text { Liver }\end{array}$ & $\begin{array}{l}\text { Increases heart rate and force of contraction } \\
\text { Activates gluconeogenesis and glycogenolysis }\end{array}$ \\
\hline $\mathbf{\beta 2}$ & Heart & $\begin{array}{l}\text { Increases contractility } \\
\text { Activates gluconeogenesis and glycogenolysis }\end{array}$ \\
\hline
\end{tabular}




\begin{tabular}{|l|l|l|}
\hline & $\begin{array}{l}\text { Skeletal Muscle } \\
\text { Smooth Muscle }\end{array}$ & $\begin{array}{l}\text { Increases glycogenolysis } \\
\text { Relaxation }\end{array}$ \\
\hline $\mathbf{\beta 3}$ & Adipose tissue & $\begin{array}{l}\text { Activates lipolysis } \\
\text { Vasodilation }\end{array}$ \\
\hline
\end{tabular}

(Perez, 2005)

The $\alpha_{1}$ adrenergic receptors are coupled to the $\mathrm{G}_{q}$ alpha subunit $\left(\alpha_{\mathrm{q}}\right)$; activation of all three $\alpha_{1}$ subtypes causes phosphatidylinositol 4,5-bisphosphate ( $\left.\mathrm{PIP}_{2}\right)$ hydrolysis by PLC which elicits calcium mobilization (Cotecchia, 2010). Activation of the $\alpha_{2}$ adrenergic receptor results in inhibition of $\mathrm{AC}$ and a subsequent decrease in intracellular 3', 5' -cyclic adenosine monophosphate (cAMP) via the inhibitory $\mathrm{Gi}_{\mathrm{i}}$ alpha protein $\left(\alpha_{\mathrm{i}}\right)$. This results in a reduction of protein kinase A (PKA) dependent pathways such as lipolysis and glycogenolysis. Activation of the $\alpha_{2}$ receptor can trigger calcium mobilization through activation of the $\mathrm{Gi}_{\mathrm{i}}$ alpha protein $\left(\alpha_{\mathrm{i}}\right)$ and PIP2 hydrolysis by PLC, similarly to the $\alpha_{1}$ receptor (Tian et al., 1994). In the pancreas this can inhibit insulin release and increase glucagon secretion (Gromada et al., 1997; Hamilton et al., 2018; Hirose et al., 1992). 


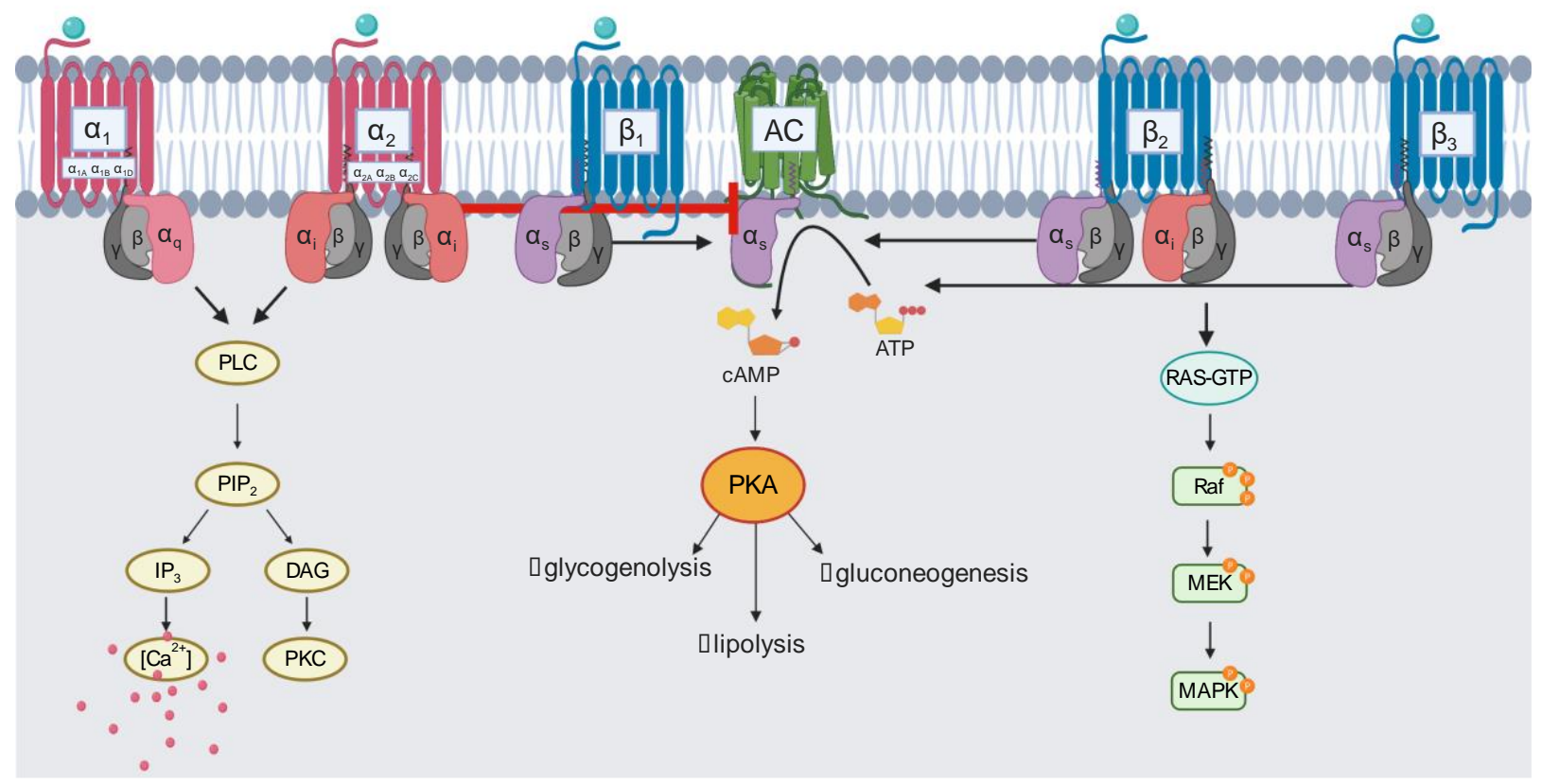

Figure 1.1 Schematic diagram of select adrenergic receptor signalling pathways. Ligand binding to the adrenergic receptors initiates conformational changes in the receptor that triggers the interaction between the receptor and its coupled G-protein. The G-protein stimulatory alpha subunit $\left(\alpha_{s}\right)$ and inhibitory $\left(\alpha_{i}\right)$ subunit regulate the activity of adenylyl cyclase, a key effector enzyme involved in cAMP production; $\alpha$ s activates, while $\alpha_{i}$ inhibits adenylyl cyclase. cAMP activates PKA, leading to increases in glycogenolysis, lipolysis and gluconeogenesis. The $\alpha_{q}$ and $\alpha_{i}$ subgroups activate PLC increasing PIP2 hydrolysis to diacylglycerol (DAG) and inositol trisphosphate $\left(\mathrm{IP}_{3}\right) . \mathrm{IP}_{3}$ results in calcium release from intracellular stores. The $\alpha_{i}$-mediated pathway can also lead to MAPK activation by the $\beta_{2}$ adrenergic receptor. Receptors can be coupled to multiple G-proteins and switch between G-proteins depending on the tissue and ligand. ATP, adenosine triphosphate; cAMP, cyclic adenosine monophosphate; DAG, diacylglycerol; MAPK, mitogen-activated protein kinase; IP3, inositol triphosphate; MEK mitogen-activated protein kinase kinase; NOS, nitric oxide synthase; PIP2, phosphatidylinositol 4,5-bisphosphate; PKA, protein kinase A; PLC, phospholipase C; PKC, protein kinase C. Note: Figure was created with BioRender.com. 
The $\beta$-adrenergic receptors are primarily coupled to the $\mathrm{G}$ stimulatory alpha subunit $\left(\alpha_{\mathrm{s}}\right)$ which results in adenylyl cyclase activation. Adenylyl cyclase propagates the signal downstream through the production of cAMP, which subsequently activates PKA. As mentioned, PKA can phosphorylate numerous enzymes and regulate a variety of metabolic pathways throughout the body including gluconeogenesis, glycogenolysis, and lipolysis. A more detailed explanation of these processes will be given later in this review.

\subsubsection{Regulation of adrenergic receptors}

As with all GPCR, adrenergic receptors can undergo three regulatory processes, desensitization, internalization, and downregulation (Cotecchia, 2010; Perez, 2005).

Desensitization is described as a reduction in the receptor response following continuous agonist exposure and is characterized by the uncoupling of the receptor to its G-protein (Daaka et al., 1997; Hausdorff et al., 1990). The mechanisms behind desensitization are not fully elucidated but involves receptor phosphorylation and interactions with $\beta$-arrestins which interfere with coupling of the receptor to its G-protein (Luttrell \& Lefkowitz, 2002). Internalization is the process by which receptors are sequestered away from the cell membrane where they can be degraded in lysosomes or recycled back to the cell membrane (Luttrell \& Lefkowitz, 2002). Desensitization can occur rapidly within seconds to minutes, while internalization is often a slower process (minutes to hours) (Luttrell \& Lefkowitz, 2002). Downregulation is a more permanent process, where the total number of receptors in the cell is decreased. Downregulation can occur from a decrease in receptor synthesis, increase in receptor degradation, or destabilization of the receptor mRNA (Bouvier et al., 1989; Perez, 2005). 


\subsubsection{Tissue specific effects of catecholamines}

Human studies investigating the metabolic effects of catecholamines have found that epinephrine plays a larger role in the metabolic effects of fuel mobilization than norepinephrine (gluconeogenesis, glycogenolysis, increases in glucagon, lipolysis) (Bearn et al., 1951; Connolly et al., 1991; Ensinger et al., 2002; Fröberg et al., 1975; McGuinness et al., 1997). These effects are attributable to epinephrine's greater affinity to bind at the $\beta$-adrenergic receptors (Hoffman \& Lefkowitz, 1980). For the purpose of this thesis, emphasis will be placed on the metabolic effects of epinephrine due to its central role in stimulating glucose output (Bearn et al., 1951; McGuinness et al., 1997).

Skeletal Muscle. Skeletal muscle holds a considerable reservoir of fuel stored in the form of glycogen, protein, and fat. Epinephrine coordinates many of the substrate mobilizing effects of exercise through glycogenolysis and lipolysis. Glycogenolysis, the process whereby glycogen is broken down to glucose for energy, is activated through PKA. PKA subsequently phosphorylates phosphorylase kinase which in turn activates glycogen phosphorylase, while simultaneously inactivating glycogen synthase (Jensen et al., 2007; Johanns et al., 2016). Glycogen phosphorylase catalyzes the rate limiting step in glycogenolysis by cleaving glucose-1-phosphate from the terminal glycosidic bond. Glycogen phosphorylase and glycogen synthase are dependently regulated through phosphorylation, which is largely controlled by glycogen synthase kinase 3 (GSK3 $\beta$ ), PKA signalling, and insulin (Rui, 2014). Active GSK3 $\beta$ phosphorylates and inactivates glycogen synthase, thus reducing glycogenesis, while insulininduced phosphorylation of GSK3 $\beta$ prevents glycogen synthase phosphorylation, promoting glycogenesis. Skeletal muscle lipolysis is induced through $\beta$-adrenergic activation of PKA to breakdown triacylglycerides (TAGs) to free fatty acids (FFAs) and glycerol. TAGs are 
sequentially hydrolyzed to diacylglycerides (DAGs) and monoacylglycerides (MAGs) by the enzymes adipose triglyceride lipase (ATGL), hormone sensitive lipase (HSL), and monoacylglycerol lipase (MGL), respectively (Peters et al., 1998). The contractile properties of skeletal muscle are also altered by catecholamines, with activation of $\beta$-adrenergic receptors potentiating muscle contractility and force (Hostrup et al., 2014).

Liver. The liver contains an abundance of fuel stored as glycogen and TAGs that can be rapidly mobilized with catecholamine stimulation. Similar to skeletal muscle, catecholamines induce glycogen breakdown through PKA phosphorylation and activation of glycogen phosphorylase. During exercise, epinephrine and glucagon-induced increases in PKA coordinate the initiation of glycogen breakdown (Berg et al., 2002; Cherrington \& Exton, 1976; Cohen, 2002). Catecholamines also induce lipolysis within the liver; the mobilized FFAs can be transported to the mitochondrial for $\beta$-oxidation or packaged into VLDL and secreted into the circulation. Glycerol can be metabolized to dihydroxyacetone phosphate (DHAP) to be used in gluconeogenesis. Glycerol can also be metabolized to various intermediates of the tricarboxylic acid cycle (Ross et al., 1967). Gluconeogenesis is the process by which glucose is produced from non-carbohydrate substrates, such as lactate, pyruvate, alanine, amino acids, or glycerol. Catecholamines induce gluconeogenesis through PKA-induced activation of numerous genes, including glucose-6-phosphatase (G6pc) and phosphoenolpyruvate carboxykinase (Pepck) (Xie et al., 2018). Phosphoenolpyruvate carboxykinase (PEPCK) and glucose-6-phosphatase (G6Pase) are two key gluconeogenic enzymes which are predominantly regulated at the transcriptional level (Puigserver et al., 2003). PEPCK catalyses the conversion of oxaloacetate to phosphoenolpyruvate, which is subsequently broken down to fructose-6-phosphate and then glucose-6-phosphate. Once transported into the endoplasmic reticulum, G6Pase catalyzes the 
dephosphorylation of G6P to produce glucose. Glucose is exported from the liver by facilitated diffusion through the GLUT2 (and GLUT1) glucose transporters (Seyer et al., 2013).

Epinephrine also stimulates the uptake of gluconeogenic precursors (Exton et al., 1966; Exton \& Park, 1967; Iles et al., 1981; Issekutz \& Allen, 1972; Ochs \& Lardy, 1983). In situ studies in perfused rat livers demonstrate increased rates of lactate uptake and glucose production with increasing concentrations of epinephrine (Exton et al., 1966; Exton \& Park, 1967). In a study by Sacca et al., subjects were infused with epinephrine and radiolabeled alanine for 90 minutes to measure the role of gluconeogenesis in epinephrine-induced hepatic glucose output. Epinephrine increased the rates of splanchnic lactate, glycerol, and alanine uptake, as well as circulating blood levels of lactate and glycerol during the infusion period (L. Sacca et al., 1983).

Adipose tissue. In adipose tissue, catecholamines induce PKA activity through $\beta$-adrenergic receptor activation. This stimulates lipolysis through PKA-mediated phosphorylation and activation of HSL (Anthonsen et al., 1998; Strålfors et al., 1984). Catecholamines also act through the $\alpha_{2}$ adrenergic receptors in adipose tissue, which inhibit adenylyl cyclase activity and thus have anti-lipolytic effects. The ratio of $\alpha_{2} / \beta$ receptors in adipose tissue depots can dictate the net effect of catecholamines on lipid metabolism. In obese animals and humans there is an increase in the ratio of $\alpha_{2} / \beta$-adrenergic receptors, potentially contributing to the reduced catecholamine-induced lipolytic response in obesity (Carpene et al., 1983, 1990; Reynisdottir et al., 1994; Valet et al., 2000).

Pancreas. In the pancreas, epinephrine stimulates glucagon secretion from the $\alpha$-cells of the pancreas and inhibits insulin release from $\beta$-cells (Gromada et al., 1997; Hamilton et al., 2018; Peterhoff et al., 2003). Epinephrine binds at $\beta$-adrenergic receptors on pancreatic $\alpha$-cells to 
activate PKA and EPAC2 (exchange protein directly activated by cAMP) (Hamilton et al., 2018). Together, PKA and EPAC signalling pathways converge to increase intracellular calcium into the cytosol, through opening of voltage-gated $\mathrm{Ca}_{2}+$ channels, resulting in $\mathrm{Ca}_{2}+$ dependent glucagon secretion (Gromada et al., 1997; Hamilton et al., 2018). Similar to glucagon, insulin secretion is triggered by elevations in cytosolic calcium, however, insulin secretion is inhibited by the actions of epinephrine at the $\alpha_{2}$ adrenergic receptors of pancreatic $\beta$-cells. $\alpha_{2}$ receptor activation results in adenylyl cyclase inhibition, reduced PKA activation, and decreased $\mathrm{Ca} 2+$ influx (Peterhoff et al., 2003; Ying Zhang et al., 2009). Epinephrine also activates $\mathrm{K}_{+}$channels, causing an outflux of potassium, hyperpolarization of the membrane, and in turn, inhibits opening of the voltage gated $\mathrm{Ca} 2+$ channels (Ying Zhang et al., 2009). The resultant effect of epinephrine at the pancreas is an increase in glucagon and inhibition of insulin release.

Glucagon and insulin are both gluco-regulatory hormones that work to either increase or decrease circulating glucose levels, respectively. Glucagon binds at the glucagon receptor, a GPCR that is coupled to the $\mathrm{G}_{\mathrm{s}}$ alpha subunit, which activates adenylyl cyclase to increase intracellular cAMP (Jiang \& Zhang, 2003). Similar to epinephrine, this results in glucose production through PKA-induced glycogenolysis and gluconeogenesis (Jiang \& Zhang, 2003). The glucagon receptor is also coupled to the $\mathrm{G}_{q}$ alpha subunit, resulting in calcium release via PLC.

Insulin signals through the insulin receptor, initiating multiple signalling pathways controlling glucose, fatty acid, and amino acid uptake and storage (Saltiel \& Kahn, 2001). Receptor activation results in tyrosine phosphorylation and activation of insulin receptor substrate protein 1 and 2 (IRS-1, IRS-2) which can then bind to proteins containing the SH2 (Src-homology 2) domain. IRS-1 is the primary mediator of insulin stimulated glucose uptake in 
skeletal muscle, whereas in the liver both IRS-1 and IRS-2 are necessary for the metabolic actions of insulin (Kubota et al., 2016; Thirone et al., 2006). Activated IRS-1 binds to the p85 regulatory subunit of the type IA phosphatidylinositol 3-kinase (PI3K), which subsequently activates its p110 catalytic subunit. PI3K phosphorylates phosphatidylinositol 4,5-biphosphate ( $\left.\mathrm{PIP}_{2}\right)$ to phosphatidylinositol 3,4,5-trisphoshpate (PIP3) (Saltiel \& Kahn, 2001). PIP 3 induces a conformational change in protein kinase B (AKT) leading to phosphoinositide-dependent protein kinase-1 (PDK1)-dependent phosphorylation and activation of AKT (Saltiel \& Kahn, 2001). AKT increases glycogenesis through phosphorylation and inactivation of GSK3 $\beta$; active GSK3 $\beta$ phosphorylates and inactivates glycogen synthase (Cross et al., 1995). Insulin inhibits gluconeogenesis in the liver through transcriptional regulation of gluconeogenic genes Pckl and G6pc. This can occur via AKT-mediated phosphorylation and deactivation of transcription factor FOXO1 (Puigserver et al., 2003), insulin-mediated inhibition of CRTC2, and/or acetylation and phosphorylation of PGC1 $\alpha$, decreasing transcriptional activation of Pckl and G6pc.

\subsubsection{Negative regulators of catecholamine signalling}

Downstream signaling events of $\beta$-adrenergic activity are largely mediated through cAMP and cGMP. Intracellular levels of cAMP and cGMP are regulated by cyclic nucleotide phosphodiesterase enzymes (PDE) which work through hydrolysis and subsequent degradation of these mediators. Phosphodiesterases have become a popular pharmacological target for drug development, with PDE inhibitors already on the market for various conditions such as erectile dysfunction, chronic obstructive pulmonary disorder, vascular disease, and psoriasis (Baillie et al., 2019). Numerous PDE inhibitors are being investigated for their use in obesity and type 2 diabetes, for potential chemoprotective roles in squamous cell carcinomas, Alzheimer's disease, breast cancer, and colorectal cancer (Baillie et al., 2019). PDEs can be phosphorylated and 
activated in times of energetic stress by 5'AMP-activated protein kinase (AMPK), and by insulin through AKT (Berger et al., 2009; Johanns et al., 2016; Kitamura et al., 1999). Phosphorylation of PDE4B, the isoform predominantly expressed in the mouse liver, by AMPK increases its activity and contributes to AMPK-induced reductions in cAMP signalling (Johanns et al., 2016). PDE3B is the main insulin-activated isoform in liver and adipose tissue, and is phosphorylated by AKT (Kitamura et al., 1999). PDE3B is also activated by PKA phosphorylation, functioning as a negative-feedback mechanism in cAMP signalling (Omori \& Kotera, 2007).

\subsection{The metabolic effects of exercise}

\subsubsection{Rodent models of exercise training}

The beneficial effects of exercise are well characterized and include improvements in muscle glucose uptake, insulin sensitivity, increases in mitochondrial content in various tissues (muscle, adipose), anti-inflammatory effects, and improvements in cognitive performance (Holloszy \& Coyle, 1984; Robison et al., 2018; Zoladz et al., 2016). The benefits of exercise can vary according to exercise modalities, as varying intensities as well as differing modes can provoke different metabolic effects (Toti et al., 2013). Commonly used exercise modalities in mouse research include treadmill training, swim training, and voluntary wheel running (VWR).

While treadmill running may seem analogous to the human use of treadmills, treadmill training of rodents often occurs during their sleep cycle and can be stressful. Both treadmill and swim trained rodents show psychological and physiological responses suggestive of chronic stress, which may interfere with the metabolic outcomes of the exercise intervention (Moraska et al., 2000; Svensson et al., 2016). Voluntary wheel running allows the rodents to exercise in a familiar environment, without stress-inducing motivators, and requires minimal intervention from investigators; for that reason, it is often a preferred choice for investigators in modelling 
human aerobic exercise (American Physiological Society, 2006; Davidson et al., 2006).

However, translation to humans is still limited given that mice will run on the wheel intermittently throughout their dark cycle, whereas human exercise typically occurs in a shorter time frame (American Physiological Society, 2006).

\subsubsection{Acute effects of exercise}

Skeletal Muscle. Exercise increases the demand for adenosine triphosphate (ATP) to fuel muscle contractions. ATP is stored in very small amounts in the cell (approximately $8 \mathrm{mmol} / \mathrm{kg}$ wet weight) and thus resting levels are insufficient to sustain the energetic demands of exercise (Baker et al., 2010). Endogenous ATP generation occurs through the breakdown of carbohydrates and fat, which are stored in complex molecules such as glycogen and TAGs. The metabolic processes that synthesize ATP have sensitive control systems that allow for rapid production during exercise. Hydrolysis of ATP produces ADP, AMP and an inorganic phosphate (Pi) (Steinberg \& Carling, 2019). The increase in the AMP:ATP ratio activates 5'AMP-protein kinase (AMPK), a key metabolic protein known for its central role as a cellular energy sensor. Activation of AMPK initiates numerous energy producing processes including glucose uptake and $\beta$-oxidation (Steinberg \& Carling, 2019).

Liver. The liver is a highly metabolically active organ, acting as an energy reserve in times of stress and as a storage sink in times of energetic excess. During exercise, the liver increases glucose production to meet the increased utilization of glucose by skeletal muscle (Knudsen, Biens $\varnothing$ and Pilegaard, 2015). Hepatic glucose production is increased through glycogenolysis and gluconeogenesis. In the early stages of exercise, glycogenolysis is thought to be the primary driver of liver glucose production, while in the later stages when glycogen stores have decreased,

gluconeogenesis takes precedence (D. Wasserman, 1995). Aside from storing glycogen, the liver 
also stores energy in the form of TAGs. TAGs are synthesized from circulating free fatty acids and glycerol. During exercise, epinephrine stimulates lipolysis in the liver, adipose tissue, and muscle, through PKA-mediated phosphorylation of HSL to mobilize FFAs and glycerol from TAGs (Ghosh et al., 2012).

Adipose Tissue. During exercise, adipose tissue lipolysis is a major contributor to the pool of gluconeogenic substrates provided to the liver, through the production and release of glycerol into the circulation. Glycerol is taken up by the liver through aquaglyceroporins, and used for glucose production in gluconeogenesis (Jelen et al., 2011). Two important lipases for lipolysis are ATGL and HSL. In studies of ATGL knockout (KO) mice, mobilization of FFA during exercise is significantly impaired and paralleled with TAG accumulation in adipose tissue, muscle, and liver (Huijsman et al., 2009). Similarly, HSL KO mice have reduced resting FFA concentrations and show significant reductions in epinephrine- and exercise- induced lipolysis (Fernandez et al., 2008).

\subsection{Adaptations to endurance exercise}

Endurance training elicits numerous physiological adaptations that ultimately work to minimize exercise-induced homeostatic perturbations, improve exercise performance, and prolong the time to fatigue (Holloszy \& Coyle, 1984; Manabe et al., 2013). During exercise, muscle glycogen stores are the first to be broken down to provide glucose at the local working muscle for ATP synthesis. Rates of glycogen depletion are proportional to exercise intensity, with glycogen being the main fuel source during high intensity exercise (80\% and up $\mathrm{VO}_{2 m a x}$ )

(Gonzalez et al., 2016; Loon et al., 2001; Romijn et al., 1993). Fat is more abundant throughout the body than glycogen and is predominantly used during low to moderate intensity exercise (30$65 \%$ of $\mathrm{VO}_{2 \max }$ ); in an average $70 \mathrm{~kg}$ man, fat stores provide $\sim 100,000 \mathrm{kcals}$ of energy, while 
glycogen stores only account for 2400 kcals (Berg et al., 2002; Bleich \& Boro, 1975; Murray \& Rosenbloom, 2018; Romijn et al., 1993).

\subsubsection{Glycogen sparing}

A large factor in delaying the onset of fatigue during exercise is maintaining euglycemia. Endurance trained muscle can store larger amounts of glycogen and have an increased ability to oxidize fat, which conserves glycogen stores for the later stages of exercise (Bergström et al., 1967; Holloszy \& Coyle, 1984). The glycogen sparing adaptation is well defined in skeletal muscle from extensive human and animal research (Baldwin et al., 1975; Constable et al., 1987; Fitts et al., 1975; Green et al., 1992; Karlsson et al., 1974; Saltin et al., 1976; van Loon et al., 1999). A similar glycogen sparing effect has also been demonstrated in livers from trained rats (Baldwin et al., 1975; Fitts et al., 1975). In a study by Fitts et al., rats were treadmill trained at various durations 5 days/week for 13 weeks, then subjected to a 30-minute exercise test. In the livers of rats trained for $120 \mathrm{~min} /$ day, glycogen levels were unaffected by the exercise test, while rats from all other training durations (10, 30, or $60 \mathrm{~min} /$ day) had reduced glycogen levels (Fitts et al., 1975). In a similar study, rats were swim trained for 14 weeks before a 45 -minute progressive treadmill exercise test. Similarly, after the exercise test, liver glycogen stores were higher in exercised rats at rest and had lower depletion rates than the untrained rats (Baldwin et al., 1975).

In humans, exercise trained subjects have a decreased reliance on carbohydrate utilization during exercise (Coggan et al., 1995; Mendenhall et al., 1994). It has been repeatedly shown that endurance training reduces the rate of glucose oxidation and rates of glucose appearance during submaximal exercise, with decreases evident after just 10 days of training, suggesting reduced rates of liver glycogen depletion (Coggan et al., 1990; Mendenhall et al., 1994). 


\subsubsection{Effects of endurance exercise on skeletal muscle metabolism}

The reduced rate of glucose utilization and the upregulation of fat oxidation in trained subjects is partially explained by increases in the oxidative capacity of the muscle. It is well established that exercise increases mitochondrial biogenesis in skeletal muscle (Fitts et al., 1975; Holloszy, 1967). One key mechanism of exercise induced mitochondrial biogenesis is through AMPK-activation of the transcriptional co-activator peroxisome proliferator-activated receptor $\gamma$ coactivator-1 $\alpha$ (PGC-1 $\alpha$ ) (Brault et al., 2010; Tiraby et al., 2003; Wan et al., 2014). PGC-1 $\alpha$ plays a pivotal role in mitochondrial biogenesis through transcriptional activation of numerous mitochondrial proteins. Briefly, it increases mitochondrial enzymes required for oxidative phosphorylation (cytochrome $\mathrm{C}$, cytochrome oxidase (COX) subunit I), increases fatty acid transport through fatty acid translocate (FAT/CD36), and increases skeletal muscle glucose uptake by stimulating GLUT4 gene expression (Baar et al., 2002; Haase et al., 2011; Summermatter et al., 2010).

Endurance trained athletes also have a larger proportion of oxidative, slow-twitch skeletal muscle fibers, which are more densely packed with mitochondria, contributing to an increased capacity for fat oxidation (Fink et al., 1977). Additionally, exercise confers a similar effect as in muscle to increase hepatic mitochondrial biogenesis (Haase et al., 2011). In mice, four weeks of VWR exercise training increased ADP-stimulated oxidative phosphorylation, hepatic mitochondrial biogenesis and palmitate oxidation (Fletcher et al., 2014, 2016).

\subsubsection{Hormonal adaptations to endurance exercise}

The specific mechanisms mediating exercise-induced hepatic glycogen sparing have yet to be fully elucidated. Proposed explanations for the reductions in glucose production include changes in the major glucoregulatory hormones; of interest are alterations in circulating 
catecholamine concentrations. During submaximal exercise at the same absolute intensity, trained subjects exhibit significantly lower increases in plasma catecholamines (Baldwin et al., 1975; Bloom et al., 1976; Coggan et al., 1995; Deuster et al., 1989; Phillips et al., 1996; Winder et al., 1979). In another study, the rise in circulating catecholamines in response to a 1-hour bicycling test (@85\% VO2 max) was measured before and after 22 weeks of training. The test was representative of their relative exercise intensities as $\mathrm{VO}_{2}$ max improved throughout training. Subjects did not show changes in plasma norepinephrine responses but epinephrine concentrations were slightly lower after training (Lacour et al., 1982). Similarly, trained subjects also exhibit attenuated increases in exercise-induced glucagon concentrations (Bloom et al., 1976; Winder et al., 1979). These changes have been observed as early as after 3 days of training, and can plateau after 3 weeks, suggesting that hormonal glucose regulation during exercise is rapidly impacted by training status (Green et al., 1989; Winder et al., 1978, 1979). Trained individuals also experience increased cardiac stroke volume and blood flow to working muscles during submaximal exercise (Armstrong \& Laughlin, 1984; Franke et al., 1998; Musch et al., 1987; Volianitis et al., 2004). Perhaps the attenuated rise in catecholamines with training can be attributed to enhanced catecholamine delivery and tissue clearance.

In contrast to these studies stands the theory of the sports adrenal medulla from Kjær and colleagues, which argues against the idea of training-induced decreases in catecholamines levels during exercise (Kjær, 1998). The sports adrenal medulla theory describes the enlargement of the adrenal gland with intensive exercise training and subsequent elevations in secretory capacity (Kjær, 1998). The argued benefit of the sports adrenal medulla is a higher capacity to secrete epinephrine, resulting in an advantageous increased ability for fuel mobilization during exercise (Kjær \& Galbo, 1988). Kjær has repeatedly demonstrated a training-induced increase in the 
secretory capacity of the adrenal medulla in rodents and humans, with studies showing increased circulating epinephrine concentrations in trained men after an exhaustive treadmill or cycling test (Kjær et al., 1985, 1986). This phenomenon of increased epinephrine secretion in trained subjects was shown to occur even when working at the same relative exercise intensity (Kjær et al., 1986). A key factor to note is that this effect occurs during intensive and exhaustive exercise, and does not apply to submaximal exercise modalities used in the earlier mentioned studies (Baldwin et al., 1975; Bloom et al., 1976; Phillips et al., 1996; Winder et al., 1979). Additionally, these modifications have not been demonstrated in longitudinal training studies (Howard Hartley et al., 1972; Lacour et al., 1982). In a follow up from one of Kjær's study, the participants capacity to secrete epinephrine was not altered by a 5-week cessation of exercise, bringing forth questions regarding the permanence and mechanisms behind secretory capacity modifications (Kjær et al., 1992). The authors also mentioned the possibility of genetic predispositions (for athletes) to have higher epinephrine secretory capacities. Despite the abundance of evidence from Kjær's group, increased secretion of catecholamines during exercise would not explain the hepatic glycogen sparing effect seen in exercise trained subjects (Baldwin et al., 1975), and reiterates the need to investigate the mechanisms behind hepatic glycogen sparing.

\subsubsection{Training induced changes in the adrenergic responsiveness to catecholamines}

Training-induced reductions in liver glycogen depletion may be caused by changes in the adrenergic response to catecholamines. In multiple disease states, there are compensatory and adaptive changes in $\beta$-adrenergic responsiveness. Patients with heart failure have decreased cardiac $\beta$-adrenergic density and a reduced sensitivity to isoproterenol and catecholamines (Bristow et al., 1986; Leosco et al., 2013; Rockman et al., 1998). The same reduced $\beta$-adrenergic sensitivity is also characteristic of adipocytes from obese subjects, who show blunted 
catecholamine-induced lipolysis (Horowitz \& Klein, 2000; Jocken et al., 2008; Mowers et al., 2013; Snook et al., 2017). However, exercise has been shown to alter adrenergic responsiveness in multiple tissues. Four weeks of treadmill training increased $\beta$-adrenergic responsiveness in cultured murine epididymal white adipose tissue, shown by increases in CL 316-243, a $\beta_{3}$ adrenergic agonist,- induced HSL phosphorylation and FFA accumulation (Snook et al., 2017). In a group of obese males, a single 2-hour bout of cycling $\left(50 \% \mathrm{VO}_{2 \max }\right)$ increased the lipolytic response to isoprenaline ( $\beta$-adrenergic agonist) in isolated subcutaneous adipose tissue, shown by greater increases in glycerol concentrations (Harant et al., 2002). Aging rats subject to 12 weeks of treadmill training showed significantly higher cardiac adenylyl cyclase activation in response to isoprenaline and were able to restore their $\beta$-adrenergic receptor density to comparable levels of the young rats (Leosco et al., 2007). Using a similar exercise protocol, but in a rat model of heart failure, exercise was able to restore cardiac $\beta$-adrenergic receptor signalling and density (Leosco et al., 2008).

Exercise training can also alter the adrenergic response to catecholamines in skeletal muscle and lymphocytes (Fujii et al., 1993; Mazzeo et al., 1995; Plourde et al., 1993). In skeletal muscles of rats, there is an effect of exercise training to increase $\beta$-adrenergic receptor density and response. Specifically, isoproterenol-stimulated adenylyl cyclase activity was enhanced in soleus and gastrocnemius muscles of treadmill trained rats compared to sedentary controls (Plourde et al., 1993; Williams et al., 1984).

In studies of trained male and female runners, the lipolytic response of adipocytes to epinephrine was significantly increased in comparison to those from sedentary subjects (Crampes et al., 1986; Riviere et al., 1989). In isolated hepatocytes from fasted treadmill trained rats, epinephrine-induced gluconeogenesis was greater than in hepatocytes from sedentary rats 
(Sumida et al., 2003), though it should be noted that this is not a universal finding as there are inconsistent findings on the effects of exercise training on adrenergic adaptations in the liver (Podolin et al., 1996). Nevertheless, these studies demonstrate the ability of exercise to alter adrenergic receptor activity and signalling.

\subsubsection{Exercise-mediated regulation of adrenergic receptors}

Repeated spikes in epinephrine during each training session may evoke a transient receptor desensitization or receptor downregulation. Agonist-induced desensitization of the $\beta$ adrenergic receptor has been extensively studied in vitro in adipose, liver, and skeletal muscle cell lines (Perez, 2005). While the mechanisms involved in desensitization vary with tissue and animal, repeated epinephrine-exposure has consistently reduced the adrenergic responsiveness in vivo in rodent studies. In rats treated twice-daily with epinephrine for 28 days $(0.3 \mathrm{mg} / \mathrm{kg})$, there was a marked reduction in the whole body glucose response to an acute epinephrine challenge in comparison to untreated rats (Rousseau-Migneron et al., 1975, 1980). Another study showed attenuated decreases in muscle glycogen following an acute epinephrine challenge in rats treated daily with epinephrine for 6 weeks (Fell et al., 1981). In a shorter-term study, 6 days of continual norepinephrine infusion reduced $\beta 1$ and $\beta 2$ adrenergic receptor density in guinea pig adipocytes and this was paralleled by a blunted lipolytic response to isoproterenol, norepinephrine, and epinephrine (Carpene et al., 1993). Another study demonstrated evidence of epinephrine-induced desensitized adenylyl cyclase responses in rat livers; isolated hepatocytes were preincubated with varying amounts of epinephrine and then treated with a fixed amount of epinephrine. The percent change in adenylyl cyclase activity in response to epinephrine was significantly decreased in pretreated samples, showing a dose-dependent response. This suggests that adrenergic desensitization is not unique to adipose tissue (Lam \& Bär, 1976). 


\subsection{Summary}

This literature review summarizes past findings related to exercise training adaptations and the flexibility of the adrenergic response in skeletal muscle, adipose tissue, and the liver. Epinephrine plays a pivotal role in the regulation of fuel mobilization during exercise through adrenergic signaling. Previous research has shown that chronic exposure to $\beta$-adrenergic agonists can downregulate adrenergic receptors and decrease adrenergic responsiveness. Similarly, exercise training can alter the $\beta$-adrenergic effects of epinephrine, including lipolysis and glycogenolysis. Of particular interest, is the glycogen sparing effect in the liver, in which exercise training decreases the reliance on hepatic glycogen stores in the early stages of moderate intensity exercise. The mechanisms are not fully elucidated; however, the repeated exerciseinduced epinephrine exposure may play a significant role. 


\section{CHAPTER 2: Aims of Thesis}

\subsection{Specific aims and purpose of thesis}

Endurance exercise confers a plethora of metabolic adaptations, including changes in substrate utilization during exercise. Of interest, is the glycogen sparing mechanism whereby muscle and liver glycogen stores are conserved for the later stages of exercise. Secretion of epinephrine during exercise stimulates hepatic glucose production through glycogenolysis and gluconeogenesis. Previous research has shown exercise-training adaptations in adipose tissue, skeletal and cardiac muscle's response to catecholamines, however the effects of exercise training on the liver's response to epinephrine remains largely uncertain. Therefore, the aim of this thesis was to determine whether exercise training via VWR would affect the liver's glucostimulatory response to an epinephrine challenge. It was hypothesized that:

Exercise training via VWR would attenuate hepatic responsiveness to epinephrine as shown by attenuated increases in PKA signaling, liver glycogen breakdown, and blood glucose. 


\section{CHAPTER 3: Epinephrine Responsiveness is Reduced in Livers from Trained Mice}

Hana A. Dibe, Logan K. Townsend, Greg L. McKie and David C. Wright.

Department of Human Health and Nutritional Sciences, University of Guelph, Guelph, ON, Canada

Presented as the revised submission to Physiological Reports 


\subsection{Abstract}

The liver is the primary metabolic organ involved in the endogenous production of glucose through glycogenolysis and gluconeogenesis. Hepatic glucose production (HGP) is increased via neural-hormonal mechanisms such as increases in catecholamines. To date, the effects of prior exercise training on the hepatic response to epinephrine have not been fully elucidated. To examine the role of epinephrine signaling on indices of HGP in trained mice, male C57BL/6 mice were either subjected to 12 days of voluntary wheel running or remained sedentary. Epinephrine, or vehicle control, were injected intraperitoneally on day 12 prior to sacrifice with blood glucose being measured 15 minutes post-injection. Epinephrine caused a larger glucose response in sedentary mice and this was paralleled by a greater reduction of liver glycogen in sedentary compared to trained mice. There was a main effect of epinephrine to increase the phosphorylation of protein kinase-A (p-PKA) substrates in the liver, which was driven by increases in the sedentary, but not trained, mice. Similarly, epinephrine-induced increases in the mRNA expression of hepatic adrenergic receptors (Adral/2a, Adrb1), and glucose-6phosphatase $(G 6 p c)$ were greater in sedentary compared to trained mice. The mRNA expression of cAMP-degrading enzymes phosphodiesterase 3B and 4B (Pde3b, Pde4b) was greater in trained compared to sedentary mice. Taken together, our data suggest that prior exercise training reduces the liver's response to epinephrine. This could be beneficial in the context of traininginduced glycogen sparing during exercise.

\subsection{Introduction}

Exercise-induced activation of the sympathetic nervous system results in increased production and secretion of the catecholamines epinephrine and norepinephrine, from the adrenal medulla and postganglionic neurons, respectfully (Leosco et al., 2013). Plasma catecholamine 
levels increase at the onset of exercise and continue to rise in an intensity and duration dependent manner (Howlett et al., 1999). Norepinephrine and epinephrine bind to G-protein coupled beta adrenergic receptors $(\beta 1, \beta 2, \beta 3)$, albeit with different affinities, to facilitate the physical interaction between the receptor and its stimulatory protein subunit (i.e., Gs $\alpha$ ) leading to a conformational change in Gs $\alpha$ that activates adenylyl cyclase (Molinoff, 1984). Adenylyl cyclase propagates the signal downstream by increasing cytosolic levels of 3', 5'-cyclic AMP (cAMP) which subsequently activates protein kinase A (PKA) (Erraji-Benchekroun et al., 2005; Pierce et al., 2002). When activated, PKA can phosphorylate numerous enzymes, regulating a variety of metabolic pathways throughout the body. In skeletal muscle and liver, the activation of PKA increases glycogen breakdown (Jensen et al., 2007; Johanns et al., 2016). In the liver, PKA also stimulates gluconeogenesis through the transcriptional activation of numerous genes, including glucose-6-phosphatase (G6pc) and phosphoenolpyruvate carboxykinase (Pepck) (Xie et al., 2018). In adipose tissue, increases in PKA activity stimulates lipolysis through the phosphorylation of perilipin proteins and multiple lipases such as hormone sensitive lipase (Anthonsen et al., 1998; Strålfors et al., 1984). In the pancreas, epinephrine stimulates glucagon secretion from the $\alpha$-cells of the pancreas, and inhibits insulin release from $\beta$-cells (Hamilton et al., 2018; Han \& Bonen, 1998; Peterhoff et al., 2003). cAMP-PKA signaling is attenuated by cyclic nucleotide phosphodiesterases (PDE), which can be activated in response to various cellular signals including protein kinase B (AKT) and 5'AMP-activated protein kinase (AMPK) (Berger et al., 2009; Johanns et al., 2016).

Exercise training influences the metabolic responsiveness to catecholamines in adipose tissue, skeletal muscle, and the liver (Plourde et al., 1993; Podolin et al., 1996; Riviere et al., 1989; Sumida et al., 2003). For example, isoproterenol-stimulated adenylyl cyclase activity was 
significantly elevated in soleus muscles from trained compared to sedentary rats (Plourde et al., 1993). In trained subjects, the lipolytic response of adipocytes to epinephrine was increased in comparison to fat cells from sedentary subjects (Riviere et al., 1989). Similarly, epinephrine stimulated gluconeogenesis was greater in hepatocytes isolated from trained compared to sedentary rats (Sumida et al., 2003), though it should be noted that this has not been a universal finding (Podolin et al., 1996).

Exercise training confers a glycogen sparing effect, such that reductions in liver glycogen during exercise are attenuated in trained compared to sedentary subjects (Baldwin et al., 1975; Fitts et al., 1975; Gonzalez et al., 2016). The specific cellular mechanisms mediating this effect are not known but it is tempting to speculate that alterations in the ability of epinephrine to stimulate hepatic glycogenolysis could be involved. Within this framework, the purpose of the present investigation was to examine the impact of exercise training on epinephrine induced increases of indices of PKA signaling and glycogenolysis in liver. We hypothesized that exercise training would attenuate hepatic responsiveness to epinephrine, as shown by attenuated increases in PKA signaling, liver glycogen breakdown, and blood glucose.

\subsection{Methods}

\subsubsection{Animals and ethics}

Eight-week old male C57BL/6 mice (Charles River, Saint-Constant QC, Canada) were individually housed at room temperature $\left(\sim 22^{\circ} \mathrm{C}\right)$ and kept on a $12: 12 \mathrm{~h}$ light-dark cycle $(800 \mathrm{~h}$ to 2000 h). Mice were given one week to acclimate to their environment before experiments began. Mice had ad libitum access to a standard rodent diet (cat no. 7004; Teklad, Madison, WI, USA) and water. All cages contained standard corncob bedding and a tube for environmental enrichment. All animal protocols were approved by the University of Guelph Animal Care Committee and 
followed the Canadian Council on Animal Care guidelines. A total of 108 mice were used for the experiments described below.

\subsubsection{2-day exercise intervention}

Following a one-week acclimation period, mice were weight-matched into sedentary (SED) and exercise trained (TR) groups ( $n=10 /$ group). SED mice remained individually housed in standard shoebox cages while TR mice were moved to individual cages with running wheels and wired bike computers (M3.1 WR VDO Cycle Computing, Neustadt, Germany) to track distance and speed. TR mice had access to wheels for 12 days, a length chosen based off previous work that demonstrated significant metabolic adaptations with this 12-day voluntary wheel running (VWR) protocol (Knuth et al., 2018). Food intake, body weight, running distance and running time were recorded every other day for all mice.

\subsubsection{Glucose tolerance test}

On day 10 of the 12-day exercise intervention, a subset of mice from each group $(n=10)$ were subject to an intraperitoneal (i.p.) glucose tolerance test (GTT) at $\sim 1500 \mathrm{~h}$. SED and TR mice were fasted for $4 \mathrm{~h}$ prior to the GTT with a wheel lock in place for the TR mice overnight so as to avoid any residual effects of the last bout of exercise (Knuth et al., 2018). Mice were injected i.p. with a weight-adjusted bolus of D-glucose $(2 \mathrm{~g} \cdot \mathrm{kg}-1 \mathrm{BW})$. Blood was sampled from a tail snip and glucose measured with a handheld glucometer (Freestyle Lite, 70 Abbott Laboratories, Abbott Park, IL, USA) immediately pre-injection (time point 0 ) and at 15, 30, 60, 90, and 120 min post-injection.

\subsubsection{Epinephrine challenge and tissue collection}

Norepinephrine is 30 -fold less effective in stimulating HGP than epinephrine, and thus plays a minor role in glucose regulation compared to epinephrine (Coker et al., 1997; Connolly et al., 1991; Luigi Sacca et al., 1980); therefore, we chose to focus solely on epinephrine in this study. 
Thus, an epinephrine dose-response experiment was first conducted in vivo to determine the lowest dosage that would stimulate a significant increase in HGP. Mice were injected i.p. with epinephrine or vehicle at a dose of $0.5,0.25$, or $0.125 \mathrm{mg} \cdot \mathrm{kg}_{-1} \mathrm{BW}$, and blood glucose was measured at baseline and at 15 minutes post-injection. We chose this time point in an effort to minimize compensatory neuroendocrine changes brought about by prolonged increases in blood glucose. At 15 minutes, blood glucose concentrations were significantly elevated in the $0.5 \mathrm{mg} \cdot \mathrm{kg}-1 \mathrm{BW}$ group only $(P<0.05$; Table 3.1). As such, this dose and time point were chosen for use in subsequent experiments. On day 12 of the 12-day exercise intervention, mice were weight and distance matched into groups receiving an i.p. injection of epinephrine (EPI) $(0.5 \mathrm{mg} \cdot \mathrm{kg}-1 \mathrm{BW})$ or vehicle (VEH). TR mice had wheels locked $4 \mathrm{~h}$ before injection. Mice had access to food during the experiment which began at $1300 \mathrm{~h}$. Blood glucose was measured at baseline and 15 min postinjection. After $15 \mathrm{~min}$, mice were anesthetized with sodium pentobarbital ( $5 \mathrm{mg} \cdot 100 \mathrm{~g}-1 \mathrm{BW})$ and blood collected via cardiac exsanguination. Liver and triceps were collected, immediately frozen in liquid nitrogen and stored at $-80^{\circ} \mathrm{C}$. Blood was allowed to clot at room temperature and centrifuged at 2,000 $\mathrm{g}$ for $10 \mathrm{~min}$ before serum was aliquoted and stored at $-80^{\circ} \mathrm{C}$.

Table 3.1 Blood glucose 15 minutes after epinephrine injection of varying doses

\begin{tabular}{lllll}
\hline \multicolumn{5}{c}{ Epinephrine dose $(\mathbf{m g} \cdot \mathbf{k g}-\mathbf{1}$ BW) } \\
\hline & VEH & $\mathbf{0 . 1 2 5}$ & $\mathbf{0 . 2 5}$ & $\mathbf{0 . 5}$ \\
\hline Blood Glucose & $8.86 \pm 0.67$ & $10.38 \pm 0.71$ & $10.24 \pm 1.54$ & $13.16 \pm 1.131 *$ \\
\hline
\end{tabular}

Note: Data presented as mean \pm SEM ( $n=5$ mice/group). * denotes significant $(P<0.05)$ difference from VEH. VEH - vehicle. 


\subsubsection{Acute voluntary wheel running}

To determine if a single bout of exercise could affect liver responsiveness to epinephrine, we utilized a single overnight VWR model. Following a one-week acclimation period, mice $(n=7)$ were weight matched into sedentary (SED) and exercised (EX) groups, and cages set up as described above. Mice had access to wheels from $1600 \mathrm{~h}$ to $0800 \mathrm{~h}$ the following day. Body weights, food intake, and distance ran were recorded after the night of running. Wheels were locked at $0800 \mathrm{~h}$ and mice were subject to epinephrine or vehicle injection as described above. Blood glucose was measured at baseline and 15 min post-injection with tissues collected as previously described.

\subsubsection{Serum measurements}

Non-esterified fatty acids (NEFA; Wako Diagnostics, Richmond, VA, USA) and glycerol (cat no. F6428; Sigma Aldrich, Oakville, ON, Canada) were measured on a 96-well plate as previously described (MacPherson et al., 2014). Glucagon and insulin were measured via enzyme-linked immunosorbent assays (ELISA) (cat no.10-1281-01; 10-1247-013; Mercodia, Winston-Salem, NC, USA). All assays were conducted in accordance with the manufacturer's instructions.

\subsubsection{Hepatic glycogen content}

Livers from all mice were freeze-dried and dissected free of visible blood and contaminating hair for glycogen analysis. Glycogen content was determined from an 0.1-2.0 mg aliquot of freezedried liver (McKie et al., 2019). Glucose and hexose monophosphates were degraded using 0.1 M $\mathrm{NaOH}$ incubated in an $80^{\circ} \mathrm{C}$ water bath for $10 \mathrm{~min}$. Samples were then neutralized in a buffer containing $0.1 \mathrm{M} \mathrm{HCl}, 0.2 \mathrm{M}$ citric acid, and $0.2 \mathrm{M} \mathrm{Na}_{2} \mathrm{HPO}_{4} \cdot \mathrm{H}_{2} \mathrm{O}$. Glycogen was enzymatically hydrolyzed to glucose with amyloglucosidase (cat no. A7095; Sigma Aldrich, Oakville, ON, Canada) and incubated for $1 \mathrm{~h}$ at room temperature. Glucose was measured directly by 
fluorometric assay using equal volumes of hexokinase (cat no. H-4502; Sigma Aldrich, Oakville, ON, Canada) and glucose-6-phosphate dehydrogenase (cat no. G-5885; Sigma Aldrich, Oakville, ON, Canada) (Liang et al., 2002). Glycogen concentrations were calculated from the molar absorptivity of NADPH $\left(340 \mathrm{~nm}=6.22 \mathrm{~cm} 2 \mathrm{~mol}-1\right.$ at $\left.37^{\circ} \mathrm{C}\right)$ and expressed as mmol $\cdot \mathrm{kg}_{-1}$ dry weight.

\subsubsection{Western blotting}

Tissues were homogenized in 30x or 20x (liver or tricep tissue weight, respectively) cell lysis buffer (cat no. FNN0021; ThermoFisher, Mississauga, ON, Canada) containing phenylmethylsulfonyl, and protease inhibitor (Sigma Aldrich, St. Louis, MO, USA). Following this, samples were centrifuged $\left(4^{\circ} \mathrm{C}\right.$ for $10 \mathrm{~min}$ at $\left.5000 \mathrm{~g}\right)$ and the supernatant collected. A bicinchoninic acid assay was used to determine protein content in order to prepare samples to a final concentration of $1 \mathrm{ug} / \mathrm{ul}$ (Smith et al., 1985). Samples were prepared with cell lysis buffer and 2x laemmli sample buffer. Samples were loaded in equal amounts, separated on 15-well, 10\% or 5\% SDS-polyacrylamide gels, and transferred onto a nitrocellulose membrane. Membranes were blocked with non-fat skim milk powder diluted (5\%) in TBST for $1 \mathrm{~h}$ and incubated overnight at $4^{\circ} \mathrm{C}$ with primary antibody (diluted $1: 1000$ ). The following day membranes were incubated with the corresponding secondary antibody (anti-rabbit or anti-mouse horseradish peroxidase-

conjugated antibody) for $1 \mathrm{~h}$ at room temperature. ECL substrate (cat no. 1705061; Bio-Rad Laboratories, Hercules, CA, USA) was used to visualized bands through chemiluminescence on a FluorChem FC2 machine and protein content was quantified by densitometry using AlphaView Software (Cell Biosciences, Santa Clara, CA, USA). Ponceau S (cat no. P7170; Sigma Aldrich, Oakville, ON, Canada) staining or a housekeeping protein (Vinculin or GAPDH) were used as a loading control (Townsend et al., 2019). Phosphorylated and total protein were expressed relative 
to their within-gel loading control, then phosphorylated proteins were normalized to total protein (i.e. phosphor/total).

Primary antibodies were obtained from Cell Signaling (Danvers, MA, USA) for protein kinase B total (Akt, cat no. 9272), phosphorylated protein kinase b (pAktser473, cat no.9271; pAktThr308, cat no. 9275), acetyl-CoA carboxylase total (ACC, cat no. 3676), phosphorylated acetyl-CoA carboxylase (pACC Ser79, cat no. 3661), AMPK $\alpha$ (cat no. 2532), phosphorylated-AMPK $\alpha$ Thr172 (pAMPK $\alpha$, cat no. 2535), phosphorylated protein kinase A substrates (pPKA-s, cat no. 9624), cytochrome c (CYTO C, cat no. 4272), hexokinase II (HKII, cat no. 2106); from Abcam (Toronto, ON, Canada) for ubiquinol-cytochrome C reductase (CORE1, cat no. 110252), cytochrome c oxidase subunit IV (COX IV, cat no. 16056), peroxisome proliferator-activated receptor- $\gamma$ coactivator-1 $\alpha$ (PGC1 $\alpha$, cat no. 54481), citrate synthetase (CS, cat no. 129095); from Cayman Chemicals (Ann Arbor, MI, USA) for phosphoenolpyruvate carboxykinase (PEPCK, cat no. 10004943); from Santa Cruz Biotechnology (Dallas, TX, USA) for glucose-6-phosphatase (G6Pase, cat no. 25840) and from Origene (Rockville, MD, USA) for phosphodiesterase 4B (PDE4B, cat no. TA503471).

\subsubsection{Real-time quantitative PCR}

Liver $(30-40 \mathrm{mg}$ ) was homogenized in $1 \mathrm{~mL}$ of TRIzol (cat no. 15596018; ThermoFisher Scientific, Waltham, MA, USA) and RNA was extracted using Bio Basic EZ-10 Spin Column Total RNA Miniprep Super Kits (cat no. BS784; Bio Basic, Markham, ON, Canada) as described previously (Frendo-Cumbo et al., 2016; Peppler et al., 2018; Townsend et al., 2019). Synthesis of cDNA was completed using Superscript II (cat no. 4368814; ThermoFisher Scientific, Waltham, MA, USA) and reverse transcription quantitative PCR was run using SYBR Green Supermix (cat no. 1725271; Bio-Rad Laboratories, Hercules, CA, USA) using PCR primers (Table 3.2) on a Bio- 
Rad CFX Connect system. All values are expressed relative to the housekeeping gene Ppib and

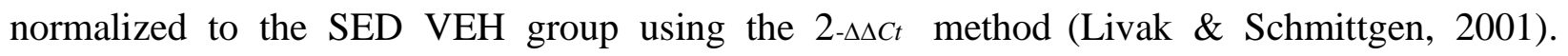
Expression of the housekeeping gene was stable and did not change with intervention.

Table 3.2 mRNA primers

\begin{tabular}{|c|c|c|}
\hline & \multicolumn{2}{|c|}{ Primer Sequence, 5' - 3' } \\
\hline Gene (Ref) & Forward & Reverse \\
\hline $\begin{array}{l}\text { Adrala } \\
\text { (Spandidos } \\
\text { et al., 2009) }\end{array}$ & AGTGGGTGTCTTCCTAGCC & GCCTAGAACCTCCATAGTGGC \\
\hline $\begin{array}{l}\text { Adra2a } \\
\text { (Spandidos } \\
\text { et al., 2009) }\end{array}$ & GGTGACACTGACGCTGGTTT & ACTGGTGAACACCGCGATAATA \\
\hline $\begin{array}{l}\text { Adrbl } \\
\text { (Hauck et } \\
\text { al., 2017) } \\
\end{array}$ & CTCATCGTGGTGGGTAACGTG & ACACACAGCACATCTACCGAA \\
\hline $\begin{array}{l}\text { Adrb2 } \\
\text { (Hauck et } \\
\text { al., 2017) }\end{array}$ & GGGAACGACAGCGACTTCTT & GCCAGGACGATAACCGACAT \\
\hline $\begin{array}{l}\text { G6pc (Gray } \\
\text { et al., 2015) }\end{array}$ & AGGAACGCCTTCTATGTCCTCTTTC & GCGTTGTCCAAACAGAATCCACTTG \\
\hline $\begin{array}{l}\text { Pckl (Gray } \\
\text { et al., 2015) }\end{array}$ & $\begin{array}{l}\text { CGGAAGAGGACTTTGAGAAAGCTT } \\
\text { C }\end{array}$ & $\begin{array}{l}\text { GCGAGTCTGTCAGTTCAATACCAAT } \\
\text { C }\end{array}$ \\
\hline $\begin{array}{l}P d e 3 b \\
\text { (Niiya et al., } \\
\text { 2001) }\end{array}$ & TGAGTGGCAGAACCAGTTTCC & TGCGATCCCACCTTGAACA \\
\hline $\begin{array}{l}P d e 4 b \\
\text { (Avila et al., } \\
2016 \text { ) }\end{array}$ & GACCGGATACAGGTTCTTCG & CAGTGGATGGACAATGTAGTCA \\
\hline $\begin{array}{l}\text { Ppib } \\
\text { (Spandidos } \\
\text { et al., 2009) }\end{array}$ & GGAGATGGCACAGGAGGAA & GCCCGTAGTGCTTCAGCTT \\
\hline
\end{tabular}

\subsubsection{Statistical analyses}

Data were screened for outliers using the Extreme Studentized Deviate (ESD) method. This method is used to detect outliers in univariate data sets with approximately normal distribution. Identified outliers were not included in data analyses. Normality of residuals was assessed using the Shapiro-Wilk test. Data in figures $1 A$-cytochrome C, $3 D, 4 D, 6 A$-pAKT S473 and $7 C$ were $\log _{10}$ transformed as they did not pass the test $(P \leq 0.05)$. Data were analyzed using either an 
unpaired student's t-test (e.g. average body weight change and delta liver glycogen) or a two-way analysis of variance (ANOVA; e.g. to test the effects of, or interactions between, exercise and epinephrine). Post hoc tests using Tukey's multiple comparisons test were performed when significant interactions were reported. Statistical analyses and graphs were made using Prism 6.0 (GraphPad Software, La Jolla, CA, USA). Significance was set at an alpha level of 0.05 and data is displayed as the mean $\pm \mathrm{SEM}$ with individual data points shown when possible.

\subsection{Results}

\subsubsection{2 days of VWR exercise training attenuates weight gain despite similar food intake}

We first wanted to verify the efficacy of our 12-day exercise training model. Average body weight of TR mice did not change throughout the intervention while SED mice gained an average of 1.5 g $(P<0.05$; Fig. 3.1A). There were no differences in food intake $(P=0.36)$ between groups (Fig 3.1B). There were no differences in running distance and time between TR-VEH and TR-EPI groups. TR-VEH and TR-EPI mice ran an average of $60.5 \pm 7.6 \mathrm{~km}$ and $57.6 \pm 6.1 \mathrm{~km}$ for a total average of $70.6 \pm 4.2 \mathrm{~h}$ and $69.8 \pm 1.0 \mathrm{~h}$, respectively. Results of the GTT (Fig. 3.1D) indicated a non-significant trend $(P=0.052)$ in glucose tolerance between groups. Exercise is well known to increase skeletal muscle oxidative capacity (Knuth et al., 2018; McKie et al., 2019; Peppler et al., 2018; Stanford et al., 2015) and in the current study, we observed consistent exercise-induced increases in the protein content of HKII $(P<0.001)$, CYTO C, COX IV, and PGC1 $\alpha(P<0.05$; Fig. $3.1 E$ ) in the triceps muscle. 

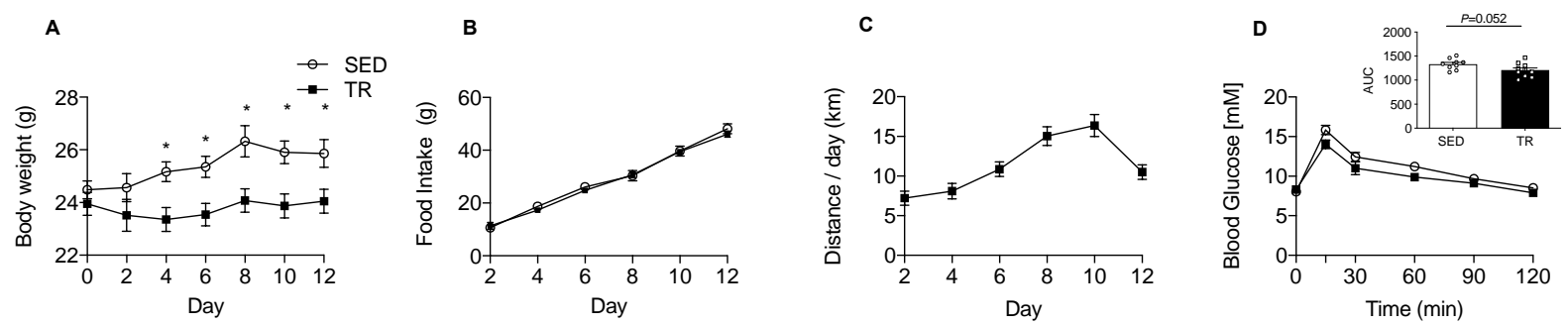

$E$
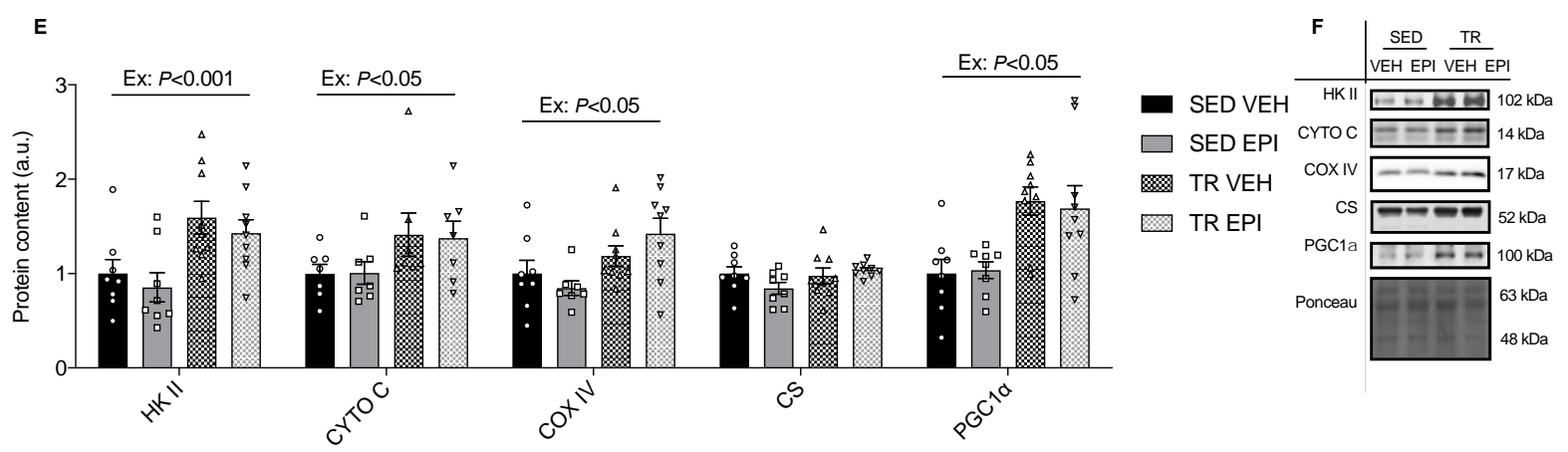

Figure 3.1 12 days of voluntary wheel running attenuated weight gain despite similar food intake and increased markers of mitochondrial content in triceps muscles. Body weight $(A)$ and food intake $(B)$ was measured every other day over a 12-day period in SED and TR mice $(n$ $=10)$. Average VWR distance recorded every two days in TR mice $(n=10)(C)$. Glucose tolerance test $(n=10)$ conducted on the 10th day of VWR, with inset showing AUC for entire 120 minutes $(D)$. Quantified western blots for triceps protein content of HKII, CYTO C, COX IV, CS, PGC1 $\alpha$ $(E)$ and representative western blot images $(F)(n=8-9)$, as well as a representative ponceau image. Average body weight was analyzed by multiple t-tests using the Holm-Sidak Method. AUC was analyzed by an unpaired t-test. * denotes statistical significance $(P<0.05)$ between groups. Triceps protein content was analyzed by two-way ANOVA. Ex - denotes main effect of exercise training. Epi - denotes main effect of epinephrine. Individual data points are shown where possible. All data are presented as mean \pm SEM.

\subsubsection{Exercise training attenuates the increase in blood glucose in response to epinephrine}

After characterizing our 12-day exercise training model, we sought to determine if exercise training impacted acute epinephrine-induced increases in blood glucose. SED EPI mice had a significantly larger spike in blood glucose 15 min post-epinephrine administration compared to TR EPI mice $(P<0.05$; Fig. $3.2 A)$. Additionally, the change in glucose from baseline ( $\mathrm{t}=0)$ to 15 min post-epinephrine $(\mathrm{t}=15)$, was greater in SED-EPI compared to TR-EPI mice $(P<0.05$; Fig. 3.2B). Epinephrine is well known to decrease liver glycogen content, however, we wanted to investigate if there was an exercise training adaptation to attenuate epinephrine-induced glycogen depletion. Interestingly, as little as 15 min after epinephrine administration, there was a reduction 
in hepatic glycogen content in SED and TR mice $(P<0.05$; Fig. $3.2 C)$. The relative change in glycogen content following epinephrine administration was calculated by subtracting the individual glycogen values of the epinephrine treated groups from the average value of the vehicle control group. In doing so, the relative decline in glycogen in EPI compared to VEH controls, was larger in SED than TR mice $(P<0.05$; Fig. 3.2D).

A

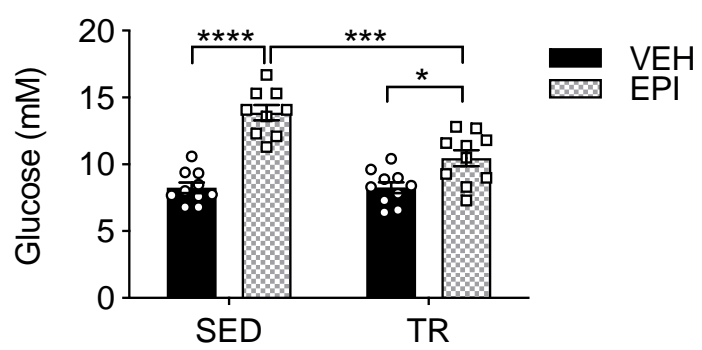

C

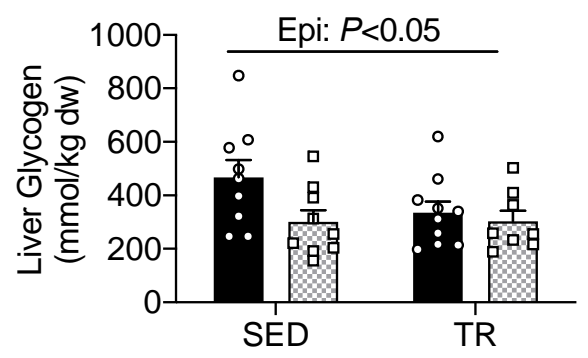

B

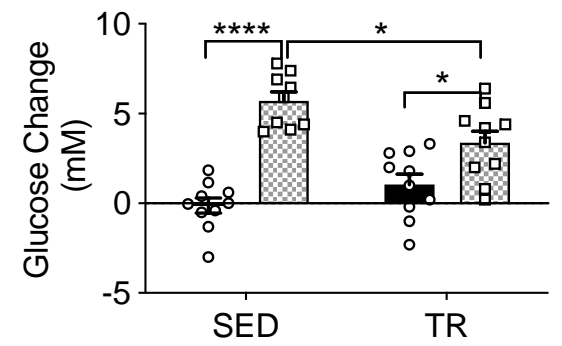

D

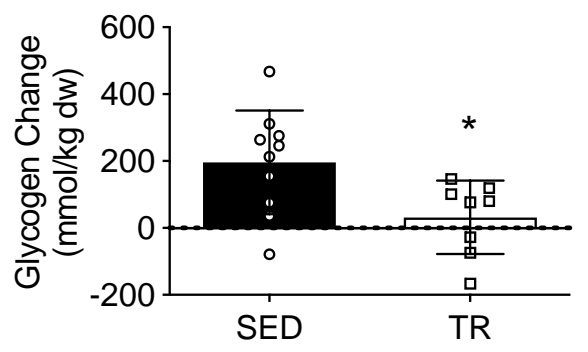

Figure 3.2 The acute blood glucose response to an epinephrine injection is blunted by exercise training. VWR attenuated the blood glucose response at 15 minutes after an epinephrine injection $\left(0.5 \mathrm{mg} \cdot \mathrm{kg}_{-1} \mathrm{BW}\right)(A ; n=10)$. The change in blood glucose from baseline $(\mathrm{t}=0)(B)$. Hepatic glycogen content $(C ; n=10)$ and the relative decline in glycogen between SED and TR mice after epinephrine administration $(D)$. Data analyzed by two-way ANOVA. Epidenotes main effect of epinephrine. Significant interactions analyzed by post-hoc comparison denoted by $* P<0.05$, $* * * P<0.001, * * * * P<0.0001$. Individual data points are shown where possible. All data are presented as mean \pm SEM. 


\subsubsection{Exercise training does not impact the effect of epinephrine on circulating markers of}

lipolysis and pancreatic hormones

Previous studies have demonstrated that exercise training enhances catecholamine stimulated lipolysis (Bloom et al., 1976; Riviere et al., 1989). To determine if exercise impacted indices of lipolysis following acute epinephrine exposure, we measured serum NEFA and glycerol 15 minutes post-epinephrine or vehicle injections. There was a main effect of exercise to reduce circulating NEFA concentrations $(P<0.05)$, despite circulating glycerol concentrations being similar between groups $(P=0.25$; Fig. $3.3, A$ and $B)$.

In addition to having direct effects on the liver, epinephrine increases glucagon while reducing serum insulin concentrations (Hamilton et al., 2018; Sherwin \& Sacca, 1984; Yong Zhang et al., 2018). As insulin suppresses, and glucagon increases, hepatic glycogenolysis and hepatic gluconeogenesis (Heyworth et al., 1983; Petersen et al., 1998; D. H. Wasserman et al., 1989), we wanted to determine if the blunted epinephrine mediated increase in blood glucose and liver glycogenolysis in exercised mice could be related to differences in these hormones. There was a main effect of both epinephrine $(P<0.0001)$ and exercise $(P<0.05)$ to increase circulating glucagon levels (Fig. 3.3C). There was a main effect of epinephrine $(P<0.0001)$ and exercise $(P<0.001)$ (Fig. $3.3 D)$ to reduce serum insulin, with a non-significant trend $(P=0.07$; Fig. $3.3 E)$ for the relative decline in insulin with epinephrine treatment to be larger in SED mice. Taken together, these findings provide evidence that epinephrine-induced changes in insulin and glucagon do not explain the blunted reduction in liver glycogen and blunted rise in blood glucose in TR mice.

\subsubsection{Exercise training reduces epinephrine-induced increases in gluconeogenic gene expression} It is well known that epinephrine activates gluconeogenic machinery in the liver (Sherwin \& Sacca, 1984; Sokal \& Sarcione, 1959). To test if the blunted increase in glucose output in trained mice 
was due to a downregulation of gluconeogenic enzymes, we measured G6Pase and PEPCK gene expression and protein content. There was an exercise by epinephrine interaction for G6pc expression such that epinephrine increased mRNA expression by $212 \%$ in SED mice, compared to a $46 \%$ decrease in TR mice $(P<0.001$; Fig. 3.4A). There was an exercise by epinephrine interaction for $P c k 1 \mathrm{mRNA}$ expression $(P=0.046)$. Specifically, exercise increased expression in VEH mice by $59 \%$ ( $P<0.05$; Fig. 3.4B). However, there were no differences in the protein content of G6Pase and PEPCK across groups (Fig. 3.4, $C$ and $D$ ).
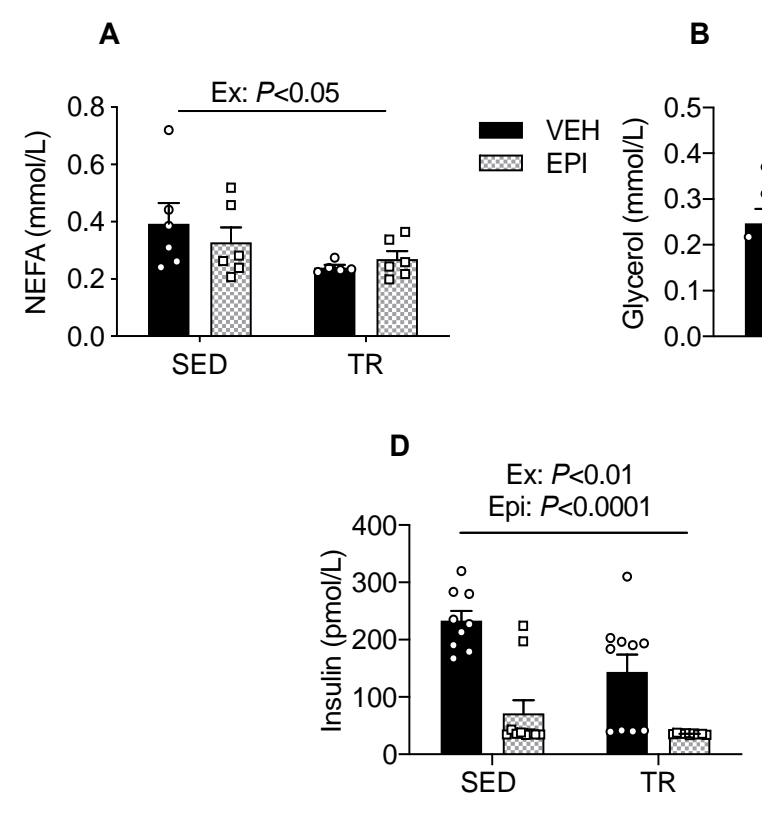

B

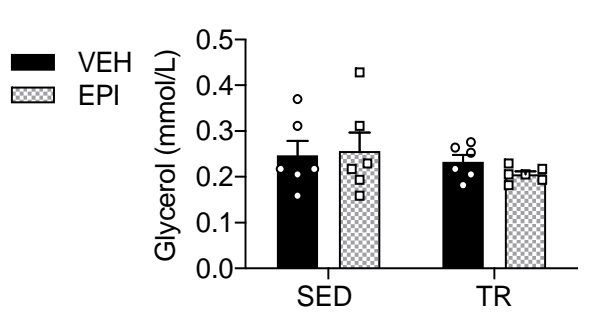

C

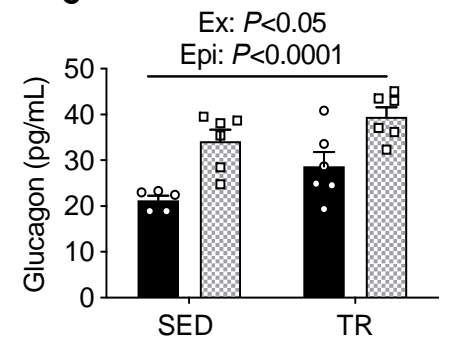

E

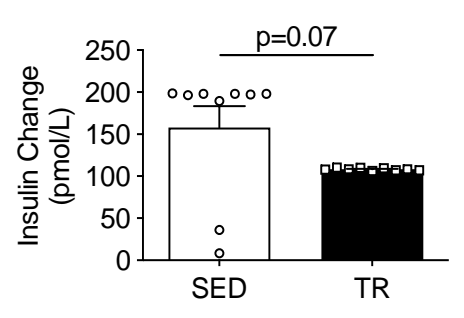

Figure 3.3 Circulating metabolites and glucoregulatory hormones are altered in response to an acute epinephrine injection. Serum NEFA $(A)$, glycerol $(B)$, glucagon $(C)$, and insulin $(D)$ concentrations and the relative change in insulin $(E)$ following termination $(n=6-10)$. Data were analyzed by two-way ANOVA. Ex - denotes main effect of exercise training. Epi - denotes main effect of epinephrine. Individual data points are shown where possible. All data are presented as mean \pm SEM 
A
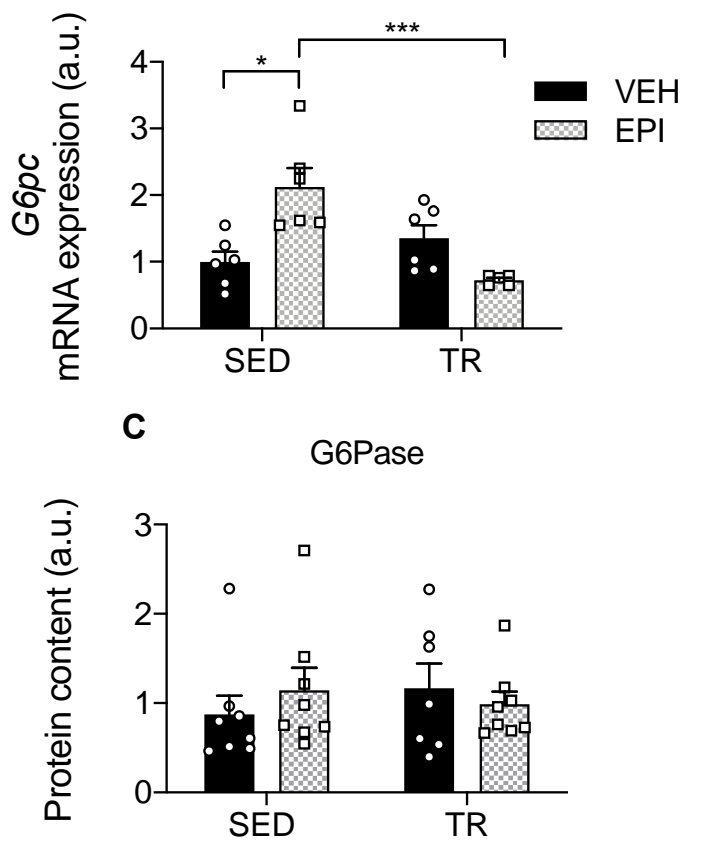

E

\begin{tabular}{l|l|l} 
& $\frac{\text { SED }}{\text { VEH EPI VEH EPI }}$ \\
\hline G6Pase & $=-\cdots \mathrm{kDa}$ \\
PEPCK & & \\
Vinculin & $=\square \mathrm{kDa}$ \\
& $124 \mathrm{kDa}$
\end{tabular}

B

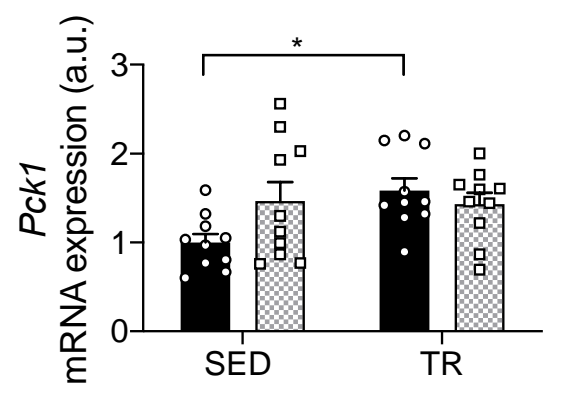

D

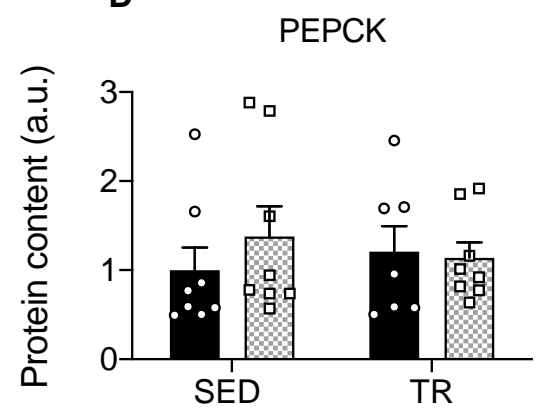

Figure 3.4 Hepatic gene expression and protein content of gluconeogenic markers. Relative hepatic mRNA expression of $G 6 p c(A)(\mathrm{n}=6)$ and $P C K 1(B)(n=10)$. Protein content of G6Pase $(C)$ and PEPCK $(D)(\mathrm{n}=7-8)$ and representative Western blot images $(E)$. Data were analyzed by twoway ANOVA. Significant interactions analyzed by post-hoc comparison denoted by $* P<0.05$, $* * P<0.01, * * * P<0.001$. Individual data points are shown where possible. All data are presented as mean $\pm \mathrm{SEM}$. 


\subsubsection{Epinephrine alters $m R N A$ expression of $\alpha$ - and $\beta$-adrenergic receptors}

In order to examine if exercise impacts adrenergic receptor content, we measured $\alpha$ - and $\beta$ adrenergic receptor gene expression (Adrala, Adra2a, Adrb1 and Adrb2) in the liver. Epinephrine increased Adrala $(P<0.001)$, Adra2a $(P<0.01)$ and Adrbl $(P<0.05)$ expression in SED, but not TR mice (Fig. 3.5). There was an exercise by epinephrine interaction for Adrb2 expression $(P=0.0123)$ such that epinephrine increased expression in SED mice $(P<0.01)$ while this effect was absent in TR mice (Fig. 3.5). These data suggest that exercise alters the adrenergic receptor response to an epinephrine challenge and provides further evidence of a reduced responsiveness to epinephrine in the liver with exercise training. 
A

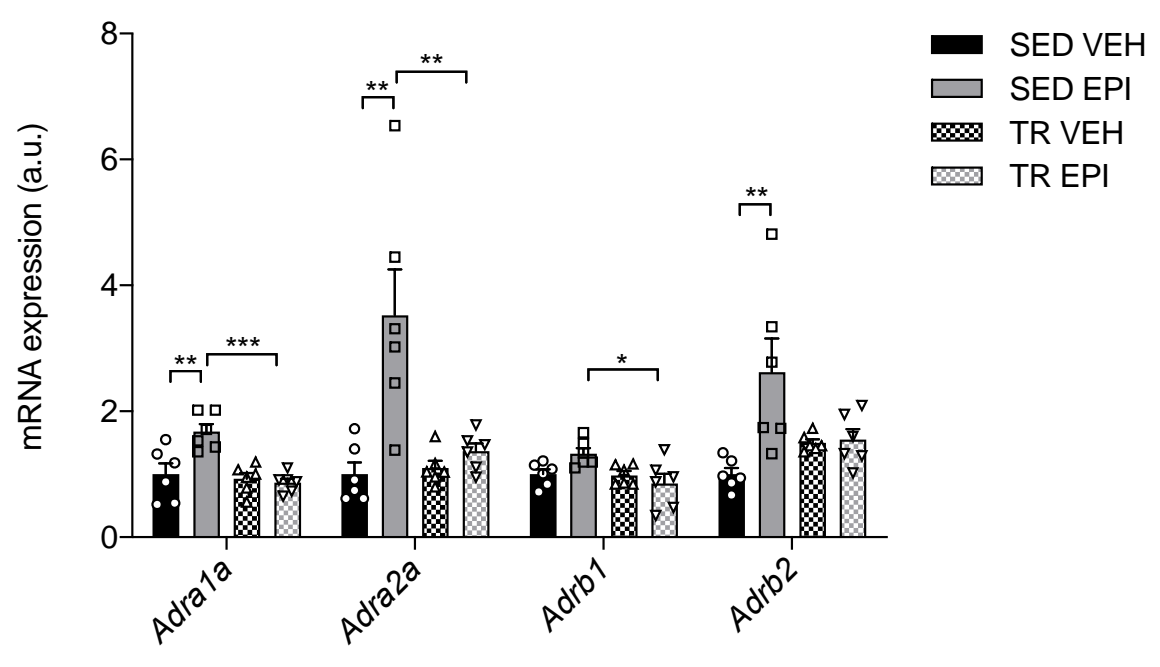

Figure 3.5 Epinephrine increases gene expression of adrenergic receptors in the liver. Relative hepatic mRNA expression of Adrala, Adra2a, Adrb1 and Adrb2 adrenergic receptors ( $n$ $=6)$. Data were analyzed by two-way ANOVA. Significant interactions analyzed by post-hoc comparison denoted by $* P<0.05, * * P<0.01, * * * P<0.001$. Individual data points are shown where possible. All data are presented as mean \pm SEM. 


\subsubsection{Epinephrine activates PKA and reduces insulin signaling in the liver from both sedentary}

and trained mice

Next, we aimed to determine whether the blunted response to epinephrine was reflected by changes in PKA signaling, and reputed negative regulators of PKA, including AMPK and AKT. The activation of PKA is known to increase glycogenolysis and gluconeogenesis and the phosphorylation status of PKA substrates can be used as an indicator of downstream PKA activity (Mowers et al., 2013). There was a main effect of epinephrine to increase the phosphorylation of PKA substrates in the livers of SED and TR mice $(P<0.001)$ (Fig. 3.6A), with post hoc analysis revealing that the main effect of epinephrine was driven by significant increases in SED $(P<0.01)$ but not TR mice. AMPK acts as a cellular energy sensor that regulates glucose and lipid metabolism and can interfere with PKA signaling in hepatocytes (Andreelli et al., 2006; Johanns

et al., 2016; Steinberg \& Carling, 2019). There were no differences in the phosphorylation of AMPK or the downstream target ACC (Fig. 3.6A). The activation of AKT has been shown to attenuate PKA signaling (Kitamura et al., 1999); As shown in Fig. 3.6, and consistent with the circulating insulin data, there was a main effect of epinephrine to reduce the phosphorylation of AKT on both threonine and serine activation sites (pAKT-Thr308, $P<0.01$; pAKT-Ser473; $P<0.01)$. Together these finding provide evidence that differences in AKT and AMPK signaling do not explain the protective effects of exercise training against epinephrine-induced increases in blood glucose and liver glycogen breakdown. 


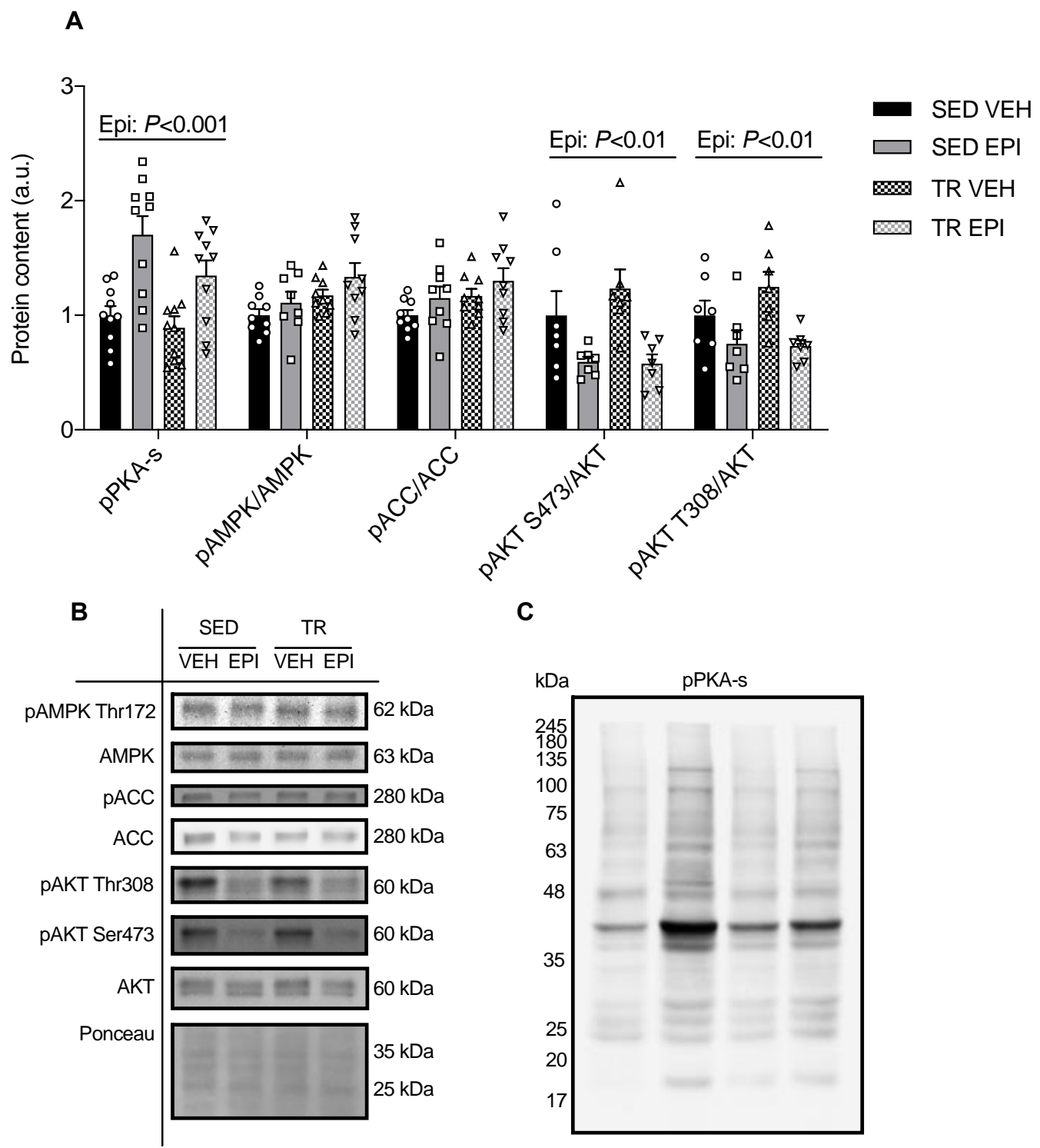

Figure 3.6 Epinephrine activates PKA and reduces markers of insulin signaling in the livers of SED and TR mice. Hepatic protein content $(A)$ and representative Western blot images $(B)$ for pPKA-s, pAMPK/AMPK, pACC/ACC, pAKT S473/AKT, and pAKT T308/AKT ( $n=9-10)$. Data were analyzed by two-way ANOVA. Ex - denotes main effect of exercise training. Epi - denotes main effect of epinephrine. Individual data points are shown where possible. All data are presented as mean \pm SEM. 


\subsubsection{PDE3B and PDE4B in liver are increased with exercise training}

Epinephrine increases hepatic glycogenolysis and HGP in a cAMP-PKA dependent pathway (Bousquet-Mélou et al., 1995; Kolnes et al., 2015; D. H. Wasserman \& Cherrington, 1991). Phosphodiesterase 3B and 4B (PDE3B, PDE4B) are the primary enzymes responsible for the degradation of cAMP in the liver (Avila et al., 2016; Berger et al., 2009; Omori \& Kotera, 2007; Wahlang et al., 2018). Therefore, in order to determine if epinephrine responsiveness was associated with changes in phosphodiesterase expression, we measured Pde3b and Pde4b gene expression in the liver. There was a main effect of exercise to increase $P d e 3 b$ and $P d e 4 b$ expression $(P<0.05, P<0.01 ;$ Fig. 3.7, $A$ and $B)$, and a main effect of epinephrine to decrease $P d e 4 b$ expression $(P<0.05)$ (Fig. 3.7B). PDE4B protein content was unaffected by exercise or epinephrine (Fig. 3. 7C). Unfortunately, we could not determine PDE3B protein content as we could not obtain a quality primary antibody. 

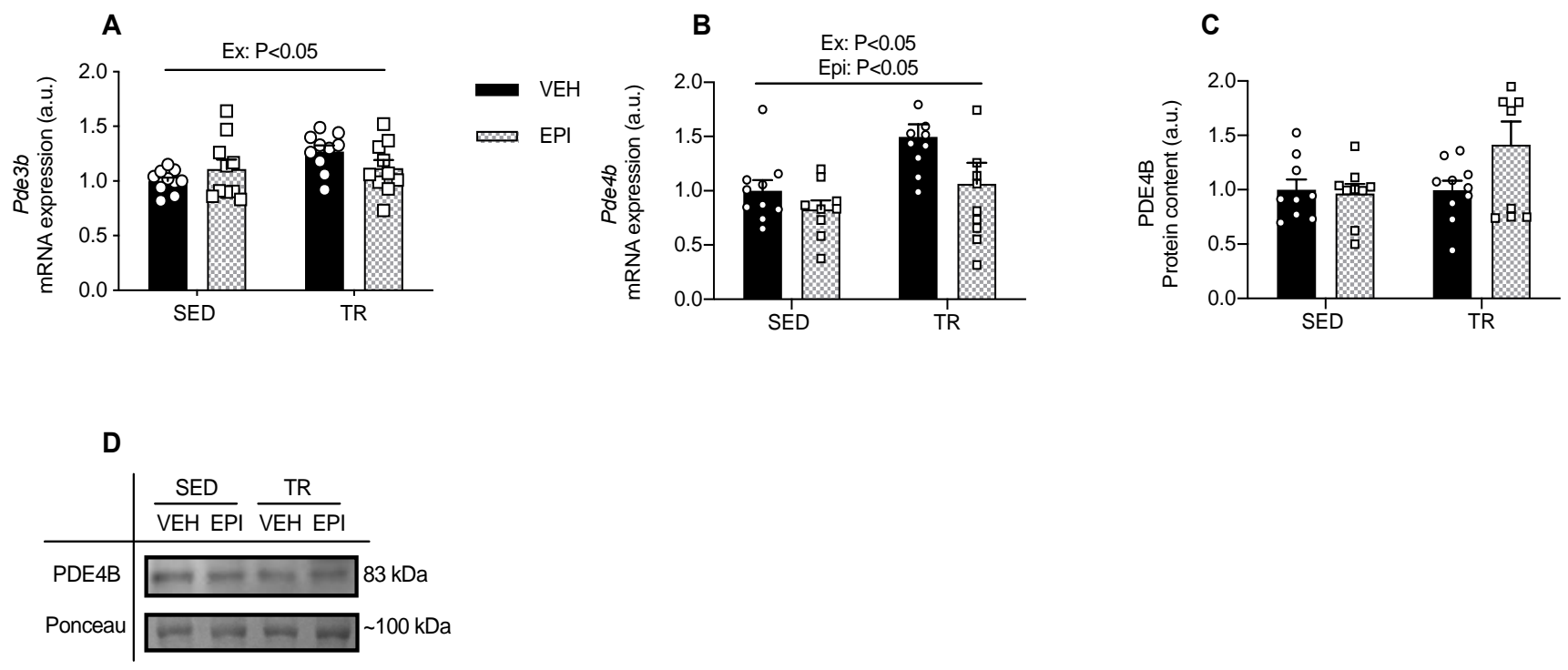

Figure 3.7 Changes in cAMP-degrading enzyme phosphodiesterase 3B and 4B do not account for altered glucose responses between SED and TR mice. Relative hepatic mRNA expression of PDE3B $(A)$ and PDE4B $(B)(n=10)$. Hepatic protein content $(C)$ and representative western blot images (D) for PDE4B $(n=10)$. Data were analyzed by two-way ANOVA. Ex denotes main effect of exercise training. Epi - denotes main effect of epinephrine. Individual data points are shown where possible. All data are presented as mean \pm SEM. 


\subsubsection{Acute VWR does not induce liver epinephrine resistance}

A single bout of exercise can have long lasting metabolic effects (Richter et al., 1926; Steenberg et al., 2019; Sylow \& Richter, 2019). Therefore, to determine if a single night of wheel running could affect liver responsiveness to epinephrine, the previous experiment was repeated, however, exercised mice (EX) ran on wheels for only one night $(16: 00 \mathrm{~h}$ to 8:00 h) instead of 12 days. EX mice ran an average of $4.07 \pm 0.58 \mathrm{~km}$ for a total average time of $7.54 \pm 0.73 \mathrm{~h}$. There was a main effect of epinephrine $(P<0.0001)$ and overnight VWR $(P<0.01)$ to increase blood glucose (Fig. 3.8A). Liver protein content of pPKA substrates were increased with epinephrine treatment with no effect of exercise $(P<0.001$, Fig. $3.8 B, G)$. Epinephrine reduced hepatic glycogen content $(P<0.001)$ and EX mice experienced a greater depletion in hepatic glycogen levels $(P<0.05$, Fig. 3.8, $C$ and $D$ ). Epinephrine and exercise did not impact serum glycerol concentrations (Fig. 3.8E), however there was a main effect of overnight VWR to reduce serum NEFA concentrations $(P<0.05$; Fig. $3.8 F)$. Thus, a single bout of exercise does not alter the hepatic response to an epinephrine challenge. 


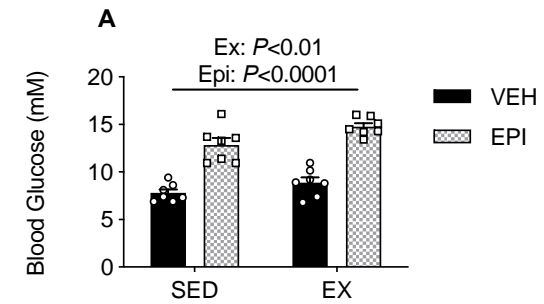

D

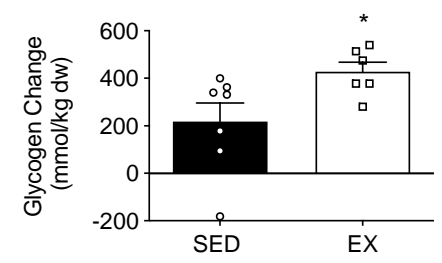

G

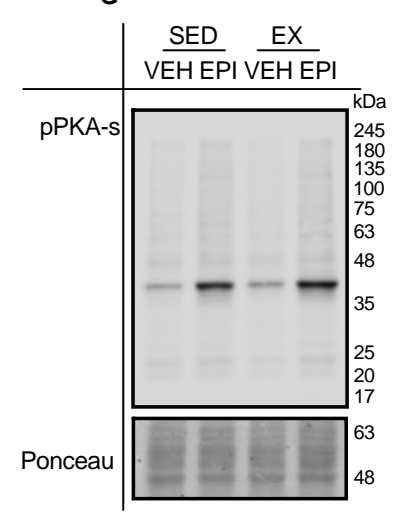

B

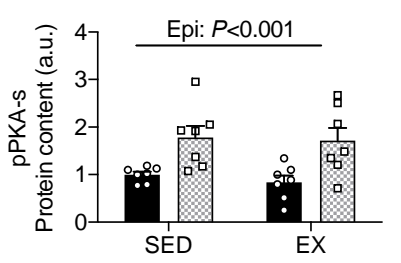

E

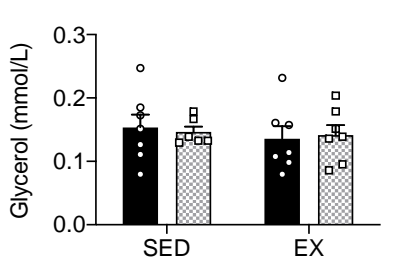

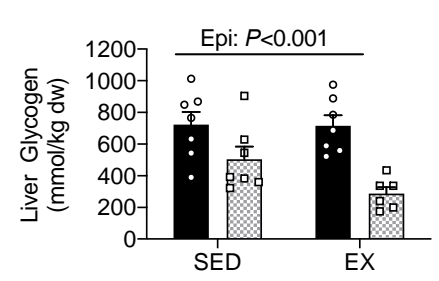

F

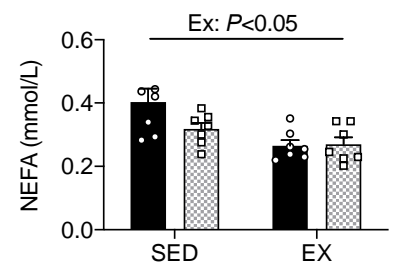

Figure 3.8 Acute VWR does not change the metabolic response to epinephrine. Blood glucose concentration 15 minutes after epinephrine injection $(A)$. Hepatic protein content $(B)$ for pPKA-s $(n=7)$. Hepatic glycogen content $(C ; n=10)$ and the relative decline in glycogen between SED and EX mice after epinephrine administration $(D)$. Glycerol $(E)$ and NEFA $(F)$ plasma concentrations calculated following termination $(n=7)$. Representative Western blot images for pPKA-s $(G)$. Data were analyzed by two-way ANOVA. Ex - denotes main effect of acute VWR. Epi - denotes main effect of epinephrine. ${ }^{*} P<0.05$. Individual data points are shown where possible. All data are presented as mean $\pm \mathrm{SEM}$. 


\subsection{Discussion}

As epinephrine plays a central role in fuel mobilization during exercise and given the large contribution of the liver to systemic glucose homeostasis, we wanted to investigate how exercise training influences hepatic $\beta$-adrenergic responsiveness. We provide evidence that exercise training reduces the response of the liver to a pharmacological epinephrine challenge in vivo. In support of this we show that in trained, compared to sedentary mice, 1) the rise in blood glucose 15 minutes following an epinephrine injection was significantly blunted, 2) the relative depletion in liver glycogen was reduced, 3) the phosphorylation of PKA substrates appeared to be attenuated and 4) the induction of a number of PKA-sensitive genes was decreased. While the relative depletion in glycogen content was larger in sedentary animals, suggestive of increased glycogenolysis, both epinephrine-treated groups displayed similar liver glycogen content. Whether the larger glucose response in sedentary mice was due to increases in the gluconeogenic pathway remains unknown. Furthermore, wheel running mediated adaptations in skeletal muscle and/or adipose tissue could also play a role in the reduced glucose response to an epinephrine challenge.

In addition to having direct effects on the liver, epinephrine also impacts the secretion of the pancreatic hormones such as glucagon (Hamilton et al., 2018) and insulin (Han \& Bonen, 1998; Peterhoff et al., 2003). There were main effects of both exercise and epinephrine to increase circulating glucagon and reduce insulin. Taken together, these findings provide evidence that epinephrine induced changes in glucagon and insulin are unlikely to explain the impaired response of the liver to epinephrine in trained mice.

Epinephrine-stimulated glycogenolysis and gluconeogenesis occurs primarily through the $\beta$-AR coupled adenylyl cyclase (AC)-cAMP cascade (Y. Kawai \& Arinze, 1983; Schmelck \& Hanoune, 1980). To determine if differences in the expression of $\beta$-adrenergic receptors could 
explain the blunted response to epinephrine, we measured the mRNA expression of both $\alpha$ - and $\beta$ adrenergic receptors. Upon epinephrine injection, we observed larger increases in hepatic Adrala, Adra $2 a$ and Adbrl gene expression in the sedentary compared to trained mice. This agrees with our primary observation of reduced blood glucose and liver glycogen depletion in the trained mice 15 minutes following epinephrine injection. While we have not been able to reliably detect the protein content of $\beta$-adrenergic receptors by Western blotting, our gene expression analysis provides evidence that the blunted effects of epinephrine on the liver are not secondary to reductions in adrenergic receptors in trained mice.

The effects of exercise training on $\beta$-adrenergic receptor sensitivity and density has been studied before in numerous tissues. In isolated human adipose tissue, a single bout of exercise increases catecholamine-induced lipolysis (Crampes et al., 1988; Riviere et al., 1989; Wahrenberg et al., 1987, 1991). In myocardial membranes from swim-trained rats, $\beta$-adrenergic receptor number was significantly reduced in comparison to sedentary rats (Werle et al., 1990). In trained diabetic rats, rates of sodium-fluoride induced adenylate cyclase activity were increased in soleus but not vastus lateralis muscles, in comparison to sedentary diabetic controls (Plourde et al., 1992). Mazzeo et al. assessed $\beta 1$ and $\beta 2$ adrenergic receptor density and affinity in the soleus, heart, and livers from treadmill trained and sedentary rats (Mazzeo et al., 1995). In the heart, $\beta$-receptor binding affinity was significantly reduced in trained animals and there was a non-significant trend of training to reduce $\beta 1$ - and $\beta 2$-receptor density. In soleus muscle, training decreased only $\beta 1$ receptor density. However, there was no effect of exercise to alter $\beta$-receptor density or binding affinity in the liver. In rats treated with epinephrine twice-daily for 28 days $(0.3 \mathrm{mg} \cdot \mathrm{kg}-1)$, there was a marked reduction in the epinephrine-induced glycogenolytic response in comparison to untreated control rats (Rousseau-Migneron et al., 1975). These findings are consistent with our 
data and would perhaps suggest that repeated surges in epinephrine with each bout of exercise could serve as a signal to reduce liver epinephrine responsiveness with training.

Activation of PDE3B or PDE4B triggers the breakdown of cAMP in the liver which can attenuate epinephrine or glucagon-stimulated increases in cAMP and PKA signaling (Johanns et al., 2016; Xie et al., 2018). Bousquet-Mélou et al. found that phosphodiesterase attenuated $\beta$ adrenergic stimulated lipolysis in adipocytes (Bousquet-Mélou et al., 1995). In our study, exercise training increased gene expression of the two main cAMP-selective phosphodiesterases found in the liver, PDE3B and PDE4B. While there were no differences within the epinephrine-treated groups, this suggests that exercise-induced increases in phosphodiesterases may underlie the liver's reduced response to epinephrine. Recently, AMPK was shown to phosphorylate and activate PDE4B, and subsequently inhibit glucagon-stimulated increases in hepatic cAMP (Johanns et al., 2016). AMPK has also been reported to regulate liver glycogenolysis during exercise (Andreelli et al., 2006; Hughey et al., 2017; Steinberg et al., 2010). However, in the current study neither exercise training nor acute treatment with epinephrine impacted liver AMPK signaling. These findings provide evidence that AMPK does not explain the attenuated responsiveness to epinephrine in livers from exercise trained mice.

Reduced hepatic $\beta$-adrenergic responsiveness would be an advantageous adaptation in the context of exercise performance and substrate selection. It is well-known that endurance trained subjects experience a reduction in glucose utilization and a consequent increase in fat oxidation during exercise, which helps to delay the onset of fatigue (Henriksson, 1977; Phillips et al., 1996). In a study by Baldwin et al., 16-weeks of swim training protected against rapid muscle and liver glycogen depletion during an acute treadmill test (Baldwin et al., 1975). The authors speculated that the reduced catecholamine levels in the trained animals may explain the glycogen sparing 
effect. Our data, showing an effect of training to blunt the glucose response to epinephrine, reduce glycogen depletion and the expression of adrenergic receptor genes, supports the effect of hepatic glycogen sparing and would suggest that an altered response to epinephrine could also be involved in this phenomenon.

To date, this is the first study to investigate the impact of exercise training on hepatic adrenergic responsiveness and the potential underlying mechanisms therein. Brief exercise training was able reduce the liver's responsiveness to an epinephrine challenge. Exercise trained mice experienced a reduced increase in blood glucose, diminished relative depletion of liver glycogen stores, and reductions in gluconeogenic gene expression. Importantly, these effects were not recapitulated with a single, overnight bout of wheel running suggesting that these adaptations were training dependent. From a mechanistic perspective, exercise training increased the gene expression of PDE3B and PDE4B enzymes, which might contribute to the blunted increase in PKA signaling in livers from trained mice. In the future, this will need to be tested more definitively and it will need to be determined if the observations in male mice can be recapitulated in females.

\section{Funding Information}

This work was funded, in part, through a National Sciences and Engineering Research Council of Canada (NSERC) grant to D.C.W., who is a Tier II Canada Research Chair in Lipids, Metabolism, and Health. H.A.D was supported by an Ontario Graduate Scholarship. G.L.M. was supported by an Ontario Graduate Scholarship and subsequently an NSERC Canada Graduate Scholarship.

L.K.T. was supported by a Dairy Farmers of Ontario Doctoral Research Assistantship and an NSERC Postgraduate Scholarship. 


\section{Author Contributions}

H.A.D. and D.C.W. planned and designed the experiments. H.A.D., L.K.T., and G.L.M. conducted the experiments. H.A.D. and D.C.W analyzed data, prepared figures, and drafted the manuscript. All authors critically reviewed and approved the final version of the manuscript.

\section{Conflict of Interest}

The authors declare no conflicts of interest. 


\section{CHAPTER 4: Additional results and extended discussion}

\subsection{Treadmill exercise test in sedentary and trained mice}

Exercise training leads to a reduced exercise-induced increase in epinephrine (Kjær, 1998; Kjær et al., 1985; Phillips et al., 1996) and blunted reduction in liver glycogen (Phillips et al., 1996). Previously, experiments have used the same absolute intensity exercise protocol for sedentary and trained subjects, despite this representing a lower relative intensity for the exercise-trained subjects (Kjær, 1998). This lower relative intensity could explain why epinephrine and liver glycogen are less perturbed in trained individuals. To assess this, we completed additional experiments using an acute treadmill exercise test designed to match absolute and relative intensities between sedentary and trained mice. This experiment was completed to determine if the blunted response to epinephrine was associated with a glycogen sparing effect in liver during exercise.

Mice were trained by VWR (EX) for 16 days or remained sedentary (SED). All mice were acclimated to the motorized treadmills by running by $5 \mathrm{~m} / \mathrm{min}$ on a $5 \%$ grade for 10 minutes on two successive days (Castellani et al., 2015). On day 14, maximal running speed was determined using a running test adapted from Toti et al. (Toti et al., 2013). Mice began running at $10 \mathrm{~m} / \mathrm{min}$ at a $5 \%$ incline for 3 minutes, and the speed was increased every 3 min by increments of $3 \mathrm{~m} / \mathrm{min}$. Maximal running speed was defined as the speed at which mice could no longer maintain the pace for $3 \mathrm{~min}$. The maximal running speed was 31.3 and $39.6 \mathrm{~m} / \mathrm{min}$ for SED and EX mice, respectively. Mice in the exercised group had access to wheels in between treadmill acclimation and maximal speed testing days. On day 16 , mice were subject to an exercise test set at $70 \%$ of their mean maximal speed, (SED: $21.9 \mathrm{~m} / \mathrm{min}$; EX: $27.7 \mathrm{~m} / \mathrm{min}$ ). A subset of trained mice ( $\mathrm{n}=7 /$ group) exercised for 120 minutes at a speed of $21.9 \mathrm{~m} / \mathrm{min}$ at a $5 \%$ 
incline, to match the absolute intensity of exercise for the sedentary mice. A subset of mice from both sedentary and trained cohorts did not undergo the running test, serving as sedentary controls. The five groups tested were Sedentary Controls, Sedentary Relative speed exercise, VWR Controls, VWR Relative speed exercise, and VWR Absolute speed exercise (SCon, SRel, VCon, VRel, VAbs, respectively). Mice were killed immediately after the acute bout of exercise, with tissues and blood collected as described in the previous chapter. All wheels were locked overnight prior to the treadmill test.

Voluntary wheel running did not confer any protective effects against glycogen depletion during a 2-hour exercise test. Final liver glycogen content did not differ between SRel and VWR groups (Fig. 4.1B). Perhaps the duration and/or intensity of the exercise challenge precluded us from detecting a significant glycogen sparing effect. Analysis of the relative glycogen change after the 2-hour exercise test revealed a trend of a decrease in glycogen depletion in the VRel group, however this did not reach statistical significance $(P=0.07)$ (Fig. 4.1C). NEFA and glycerol concentrations were significantly elevated in the SRel compared to VRel groups (Fig. 4.1C and 4.1D). Lower NEFA and glycerol concentrations in the VWR-trained groups may be indicative of an endurance training adaptation of increased fatty acid utilization (Jansson \& Kaijser, 1987; van Loon et al., 1999). There were no differences in the phosphorylation of AMPK, as analyzed by western blotting (Fig. 4.1E). 
A

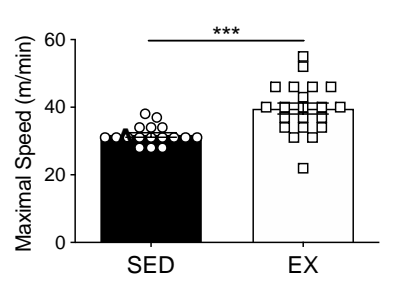

D

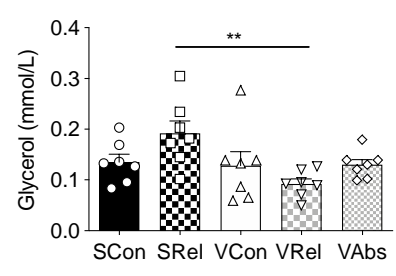

B

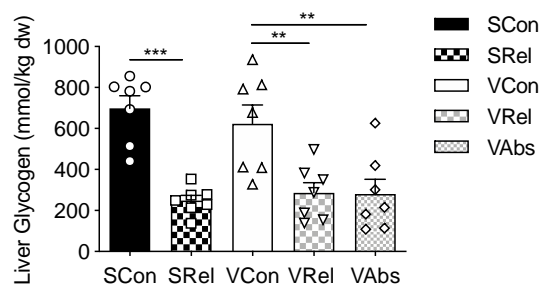

E

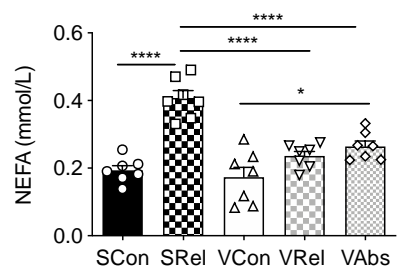

。

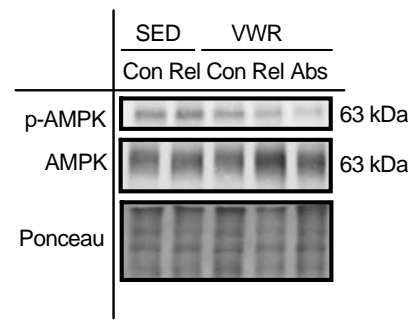

C
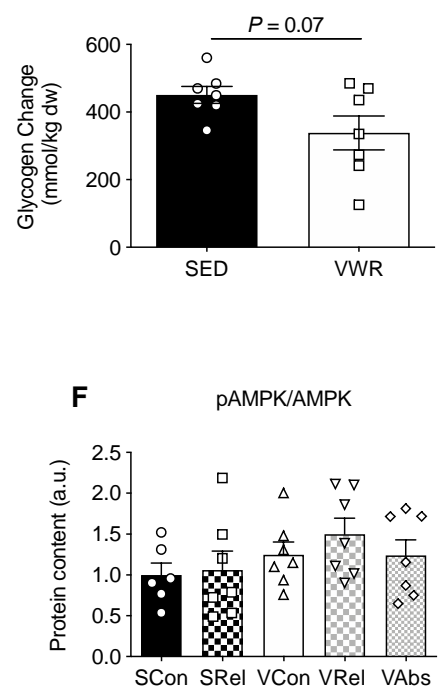

Figure 4.1 VWR training does not protect against hepatic glycogen depletion in a 2-hour treadmill exercise test. 12 days of VWR increased average maximal running speed $(A ; n=20)$. Liver glycogen after the 2-hour treadmill exercise test $(B ; n=7)$. The relative decline in glycogen between SED and VWR mice running at $70 \%$ of their maximal speeds $(C ; n=7)$. Serum glycogen $(D)$ and NEFA $(E)$ measured following termination $(n=7)$. Hepatic protein content $(F)$ and representative western blot images $(G)$ of pAMPK, AMPK, and ponceau stain $(F ; n=7)$. Maximal speed and glycogen change were analyzed by an unpaired t-test. Liver glycogen, serum glycerol and NEFA, and p-/AMPK protein content were analyzed by one-way ANOVA. Significant interactions analyzed by Tukey's multiple comparisons are denoted by $* P<0.05$, $* * P<0.01$, *** $P<0.001, * * * * P<0.0001$. Individual data points are shown where possible. All data are presented as mean $\pm \mathrm{SEM}$. 


\subsection{Limitations}

The liver clears roughly $75-80 \%$ of exogenous catecholamines upon first-pass metabolism, greatly reducing the amount released into circulation (Philpot \& Cantoni, 1941; Sokal \& Sarcione, 1959). The dose of $0.5 \mathrm{mg} / \mathrm{kg} \mathrm{BW}$ was the lowest amount of epinephrine administered intraperitoneally to elicit a significant increase in blood glucose after 15 minutes, however, this may not be representative of physiological levels that the mouse liver is exposed to during exercise or high stress situations. Typically, serum epinephrine concentrations in mice following an acute bout of treadmill exercise range from $\sim 2$ to $7 \mathrm{nmol} / \mathrm{L}$ (Brandt et al., 2017; McKie et al., 2019). Additionally we are limited by our measurements of circulating catecholamines, as the half-life of epinephrine and norepinephrine is approximately 2 minutes and pentobarbital anesthesia can reduce catecholamine concentrations by 3-7 nM (Grouzmann et al., 2003; Labrosse et al., 1961; Silverberg et al., 1978).

Additionally, this work was done in male mice only; females characteristically exhibit reduced autonomic-mediated neuroendocrine responses to exercise and show differences in substrate utilization during exercise compared to males (Davis et al., 2001; Enoksson et al., 2000; Ettinger et al., 1996; Horowitz \& Klein, 2000). It would be of interest to repeat the study in female mice.

It was hypothesized that prior VWR exercise training would reduce rates of glycogen depletion during a 2-hour treadmill test. Similar studies have demonstrated such effect in rats using an acute treadmill exercise test, however, in these studies rats ran for 30 to 45 minutes, a shorter duration of time and, trained rats had been swim or treadmill trained for 13 or 14 weeks prior to (Baldwin et al., 1975). It would be of interest if we would detect differences in liver glycogen if trained mice were VWR trained for longer than 12 days and if the exercise test was 
ceased at an earlier time point. Additionally, mice were trained by VWR but challenged with a forced treadmill exercise test; the change of exercise modality may have impacted the results.

\subsection{Conclusions}

This thesis contributes to the field of knowledge on the metabolic adaptations to exercise training and suggests a novel neuroendocrine mechanism for the hepatic glycogen sparing effect. The main finding is that 12 days of VWR in male mice reduces the gluco-stimulatory response to an intraperitoneal epinephrine injection. Our results showed decreases in epinephrine-induced glycogen depletion and gluconeogenic gene expression in exercise trained mice, changes that were not recapitulated with a single, overnight bout of wheel running, suggesting that these adaptations were training dependent. Trained mice had increased expression of cAMP degrading enzymes, PDE3B and PDE4B, suggestive of increased cAMP degradation and a potential mechanism to explain the partially blunted rise in phosphorylated PKA in trained mice. While the blunted epinephrine response could not be recapitulated in the treadmill exercise test, we speculate this to be due to divergencies in study design. Overall, this study provides evidence of a reduced response of the liver to epinephrine following exercise training and this could be a potential mechanism mediating training-induced sparing of liver glycogen during exercise. 


\section{REFERENCES}

American Physiological Society. (2006). Resource Book for the Design of Animal Exercise Protocol.

Andreelli, F., Foretz, M., Knauf, C., Cani, P. D., Perrin, C., Iglesias, M. A., Pillot, B., Bado, A., Tronche, F., Mithieux, G., Vaulont, S., Burcelin, R., \& Viollet, B. (2006). Liver AMPK alpha2 catalytic subunit is a key target for the control of hepatic glucose production by adiponectin and leptin but not by insulin. Endocrinology.

Anthonsen, M. W., Rönnstrand, L., Wernstedt, C., Degerman, E., \& Holm, C. (1998). Identification of novel phosphorylation sites in hormone-sensitive lipase that are phosphorylated in response to isoproterenol and govern activation properties in vitro. The Journal of Biological Chemistry, 273(1), 215-221. https://doi.org/10.1074/jbc.273.1.215

Armstrong, R. B., \& Laughlin, M. H. (1984). Exercise blood flow patterns within and among rat muscles after training. American Journal of Physiology - Heart and Circulatory Physiology, 15(1). https://doi.org/10.1152/ajpheart.1984.246.1.h59

Arner, P., Engfeldt, P., Hellström, L., Lönnqvist, F., Wahrenberg, H., Sonnenfeld, T., \& Brönnegård, M. (1990). $\beta$-Adrenoreceptor subtype expression in human liver. Journal of Clinical Endocrinology and Metabolism, 71(5), 1119-1126. https://doi.org/10.1210/jcem71-5-1119

Avila, D. V, Barker, D. F., Zhang, J. W., McClain, C. J., Barve, S., \& Gobejishvili, L. (2016). Dysregulation of hepatic cAMP levels via altered Pde4b expression plays a critical role in alcohol-induced steatosis. Journal of Pathology, 240(1), 96-107. https://doi.org/10.1002/path.4760

Baar, K., Wende, A. R., Jones, T. E., Marison, M., Nolte, L. A., Chen, M., Kelly, D. P., \& Holloszy, J. O. (2002). Adaptations of skeletal muscle to exercise: Rapid increase in the transcriptional coactivator PGC-1. FASEB Journal, 16(14), 1879-1886. https://doi.org/10.1096/fj.02-0367com

Baillie, G. S., Tejeda, G. S., \& Kelly, M. P. (2019). Therapeutic targeting of 3',5'-cyclic nucleotide phosphodiesterases: inhibition and beyond. Nature Reviews Drug Discovery, 18(10), 770-796. https://doi.org/10.1038/s41573-019-0033-4

Baker, J. S., McCormick, M. C., \& Robergs, R. A. (2010). Interaction among skeletal muscle metabolic energy systems during intense exercise. Journal of Nutrition and Metabolism, 2010(Figure 1). https://doi.org/10.1155/2010/905612

Baldwin, K. M., Fitts, R. H., Booth, F. W., Winder, W. W., \& Holloszy, J. O. (1975). Depletion of muscle and liver glycogen during exercise. Pflugers Archiv European Journal of Physiology, 354(3), 203-212. https://doi.org/10.1007/bf00584644 
Bearn, A. G., Billing, B., \& Sherlock, S. (1951). The effect of adrenaline and noradrenaline on hepatic blood flow and splanchnic carbohydrate metabolism in man. The Journal of Physiology, 115(4), 430-441. https://doi.org/10.1113/jphysiol.1951.sp004679

Berg, J., Tymoczko, J., \& Stryer, L. (2002). Triacylglycerols Are Highly Concentrated Energy Stores. In Biochemistry (5th Editio). https://www.ncbi.nlm.nih.gov/books/NBK22369

Berger, K., Lindh, R., Wierup, N., Zmuda-Trzebiatowska, E., Lindqvist, A., Manganiello, V. C., \& Degerman, E. (2009). Phosphodiesterase 3B is localized in caveolae and smooth ER in mouse hepatocytes and is important in the regulation of glucose and lipid metabolism. PLoS ONE, 4(3). https://doi.org/10.1371/journal.pone.0004671

Bergström, J., Hermansen, L., Hultman, E., \& Saltin, B. (1967). Diet, Muscle Glycogen and Physical Performance. Acta Physiologica Scandinavica, 71(2-3), 140-150. https://doi.org/10.1111/j.1748-1716.1967.tb03720.x

Bleich, H., \& Boro, E. (1975). Fuel Homeostasis in Exercise. The New England Journal of Medicine, 306(13), 802-805.

Bloom, S. R., Johnson, R. H., Park, D. M., Rennie, M. J., \& Sulaiman, W. R. (1976). Differences in the metabolic and hormonal response to exercise between racing cyclists and untrained individuals. The Journal of Physiology, 258(1), 1-18. https://doi.org/10.1113/jphysiol.1976.sp011403

Bousquet-Mélou, A., Galitzky, J., Moreno, C. M., Berlan, M., \& Lafontan, M. (1995). Desensitization of $\beta$-adrenergic responses in adipocytes involves receptor subtypes and cAMP phosphodiesterase. European Journal of Pharmacology: Molecular Pharmacology, 289(2), 235-247. https://doi.org/10.1016/0922-4106(95)90100-0

Bouvier, M., Collins, S., O’Dowd, B. F., Campbell, P. T., De Blasi, A., Kobilka, B. K., MacGregor, C., Irons, G. P., Caron, M. G., \& Lefkowitz, R. J. (1989). Two distinct pathways for $\mathrm{cAMP}$-mediated down-regulation of the $\beta 2$-adrenergic receptor. Phosphorylation of the receptor and regulation of its mRNA level. Journal of Biological Chemistry, 264(28), 16786-16792.

Brandt, N., Dethlefsen, M. M., Bangsbo, J., \& Pilegaard, H. (2017). PGC-1 $\alpha$ and exercise intensity dependent adaptations in mouse skeletal muscle. PLoS ONE, 12(10), 1-21. https://doi.org/10.1371/journal.pone.0185993

Brault, J. J., Jespersen, J. G., \& Goldberg, A. L. (2010). Peroxisome proliferator-activated receptor $\gamma$ coactivator $1 \alpha$ or $1 \beta$ overexpression inhibits muscle protein degradation, induction of ubiquitin ligases, and disuse atrophy. Journal of Biological Chemistry, 285(25), 19460-19471. https://doi.org/10.1074/jbc.M110.113092

Bristow, M. R., Ginsburg, R., Umans, V., Fowler, M., Minobe, W., Rasmussen, R., Zera, P., Menlove, R., Shah, P. I. R., Jamieson, S., \& Stinson, E. B. (1986). B1- and B2-Adrenergic- 
Receptor Subpopulations in Nonfailing and Failing Human Ventricular Myocardium: Coupling of Both Receptor Subtypes to Muscle Contraction and Selective B1-Receptor Down-Regulation in Heart Failure. Circulation Research, 59(3), 297-309. http://www.ncbi.nlm.nih.gov/pubmed/2876788

Bylund, B. (1992). Subtypes of a1- and a2-adrenergic receptors. FASEB Journal, 6, 832-839.

Carpene, C., Berlan, M., \& Lafontan, M. (1983). Influence of development and reduction of fat stores on the antilipolytic $\alpha 2$-adrenoceptor in hamster adipocytes: Comparison with adenosine and $\beta$-adrenergic lipolytic responses. Journal of Lipid Research, 24(6), 766-774.

Carpene, C., Galitzky, J., Collon, P., Esclapez, F., Dauzats, M., \& Lafontan, M. (1993). Desensitization of beta-1 and beta-2, but not beta-3, adrenoceptor- mediated lipolytic responses of adipocytes after long-term norepinephrine infusion. Journal of Pharmacology and Experimental Therapeutics, 265(1), 237-247.

Carpene, C., Rebourcet, M. C., Guichard, C., Lafontan, M., \& Lavau, M. (1990). Increased alpha- 2-adrenergic binding sites and antilipolytic effect in adipocytes from genetically obese rats. Journal of Lipid Research, 31(5), 811-819.

Castellani, L., Perry, C. G. R., Macpherson, R. E. K., Root-McCaig, J., Huber, J. S., Arkell, A. M., Simpson, J. A., \& Wright, D. C. (2015). Exercise-mediated IL-6 signaling occurs independent of inflammation and is amplified by training in mouse adipose tissue. Journal of Applied Physiology, 119(11), 1347-1354.

https://doi.org/10.1152/japplphysiol.00551.2015

Cherrington, A. D., \& Exton, J. H. (1976). Studies on the Role of cAMP-dependent Protein Kinase in the Actions of Glucagon and Catecholamines on Liver Glycogen Metabolism. Metabolism, 25(11), 1351-1354.

Chin, A. K., Seaman, R., \& Kapileshwarker, M. (1973). Plasma catecholamine response to exercise and cold adaptation. Journal of Applied Physiology, 34(4), 409-412. https://doi.org/10.1152/jappl.1973.34.4.409

Coggan, A. R., Kohrt, W. M., Spina, R. J., Bier, D. M., \& Holloszy, J. O. (1990). Endurance training decreases plasma glucose turnover and oxidation during moderate-intensity exercise in men. Journal of Applied Physiology, 68(3), 990-996. https://doi.org/10.1152/jappl.1990.68.3.990

Coggan, A. R., Swanson, S. C., Mendenhall, L. A., Habash, D. L., \& Kien, C. L. (1995). Effect of endurance training on hepatic glycogenolysis and gluconeogenesis during prolonged exercise in men. The American Journal of Physiology, 268(3 Pt 1), E375-83. https://doi.org/10.1152/ajpendo.1995.268.3.E375

Cohen, P. (2002). The origins of protein phosphorylation. Nature Cell Biology, 4(5). https://doi.org/10.1038/ncb0502-e127 
Coker, R. H., Krishna, M. G., Lacy, D. B., Bracy, D. P., \& Wasserman, D. H. (1997). Role of hepatic $\alpha$ - and $\beta$-adrenergic receptor stimulation on hepatic glucose production during heavy exercise. American Journal of Physiology-Endocrinology and Metabolism, 273(5), E831-E838. https://doi.org/10.1152/ajpendo.1997.273.5.e831

Connolly, C. C., Steiner, K. E., Stevenson, R. W., Neal, D. W., Williams, P. E., Alberti, K. G., \& Cherrington, A. D. (1991). Regulation of glucose metabolism by norepinephrine in conscious dogs. American Journal of Physiology-Endocrinology and Metabolism, 261(6), E764-E772. https://doi.org/10.1152/ajpendo.1991.261.6.e764

Constable, S. H., Favier, R. J., McLane, J. A., Fell, R. D., Chen, M., \& Holloszy, J. O. (1987). Energy metabolism in contracting rat skeletal muscle: Adaptation to exercise training. American Journal of Physiology - Cell Physiology, 253(2). https://doi.org/10.1152/ajpcell.1987.253.2.c316

Cotecchia, S. (2010). The $\alpha 1$-adrenergic receptors: Diversity of signaling networks and regulation. Journal of Receptors and Signal Transduction, 30(6), 410-419. https://doi.org/10.3109/10799893.2010.518152

Crampes, F., Beauville, M., Riviere, D., \& Garrigues, M. (1986). Effect of physical training in humans on the responses of isolated fat cells to epinephrine. Journal of Applied Physiology, 61(1), 25-29. https://doi.org/10.1152/jappl.1986.61.1.25

Crampes, F., Beauville, M., Riviere, D., Garrigues, M., \& Lafontan, M. (1988). Lack of Desensitization of Catecholamine-Induced Lipolysis in Fat Cells From Trained and Sedentary Women After Physical Exercise. Journal of Clinical Endocrinology and Metabolism, 67(5), 1011-1017. https://doi.org/10.1210/jcem-67-5-1011

Cross, D. A. E., Alessi, D. R., Cohen, P., Andjelkovich, M., \& Hemmings, B. A. (1995). Inhibition of glycogen synthase kinase- 3 by insulin mediated by protein kinase B. Nature, 378(6559), 785-789. https://doi.org/10.1038/378785a0

Daaka, Y., Luttrell, L. M., \& Lefkowitz, R. J. (1997). Switching of the coupling of the $\beta 2$ adrenergic receptor to different $g$ proteins by protein kinase A. Nature, 390(6655), 88-91. https://doi.org/10.1038/36362

Davidson, S. R., Burnett, M., \& Hoffman-Goetz, L. (2006). Training effects in mice after longterm voluntary exercise. Medicine and Science in Sports and Exercise, 38(2), 250-255. https://doi.org/10.1249/01.mss.0000183179.86594.4f

Davis, S. N., Galassetti, P., Wasserman, D. H., \& Tate, D. (2001). Effects of morning hypoglycemia on neuroendocrine and metabolic responses to subsequent afternoon hypoglycemia in normal man. Journal of Clinical Endocrinology and Metabolism, 86(5), 2043-2050. https://doi.org/10.1210/jc.86.5.2043

de Leeuw, P. W., Falke, H. E., Punt, R., \& Birkenhäger, W. H. (1978). Noradrenaline secretion 
by the human kidney. Clinical Science and Molecular Medicine. Supplement, 4, 1976-1978. https://doi.org/10.1042/cs055085s

Deuster, P. A., Chrousos, G. P., Luger, A., DeBolt, J. E., Bernier, L. L., Trostmann, U. H., Kyle, S. B., Montgomery, L. C., \& Loriaux, D. L. (1989). Hormonal and metabolic responses of untrained, moderately trained, and highly trained men to three exercise intensities. Metabolism. https://doi.org/10.1016/0026-0495(89)90253-9

Dimsdale, J. E., \& Moss, J. (1980). Short-Term Catecholamine Response to Psychological Stress 1. Psychosomatic Medicine, 42(5). https://journals.lww.com/psychosomaticmedicine/Fulltext/1980/09000/Short_Term_Catech olamine_Response_to_Psychological.3.aspx

Enoksson, S., Talbot, M., Rife, F., Tamborlane, W. V, Sherwin, R. S., \& Caprio, S. (2000). Impaired in vivo stimulation of lipolysis in adipose tissue by selective $\beta 2$-adrenergic agonist in obese adolescent girls. Diabetes, 49(12), 2149-2153.

https://doi.org/10.2337/diabetes.49.12.2149

Ensinger, H., Geisser, W., Brinkmann, A., Wachter, U., Vogt, J., Radermacher, P., Georgieff, M., \& Träger, K. (2002). Metabolic effects of norepinephrine and dobutamine in healthy volunteers. Shock, 18(6), 495-500. https://doi.org/10.1097/00024382-200212000-00002

Erraji-Benchekroun, L., Couton, D., Postic, C., Borde, I., Gaston, J., Guillet, J. G., \& André, C. (2005). Overexpression of $\beta 2$-adrenergic receptors in mouse liver alters the expression of gluconeogenic and glycolytic enzymes. American Journal of Physiology - Endocrinology and Metabolism, 288(4 51-4), 715-723. https://doi.org/10.1152/ajpendo.00113.2004

Ettinger, S. M., Silber, D. H., Collins, B. G., Gray, K. S., Sutliff, G., Whisler, S. K., McClain, J. M., Smith, M. B., Yang, Q. X., \& Sinoway, L. I. (1996). Influences of gender on sympathetic nerve responses to static exercise. Journal of Applied Physiology, 80(1), 245251. https://doi.org/10.1152/jappl.1996.80.1.245

Exton, J., Jefferson, S., Butcher, R., \& Park, C. (1966). Gluconeogenesis in the Perfused Liver. Medicine, 40(May).

Exton, J., \& Park, C. (1967). Control of Gluconeogenesis in Liver. II. Journal of Biological Chemistry, 243(11), 2622-2636.

Fell, R. D., Terblanche, S. E., Winder, W. W., \& Holloszy, J. O. (1981). Adaptive responses of rats to prolonged treatment with epinephrine. The American Journal of Physiology, 241(1). https://doi.org/10.1152/ajpcell.1981.241.1.c55

Fernandez, C., Hansson, O., Nevsten, P., Holm, C., \& Klint, C. (2008). Hormone-sensitive lipase is necessary for normal mobilization of lipids during submaximal exercise. American Journal of Physiology - Endocrinology and Metabolism, 295(1), 179-186.

https://doi.org/10.1152/ajpendo.00282.2007 
Fernqvist-Forbes, E., Hilding, A., Ekberg, K., \& Brismar, K. (1997). Influence of circulating epinephrine and norepinephrine on insulin-like grow th factor binding protein-1 in humans. Journal of Clinical Endocrinology and Metabolism, 82(8), 2677-2680. https://doi.org/10.1210/jcem.82.8.4167

Fink, W. J., Costill, D. L., \& Pollock, M. L. (1977). Submaximal and Maximal Working Capacity of Elite Distance Runners. Part Ii. Muscle Fiber Composition and Enzyme Activities. Annals of the New York Academy of Sciences, 301(1), 323-327. https://doi.org/10.1111/j.1749-6632.1977.tb38210.x

Fitts, R., Booth, F., Winder, W., \& Holloszy, J. (1975). Skeletal muscle respiratory capacity, endurance, and glycogen utilization. American Journal of Physiology, 228(4), 1029-1033. https://doi.org/10.1152/ajplegacy.1975.228.4.1029

Fletcher, J. A., Linden, M. A., Sheldon, R. D., Meers, G. M., Morris, E. M., Butterfield, A., Perfield, J. W., Thyfault, J. P., \& Rector, R. S. (2016). Fibroblast growth factor 21 and exercise-induced hepatic mitochondrial adaptations. American Journal of Physiology Gastrointestinal and Liver Physiology, 310(10), G832-G843. https://doi.org/10.1152/ajpgi.00355.2015

Fletcher, J. A., Meers, G. M., Linden, M. A., Kearney, M. L., Morris, E. M., Thyfault, J. P., \& Rector, R. S. (2014). Impact of various exercise modalities on hepatic mitochondrial function. Medicine and Science in Sports and Exercise, 46(6), 1089-1097. https://doi.org/10.1249/MSS.0000000000000223

Franke, W. D., Stephens, G. M., \& Schmid, P. G. (1998). Effects of intense exercise training on endothelium-dependent exercise-induced vasodilatation. Clinical Physiology, 18(6), 521528. https://doi.org/10.1046/j.1365-2281.1998.00122.x

Frendo-Cumbo, S., MacPherson, R. E. K., \& Wright, D. C. (2016). Beneficial effects of combined resveratrol and metformin therapy in treating diet-induced insulin resistance. Physiological Reports, 4(15). https://doi.org/10.14814/phy2.12877

Fröberg, S. 0., Hultman., E., \& Nilsson, L. H. :son. (1975). Effect of Noradrenaline on Triglyceride and Glycogen Concentrations in Liver and Muscle from Man. Metabolism: Clinical and Experimental, 24(2), 119-126.

Fujii, N., Miyazak, H., Homma, S., \& Ikegami, H. (1993). Dynamic exercise induces translocation of $\beta$-adrenergic receptors in human lymphocytes. Acta Physiologica Scandinavica, 148(4), 463-464. https://doi.org/10.1111/j.1748-1716.1993.tb09583.x

Ghosh, P. M., Shu, Z. J., Zhu, B., Lu, Z., Ikeno, Y., Barnes, J. L., Yeh, C. K., Zhang, B. X., Katz, M. S., \& Kamat, A. (2012). Role of $\beta$-adrenergic receptors in regulation of hepatic fat accumulation during aging. Journal of Endocrinology, 213(3), 251-261. https://doi.org/10.1530/JOE-11-0406 
Goldstein, D. S. (2010). Adrenaline and Noradrenaline. Encyclopedia of Life Sciences, September. https://doi.org/10.1002/9780470015902.a0001401.pub2

Goldstein, D. S., McCarty, R., Polinsky, R. J., \& Kopin, I. J. (1983). Relationship between plasma norepinephrine and sympathetic neural activity. Hypertension, 5(4), 552-559. https://doi.org/10.1161/01.HYP.5.4.552

Gonzalez, J. T., Fuchs, C. J., Betts, J. A., \& van Loon, L. J. C. (2016). Liver glycogen metabolism during and after prolonged endurance-type exercise. American Journal of Physiology-Endocrinology and Metabolism, 311(3), E543-E553. https://doi.org/10.1152/ajpendo.00232.2016

Gray, L. R., Sultana, R., Rauckhorst, A. J., Oonthonpan, L., Tompkins, S. C., Sharma, A., Fu, X., Miao, R., Pewa, A. D., Brown, K. S., Lane, E. E., Dohlman, A., Zepeda-Orozco, D., Xie, J., Rutter, J., Norris, A. W., Cox, J. E., Burgess, S. C., Potthoff, M. J., \& Taylor, E. B. (2015). Hepatic Mitochondrial Pyruvate Carrier 1 is Required for Efficient Regulation of Gluconeogenesis and Whole-body Glucose Homeostasis. Cell Metabolism, 22(4), 669-681.

Green, H. J., Helyar, R., Ball-Burnett, M. E., Kowalchuk, N., Symon, S., \& Farranc, B. (1992). Metabolic adaptations to training precede changes in muscle mitochondrial capacity. Journal of Applied Physiology, 72(2), 484-491. www.physiology.org/journal/jappl

Green, H. J., Jones, L. L., Houston, M. E., Ball-Burnett, M. E., \& Farrance, B. W. (1989). Muscle energetics during prolonged cycling after exercise hypervolemia. Journal of Applied Physiology, 66(2), 622-631. https://doi.org/10.1152/jappl.1989.66.2.622

Gromada, J., Bokvist, K., Ding, W. G., Barg, S., Buschard, K., Renström, E., \& Rorsman, P. (1997). Adrenaline stimulates glucagon secretion in pancreatic A-cells by increasing the $\mathrm{Ca} 2+$ current and the number of granules close to the L-type $\mathrm{Ca} 2+$ channels. Journal of General Physiology, 110(3), 217-228. https://doi.org/10.1085/jgp.110.3.217

Grouzmann, E., Cavadas, C., Grand, D., Moratel, M., Aubert, J.-F., Brunner, H. R., \& Mazzolai, L. (2003). Blood sampling methodology is crucial for precise measurement of plasma catecholamines concentrations in mice. Pflugers Arch-Eur J Physiol, 447, 254-258. https://doi.org/10.1007/s00424-003-1140-x

Haase, T. Nø., Ringholm, S., Leick, L., Biens Ø, R. S., Kiilerich, K., Johansen, S., Nielsen, M. M., Wojtaszewski, Jø. F. P., Hidalgo, J., Pedersen, P. A., \& Pilegaard, H. (2011). Role of PGC-1 $\alpha$ in exercise and fasting-induced adaptations in mouse liver. American Journal of Physiology - Regulatory Integrative and Comparative Physiology, 301(5), 1501-1509. https://doi.org/10.1152/ajpregu.00775.2010

Hamilton, A., Zhang, Q., Salehi, A., Willems, M., Knudsen, J. G., Ringgaard, A. K., Chapman, C. E., Gonzalez-Alvarez, A., Surdo, N. C., Zaccolo, M., Basco, D., Johnson, P. R. V., Ramracheya, R., Rutter, G. A., Galione, A., Rorsman, P., \& Tarasov, A. I. (2018). Adrenaline stimulates glucagon secretion by Tpc2-Dependent ca $2+$ mobilization from 
acidic stores in pancreatic a-Cells. Diabetes, 67(6), 1128-1139. https://doi.org/10.2337/db17-1102

Han, X.-X., \& Bonen, A. (1998). Epinephrine translocates GLUT-4 but inhibits insulinstimulated glucose transport in rat muscle. American Journal of Physiology-Endocrinology and Metabolism, 274(4), E700-E707. https://doi.org/10.1152/ajpendo.1998.274.4.E700

Harant, I., Marion-Latard, F., Crampes, F., De Glisezinski, I., Berlan, M., Stich, V., \& Rivière, D. (2002). Effect of a long-duration physical exercise on fat cell lipolytic responsiveness to adrenergic agents and insulin in obese men. International Journal of Obesity, 26, 13731378. https://doi.org/10.1038=sj.ijo.0802072

Hauck, L., Stanley-Hasnain, S., Fung, A., Grothe, D., Rao, V., Mak, T. W., \& Billia, F. (2017). Cardiac-specific ablation of the E3 ubiquitin ligase Mdm2 leads to oxidative stress, broad mitochondrial deficiency and early death. In PLoS ONE (Vol. 12, Issue 12). https://doi.org/10.1371/journal.pone.0189861

Hausdorff, W. P., Caron, M. G., \& Lefkowitz, R. J. (1990). Turning off the signal: densenitization of beta-adrenergic receptor function. The FASEB Journal, 4, 2881-2889.

Henriksson, J. (1977). Training Induced Adaptation of Skeletal Muscle and Metabolism During Submaximal Exercise. Journal of Physiology, 270, 661-675.

Heyworth, C. M., Wallace, A. V, \& Houslay, M. D. (1983). Insulin and glucagon regulate the activation of two distinct membrane-bound cyclic AMP phosphodiesterases in hepatocytes. Biochem. J, 214, 99-110. https://www.ncbi.nlm.nih.gov/pmc/articles/PMC1152215/pdf/biochemj00345-0103.pdf

Hirose, H., Maruyama, H., Itoh, K., Koyama, K., Kido, K., \& Saruta, T. (1992). Alpha-2 adrenergic agonism stimulates islet glucagon release from perfused rat pancreas: possible involvement of alpha-2A adrenergic receptor subtype. Acta Endocrinologica, 127(3), 279283. https://doi.org/10.1530/acta.0.1270279

Hoffman, B. B., \& Lefkowitz, R. (1980). Radioligand binding studies of adrenergic receptors: New insights into molecular and physiological regulation. Pharmocol. Toxicol., 20, 581608.

Holloszy, J. O. (1967). Biochemical Adaptations in Muscle. The Journal of Biological Chemistry, 242(9), 2278-2282. https://doi.org/10.1016/j.cell.2007.03.044.Asymmetric

Holloszy, J. O., \& Coyle, E. F. (1984). Adaptations of skeletal muscle to endurance exercise and their metabolic consequences. Journal of Applied Physiology: Respiratory, Environmental and Exercise Physiology, 56(4), 831-838. https://doi.org/10.1152/jappl.1984.56.4.831

Horowitz, J. F., \& Klein, S. (2000). Whole body and abdominal lipolytic sensitivity to epinephrine is suppressed in upper body obese women. American Journal of Physiology - 
Endocrinology and Metabolism, 278(6 41-6).

https://doi.org/10.1152/ajpendo.2000.278.6.e1144

Hostrup, M., Kalsen, A., Bangsbo, J., Hemmersbach, P., Karlsson, S., \& Backer, V. (2014). High-dose inhaled terbutaline increases muscle strength and enhances maximal sprint performance in trained men. European Journal of Applied Physiology, 114(12), 2499-2508. https://doi.org/10.1007/s00421-014-2970-2

Howard Hartley, L., Mason, J. W., Hogan, R. P., Jones, L. C., Kotchen, T. A., Mougey, E. H., Wherry, F. E., Penningston, L. L., \& Ricketts, P. T. (1972). Multiple hormonal responses to graded exercise in relation to physical training. J Appl Physiol, 33(5), 607-610.

Howlett, K., Galbo, H., Lorentsen, J., Bergeron, R., Zimmerman-Belsing, T., Bülow, J., FeldtRasmussen, U., \& Kjær, M. (1999). Effect of adrenaline on glucose kinetics during exercise in adrenalectomised humans. Journal of Physiology, 519(3), 911-921.

https://doi.org/10.1111/j.1469-7793.1999.0911n.x

Hughey, C. C., James, F. D., Bracy, D. P., Patrick Donahue, E., Young, J. D., Viollet, B., Foretz, M., \& Wasserman, D. H. (2017). Loss of hepatic AMP-activated protein kinase impedes the rate of glycogenolysis but not gluconeogenic fluxes in exercising mice. Journal of Biological Chemistry, 292(49), 20125-20140. https://doi.org/10.1074/jbc.M117.811547

Huijsman, E., Van De Par, C., Economou, C., Van Der Poel, C., Lynch, G. S., Schoiswohl, G., Haemmerle, G., Zechner, R., \& Watt, M. J. (2009). Adipose triacylglycerol lipase deletion alters whole body energy metabolism and impairs exercise performance in mice. American Journal of Physiology - Endocrinology and Metabolism, 297(2), 505-513. https://doi.org/10.1152/ajpendo.00190.2009

Iles, R. A., Cohen, R. D., Baron, P. G., Smith, J. A., \& Henderson, R. M. (1981). The effect of adrenaline on hepatic lactate uptake in the acidotic partially ischaemic rat liver. Clinical Science, 60(5), 543-548. https://doi.org/10.1042/cs0600543

Issekutz, B., \& Allen, M. (1972). Effect of catecholamines and methylprednisolone on carbohydrate metabolism of dogs. Metabolism, 21(1), 48-59. https://doi.org/10.1016/00260495(72)90019-4

Jansson, E., \& Kaijser, L. (1987). Substrate utilization and enzymes in skeletal muscle of extremely endurance-trained men. Journal of Applied Physiology, 62(3), 999-1005. https://doi.org/10.1152/jappl.1987.62.3.999

Jelen, S., Wacker, S., Aponte-Santamaría, C., Skott, M., Rojek, A., Johanson, U., Kjellbom, P., Nielsen, S., De Groot, B. L., \& Rützler, M. (2011). Aquaporin-9 protein is the primary route of hepatocyte glycerol uptake for glycerol gluconeogenesis in mice. Journal of Biological Chemistry, 286(52), 44319-44325. https://doi.org/10.1074/jbc.M111.297002

Jensen, J., Brennesvik, E. O., Lai, Y. C., \& Shepherd, P. R. (2007). GSK-3ß regulation in 
skeletal muscles by adrenaline and insulin: Evidence that PKA and PKB regulate different pools of GSK-3. Cellular Signalling, 19(1), 204-210.

https://doi.org/10.1016/j.cellsig.2006.06.006

Jiang, G., \& Zhang, B. B. (2003). Glucagon and regulation of glucose metabolism. American Journal of Physiology - Endocrinology and Metabolism, 284(4 47-4).

https://doi.org/10.1152/ajpendo.00492.2002

Jocken, J. W. E., Goossens, G. H., Van Hees, A. M. J., Frayn, K. N., Van Baak, M., Stegen, J., Pakbiers, M. T. W., Saris, W. H. M., \& Blaak, E. E. (2008). Effect of beta-adrenergic stimulation on whole-body and abdominal subcutaneous adipose tissue lipolysis in lean and obese men. Diabetologia, 51(2), 320-327. https://doi.org/10.1007/s00125-007-0866-y

Johanns, M., Lai, Y. C., Hsu, M. F., Jacobs, R., Vertommen, D., Van Sande, J., Dumont, J. E., Woods, A., Carling, D., Hue, L., Viollet, B., Foretz, M., \& Rider, M. H. (2016). AMPK antagonizes hepatic glucagon-stimulated cyclic AMP signalling via phosphorylationinduced activation of cyclic nucleotide phosphodiesterase 4B. Nature Communications, 7. https://doi.org/10.1038/ncomms 10856

Karlsson, J., Nordesjö, L. -O, \& Saltin, B. (1974). Muscle Glycogen Utilization during Exercise after Physical Training. Acta Physiologica Scandinavica. https://doi.org/10.1111/j.17481716.1974.tb05579.x

Kawai, Y., \& Arinze, I. J. (1983). beta-adrenergic receptors in rabbit liver plasma membranes. Predominance of beta2-receptors and mediation of adrenergic regulation of hepatic glycogenolysis. Journal of Biological Chemistry.

Kawai, Yumiko, Powell, A., \& Arinze, I. J. (1986). Adrenergic Receptors in Human Liver Plasma Membranes: Predominance of beta2- and alpha1-Receptor Subtypes. Journal of Clinical Endocrinology and Metabolism, 62(5).

Kitamura, T., Kitamura, Y., Kuroda, S., Hino, Y., Ando, M., Kotani, K., Konishi, H., Matsuzaki, H., Kikkawa, U., Ogawa, W., \& Kasuga, M. (1999). Insulin-Induced Phosphorylation and Activation of Cyclic Nucleotide Phosphodiesterase 3B by the Serine-Threonine Kinase Akt. Molecular and Cellular Biology, 19(9), 6286-6296. https://doi.org/10.1128/mcb.19.9.6286

Kjær, M. (1998). Adrenal medulla and exercise training. European Journal of Applied Physiology and Occupational Physiology, 77(3), 195-199. https://doi.org/10.1007/s004210050321

Kjær, M., Christensen, N. J., Sonne, B., Richter, E. A., \& Galbo, H. (1985). Effect of exercise on epinephrine turnover in trained and untrained male subjects. Journal of Applied Physiology, 59(4), 1061-1067. https://doi.org/10.1152/jappl.1985.59.4.1061

Kjær, M., Farrell, P. A., Christensen, N. J., \& Galbo, H. (1986). Increased epinephrine response and inaccurate glucoregulation in exercising athletes. Journal of Applied Physiology, 61(5), 
1693-1700.

Kjær, M., \& Galbo, H. (1988). Effect of physical training on the capacity to secrete epinephrine. Journal of Applied Physiology, 64(1), 11-16. https://doi.org/10.1152/jappl.1988.64.1.11

Kjær, M., Mikines, K. J., Linstow, M. V., Nicolaisen, T., \& Galbo, H. (1992). Effect of 5 wk of detraining on epinephrine response to insulin-induced hypoglycemia in athletes. Journal of Applied Physiology, 72(3), 1201-1204. https://doi.org/10.1152/jappl.1992.72.3.1201

Kjær, M., Secher, N. H., \& Galbo, H. (1987). Physical stress and catecholamine release. Topics in Catalysis, 1(2), 279-298. https://doi.org/10.1016/S0950-351X(87)80064-2

Knuth, C., Peppler, W., Townsend, L., Miotto, P., Gudiksen, A., \& Wright, D. (2018). Prior exercise training improves cold tolerance independent of indices associated with nonshivering thermogenesis. Journal of Physiology, 596(18), 4375-4391.

Koh, H.-J., Hirshman, M. F., He, H., Li, Y., Manabe, Y., Balschi, J. A., \& Goodyear, L. J. (2007). Adrenaline is a critical mediator of acute exercise-induced AMP-activated protein kinase activation in adipocytes. Biochemical Journal, 403(3), 473-481. https://doi.org/10.1042/bj20061479

Kolnes, A. J., Birk, J. B., Eilertsen, E., Stuenæs, J. T., Wojtaszewski, J. F. P., \& Jensen, J. (2015). Epinephrine-stimulated glycogen breakdown activates glycogen synthase and increases insulin-stimulated glucose uptake in epitrochlearis muscles. American Journal of Physiology - Endocrinology And Metabolism, 308(3), E231-E240. https://doi.org/10.1152/ajpendo.00282.2014

Kubota, N., Kubota, T., Kajiwara, E., Iwamura, T., Kumagai, H., Watanabe, T., Inoue, M., Takamoto, I., Sasako, T., Kumagai, K., Kohjima, M., Nakamuta, M., Moroi, M., Sugi, K., Noda, T., Terauchi, Y., Ueki, K., \& Kadowaki, T. (2016). Differential hepatic distribution of insulin receptor substrates causes selective insulin resistance in diabetes and obesity. Nature Communications, 7, 1-16. https://doi.org/10.1038/ncomms 12977

Labrosse, E. H., Mann, J. A. Y. D., \& Kety, S. S. (1961). The physiological and psychological effects of intravenously administered epinephrine, and its metabolism, in normal and schizophrenic men: III. Journal of Psychiatric Research, 1(22), 68-75.

Lacour, J. R., Pequignot, J. M., Geyssant, A., Coudert, J., \& Peyrin, L. (1982). [Effect of training on plasma levels of catecholamines on the course of submaximal exercise]. Journal de Physiologie, 78(9), 838-842. http://europepmc.org/abstract/MED/7187770

Lam, V., \& Bär, H. P. (1976). Adrenaline-induced desensitization of liver adenylate cyclase. Biochemical Pharmacology, 25(18), 2103-2104. https://doi.org/10.1016/00062952(76)90439-1

Leosco, D., Parisi, V., Femminella, G. D., Formisano, R., Petraglia, L., Allocca, E., \& Bonaduce, 
D. (2013). Effects of exercise training on cardiovascular adrenergic system. Frontiers in Physiology, 4(November), 1-7. https://doi.org/10.3389/fphys.2013.00348

Leosco, D., Rengo, G., Iaccarino, G., Filippelli, A., Lymperopoulos, A., Zincarelli, C., Fortunato, F., Golino, L., Marchese, M., Esposito, G., Rapacciuolo, A., Rinaldi, B., Ferrara, N., Koch, W. J., \& Rengo, F. (2007). Exercise training and $\beta$-blocker treatment ameliorate age-dependent impairment of $\beta$-adrenergic receptor signaling and enhance cardiac responsiveness to adrenergic stimulation. American Journal of Physiology - Heart and Circulatory Physiology, 293(3), 1596-1603. https://doi.org/10.1152/ajpheart.00308.2007

Leosco, D., Rengo, G., Iaccarino, G., Golino, L., Marchese, M., Fortunato, F., Zincarelli, C., Sanzari, E., Ciccarelli, M., Galasso, G., Altobelli, G. G., Conti, V., Matrone, G., Cimini, V., Ferrara, N., Filippelli, A., Koch, W. J., \& Rengo, F. (2008). Exercise promotes angiogenesis and improves $\beta$-adrenergic receptor signalling in the post-ischaemic failing rat heart. Cardiovascular Research, 78(2), 385-394. https://doi.org/10.1093/cvr/cvm109

Liang, Q., Donthi, R. V., Kralik, P. M., \& Epstein, P. N. (2002). Elevated hexokinase increases cardiac glycolysis in transgenic mice. Cardiovascular Research, 53(2), 423-430. https://doi.org/10.1016/S0008-6363(01)00495-3

Livak, K. J., \& Schmittgen, T. D. (2001). Analysis of relative gene expression data using realtime quantitative PCR and the 2- $\Delta \Delta \mathrm{CT}$ method. Methods, 25(4), 402-408. https://doi.org/10.1006/meth.2001.1262

Loon, L. J. C. Van, Greenhaff, P. L., Saris, W. H. M., \& Wagenmakers, A. J. M. (2001). The effects of increasing exercise intensity on muscle fuel utilisation in humans. Journal of Physiology, 536(1), 295-304. https://doi.org/10.1111/J.1469-7793.2001.00295.X

Luttrell, L. M., \& Lefkowitz, R. J. (2002). The role of $\beta$ - arrestins in the termination and transduction of G-protein-coupled receptor signals. Journal of Cell Science, 115(3).

MacPherson, R. E. K., Castellani, L., Beaudoin, M.-S., \& Wright, D. C. (2014). Evidence for fatty acids mediating CL 316,243-induced reductions in blood glucose in mice. American Journal of Physiology-Endocrinology and Metabolism, 307(7), E563-E570. https://doi.org/10.1152/ajpendo.00287.2014

Manabe, Y., Gollisch, K. S. C., Holton, L., Kim, Y. B., Brandauer, J., Fujii, N. L., Hirshman, M. F., \& Goodyear, L. J. (2013). Exercise training-induced adaptations associated with increases in skeletal muscle glycogen content. FEBS Journal, 280(3), 916-926. https://doi.org/10.1111/febs.12085

Marley, P. D., \& Livett, B. G. (1987). Differences between the mechanisms of adrenaline and noradrenaline secretion from isolated, bovine, adrenal chromaffin cells. Neuroscience Letters. https://doi.org/10.1016/0304-3940(87)90611-2

Mazzeo, R. S., Podolin, D. A., \& Henry, V. (1995). Effects of age and endurance training on $\beta$ - 
adrenergic receptor characteristics in Fischer 344 rats. Mechanisms of Ageing and Development, 84(2), 157-169. https://doi.org/10.1016/0047-6374(95)01643-0

McGuinness, O. P., Shau, V., Benson, E. M., Lewis, M., Snowden, R. T., Greene, J. E., Neal, D. W., \& Cherrington, A. D. (1997). Role of epinephrine and norepinephrine in the metabolic response to stress hormone infusion in the conscious dog. American Journal of Physiology Endocrinology and Metabolism, 273(4 36-4), 674-681. https://doi.org/10.1152/ajpendo.1997.273.4.e674

McKie, G. L., Medak, K. D., Knuth, C. M., Shamshoum, H., Townsend, L. K., Peppler, W. T., \& Wright, D. C. (2019). Housing temperature affects the acute and chronic metabolic adaptations to exercise in mice. The Journal of Physiology, 0, 1-20. https://doi.org/10.1113/JP278221

Mendenhall, L. A., Swanson, S. C., Habash, D. L., Coggan, R., Lisa, A., Swanson, C., \& Coggan, R. (1994). Ten days of exercise training reduces glucose production and utilization during moderate-intensity exercise. Am J Physiol Endocrinol Metab, 266.

Molinoff, P. B. (1984). Alpha- and beta-adrenergic receptor subtypes properties, distribution and regulation. Drugs, 28(2), 1-15.

Moraska, A., Deak, T., Spencer, R. L., Roth, D., \& Fleshner, M. (2000). Treadmill running produces both positive and negative physiological adaptations in Sprague-Dawley rats. In American Journal of Physiology - Regulatory Integrative and Comparative Physiology (Vol. 279, Issues 4 48-4). https://doi.org/10.1152/ajpregu.2000.279.4.r1321

Morrison, S. F., \& Cao, W. H. (2000). Different adrenal sympathetic preganglionic neurons regulate epinephrine and norepinephrine secretion. American Journal of Physiology Regulatory Integrative and Comparative Physiology, 279(5 48-5), 1763-1775. https://doi.org/10.1152/ajpregu.2000.279.5.r1763

Mowers, J., Uhm, M., Reilly, S. M., Simon, J., Leto, D., Chiang, S. H., Chang, L., \& Saltiel, A. R. (2013). Inflammation produces catecholamine resistance in obesity via activation of PDE3B by the protein kinases IKK $\varepsilon$ and TBK1. ELife, 2013(2). https://doi.org/10.7554/eLife.01119

Murray, B., \& Rosenbloom, C. (2018). Fundamentals of glycogen metabolism for coaches and athletes. Nutrition Reviews, 76(4), 243-259. https://doi.org/10.1093/NUTRIT/NUY001

Musch, T. I., Haidet, G. C., Ordway, G. A., Longhurst, J. C., \& Mitchell, J. H. (1987). Training effects on regional blood flow response to maximal exercise in foxhounds. Journal of Applied Physiology, 62(4), 1724-1732. https://doi.org/10.1152/jappl.1987.62.4.1724

Nantel, F., Bouvier, M., Strosberg, A. D., \& Marullo, S. (1995). Functional effects of long-term activation on human beta 2- and beta 3-adrenoceptor signalling. British Journal of Pharmacology, 114(5), 1045-1051./pmc/articles/PMC1510334/?report=abstract 
Niiya, T., Osawa, H., Onuma, H., Suzuki, Y., Taira, M., Yamada, K., \& Makino, H. (2001). Activation of mouse phosphodiesterase 3B gene promoter by adipocyte differentiation in 3T3-L1 cells. FEBS Letters, 505(1), 136-140. https://doi.org/10.1016/S00145793(01)02807-1

Ochs, R. S., \& Lardy, H. A. (1983). Catecholamine stimulation of hepatic gluconeogenesis at the site between pyruvate and phosphoenolpyruvate. Journal of Biological Chemistry, 258(16), 9956-9962.

Omori, K., \& Kotera, J. (2007). Overview of PDEs and their regulation. Circulation Research, 100(3), 309-327. https://doi.org/10.1161/01.RES.0000256354.95791.f1

Peppler, W. T., Townsend, L. K., Knuth, C. M., Foster, M. T., \& Wright, D. C. (2018). Subcutaneous inguinal white adipose tissue is responsive to, but dispensable for, the metabolic health benefits of exercise. American Journal of Physiology - Endocrinology and Metabolism, 314(1), E66-E77. https://doi.org/10.1152/ajpendo.00226.2017

Perez, D. M. (2005). The Adrenergic Receptors. In Humana Press. https://doi.org/10.1017/CBO9781107415324.004

Peterhoff, M., Sieg, A., Brede, M., Chao, C. M., Hein, L., \& Ullrich, S. (2003). Inhibition of insulin secretion via distinct signaling pathways in $\alpha 2$-adrenoceptor knockout mice. European Journal of Endocrinology, 149(4), 343-350. https://doi.org/10.1530/eje.0.1490343

Peters, S. J., Dyck, D. J., Bonen, A., \& Spriet, L. L. (1998). Effects of epinephrine on lipid metabolism in resting skeletal muscle. American Journal of Physiology - Endocrinology and Metabolism, 275(2 38-2), 300-309. https://doi.org/10.1152/ajpendo.1998.275.2.e300

Petersen, K. F., Laurent, D., Rothman, D. L., Cline, G. W., \& Shulman, G. I. (1998). Mechanism by which glucose and insulin inhibit net hepatic glycogenolysis in humans. Journal of Clinical Investigation, 101(6), 1203-1209. https://doi.org/10.1172/JCI579

Phillips, S. M., Tarnopolsky, M., \& Heigenhauser, G. (1996). Effects of training duration on substrate turnover and oxidation during exercise. Journal of Applied Physiology, November. https://doi.org/10.1152/jappl.1996.81.5.2182

Philpot, F. J., \& Cantoni, G. (1941). Adrenaline Destruction in the Liver and Methylene Blue. Journal of Pharmacology and Experimental Therapeutics, 138(535).

Pierce, K. L., Premont, R. T., \& Lefkowitz, R. J. (2002). Seven-transmembrane receptors. Nature Reviews Molecular Cell Biology, 3(9), 639-650. https://doi.org/10.1038/nrm908

Plourde, G., Rousseau-Migneron, S., \& Nadeau, A. (1992). Physical training increases $\beta$ adrenoceptor density and adenylate cyclase activity in high-oxidative skeletal muscle of diabetic rats. Metabolism, 41(12), 1331-1335. https://doi.org/10.1016/0026- 
0495(92)90104-I

Plourde, G., Rousseau-Migneron, S., \& Nadeau, A. (1993). Effect of endurance training on betaadrenergic system in three different skeletal muscles. Journal of Applied Physiology, 74(4), 1641-1646. https://doi.org/10.1152/jappl.1993.74.4.1641

Podolin, D. A., Gleeson, T. T., \& Mazzeo, R. S. (1996). Hormonal regulation of hepatic gluconeogenesis: influence of age and training. American Journal of Physiology, 270(2 Pt 2), R365-R372.

Puigserver, P., Rhee, J., Donovan, J., Kitamura, Y., Altomonte, J., \& Dong, H. (2003). Insulinregulated hepatic gluconeogenesis through FOXO1 - PGC-1 a interaction. Nature, 423(May). https://doi.org/10.1038/nature01606.1.

Reynisdottir, S., Wahrenberg, H., Carlström, K., Rössner, S., \& Arner, P. (1994). Catecholamine resistance in fat cells of women with upper-body obesity due to decreased expression of beta2-adrenoceptors. Diabetologia, 37(4), 428-435. https://doi.org/10.1007/BF00408482

Richter, E. A., Mikines, K. J., Galbo, H., \& Kiens, B. (1926). The effect of exercise on insulin action in diabetes. British Medical Journal, 1(3406), 648-650.

https://doi.org/10.1136/bmj.1.3406.648

Riviere, D., Crampes, F., Beauville, M., \& Garrigues, M. (1989). Lipolytic response of fat cells to catecholamines in sedentary and exercise-trained women. Journal of Applied Physiology, 66(1), 330-335. https://doi.org/10.1152/jappl.1989.66.1.330

Robison, L. S., Popescu, D. L., Anderson, M. E., Beigelman, S. I., Fitzgerald, S. M., Kuzmina, A. E., Lituma, D. A., Subzwari, S., Michaelos, M., Anderson, B. J., Van Nostrand, W. E., \& Robinson, J. K. (2018). The effects of volume versus intensity of long-term voluntary exercise on physiology and behavior in C57/B16 mice. Physiology and Behavior, 194, 218 232. https://doi.org/10.1016/j.physbeh.2018.06.002

Rockman, H. A., Chien, K. R., Choi, D. J. U., Iaccarino, G., Hunter, J. J., John Ross, J. R., Lefkowitz, R. J., \& Koch, W. J. (1998). Expression of a $\beta$-adrenergic receptor kinase 1 inhibitor prevents the development of myocardial failure in gene-targeted mice. Proceedings of the National Academy of Sciences of the United States of America, 95(12), 7000-7005. https://doi.org/10.1073/pnas.95.12.7000

Romijn, J. A., Coyle, E. F., Sidossis, L. S., Gastaldelli, A., Horowitz, J. F., Endert, E., \& Wolfe, R. R. (1993). Regulation of endogenous fat and carbohydrate metabolism in relation to exercise intensity and duration. American Journal of Physiology - Endocrinology and Metabolism, 265(3 28-3), 380-391. https://doi.org/10.1152/ajpendo.1993.265.3.e380

Ross, B. D., Hems, R., \& Krebs, H. A. (1967). The rate of gluconeogenesis from various precursors in the perfused rat liver. Biochemical Journal, 102(3), 942-951. https://doi.org/10.1042/bj1020942 
Rousseau-Migneron, S., LeBlanc, J., Depocas, F., \& Lafrance, L. (1975). Effects of adrenaline on the dynamics of carbohydrate metabolism in rats treated chronically with adrenaline. Canadian Journal of Physiology and Pharmacology, 53(1), 124-128. https://doi.org/10.1139/y75-017

Rousseau-Migneron, S., Nadeau, A., Tancrede, Gi., \& Szots, F. (1980). Adaptation to the hyperglycemic effect of adrenaline: Comparison of pre-treatment with 1 and $\mathrm{dl}$ forms of adrenaline and studies of glucagon secretion. Gen. Pharmac, 11, 225-229.

Rui, L. (2014). Energy Metabolism in the Liver. Compr Phsyiol, 4(1), 177-197. https://doi.org/10.1002/cphy.c130024.Energy

Sacca, L., Vigorito, C., \& Cicala, M. (1983). Role of gluconeogenesis in epinephrine-stimulated hepatic glucose production in humans. American Journal of Physiology - Endocrinology and Metabolism, 8(3). https://doi.org/10.1152/ajpendo.1983.245.3.e294

Sacca, Luigi, Morrone, G., Cicala, M., Corso, G., \& Ungaro, B. (1980). Influence of Epinephrine, Norepinephrine, and Isoproterenol on Glucose Homeostasis in Normal Man. 50(4), 680-684.

Saltiel, A. R., \& Kahn, C. R. (2001). Insulin signalling and the regulation of glucose and lipid metabolism. Nature, 414(December), 1-8. http://www.medgen.med.umich.edu/labs/saltiel/.

Saltin, B., Nazar, K., Costill, D. L., Stein, E., Jansson, E., Essén, B., \& Gollnick, P. D. (1976). The Nature of the Training Response; Peripheral and Central Adaptations to One-Legged Exercise. Acta Physiologica Scandinavica, 96(3), 289-305. https://doi.org/10.1111/j.17481716.1976.tb10200.x

Schmelck, P. H., \& Hanoune, J. (1980). The hepatic adrenergic receptors. Molecular and Cellular Biochemistry, 33(1-2), 35-48. https://doi.org/10.1007/BF00224570

Seyer, P., Vallois, D., Poitry-Yamate, C., Schütz, F., Metref, S., Tarussio, D., Maechler, P., Staels, B., Lanz, B., Grueter, R., Decaris, J., Turner, S., Da Costa, A., Preitner, F., Minehira, K., Foretz, M., \& Thorens, B. (2013). Hepatic glucose sensing is required to preserve $\beta$ cell glucose competence. Journal of Clinical Investigation, 123(4), 1662-1676. https://doi.org/10.1172/JCI65538

Sherwin, R., \& Sacca, L. (1984). Effect of epinephrine on glucose metabolism in humans: contribution of the liver. American Journal Physiology, 247(2 Pt 1), E157-65. https://doi.org/10.1109/etfa.2008.4638447

Silverberg, A. B., Shah, S. D., Haymond, M. W., \& Cryer, P. E. (1978). Norepinephrine: Hormone and neurotransmitter in man. American Journal of Physiology Endocrinology Metabolism and Gastrointestinal Physiology, 3(3). https://doi.org/10.1152/ajpendo.1978.234.3.e252 
Smith, P. K., Krohn, R. I., Hermanson, G. T., Mallia, A. K., Gartner, F. H., Provenzano, M. D., Fujimoto, E. K., Goeke, N. M., Olson, B. J., \& Klenk, D. C. (1985). Measurement of protein using bicinchoninic acid. Analytical Biochemistry, 150(1), 76-85.

https://doi.org/10.1016/0003-2697(85)90442-7

Snook, L. A., Trottier, S. K., Worndl, E. A., Bombardier, E., Tupling, A. R., \& MacPherson, R. E. K. (2017). Prior Endurance Training Enhances Beta-Adrenergic Signaling in Epidydimal Adipose from Mice Fed a High-Fat Diet. Obesity, 25(10), 1699-1706. https://doi.org/10.1002/oby.21933

Sokal, J. E., \& Sarcione, E. J. (1959). Effect of epinephrine on glycogen stores. American Journal of Physiology-Legacy Content, 196(6), 1253-1257. https://doi.org/10.1152/ajplegacy.1959.196.6.1253

Spandidos, A., Wang, X., Wang, H., \& Seed, B. (2009). PrimerBank: A resource of human and mouse PCR primer pairs for gene expression detection and quantification. Nucleic Acids Research, 38(SUPPL.1), 792-799. https://doi.org/10.1093/nar/gkp1005

Stanford, K. I., Middelbeek, R. J. W., \& Goodyear, L. J. (2015). Exercise effects on white adipose tissue: Beiging and metabolic adaptations. Diabetes, 64(7), 2361-2368. https://doi.org/10.2337/db15-0227

Steenberg, D. E., Jørgensen, N. B., Birk, J. B., Sjøberg, K. A., Kiens, B., Richter, E. A., \& Wojtaszewski, J. F. P. (2019). Exercise training reduces the insulin-sensitizing effect of a single bout of exercise in human skeletal muscle. Journal of Physiology, 597(1), 89-103. https://doi.org/10.1113/JP276735

Steinberg, G. R., \& Carling, D. (2019). AMP-activated protein kinase: the current landscape for drug development. Nature Reviews Drug Discovery. https://doi.org/10.1038/s41573-0190019-2

Steinberg, G. R., O’Neill, H. M., Dzamko, N. L., Galic, S., Naim, T., Koopman, R., Jørgensen, S. B., Honeyman, J., Hewitt, K., Chen, Z. P., Schertzer, J. D., Scott, J. W., Koentgen, F., Lynch, G. S., Watt, M. J., Van Denderen, B. J. W., Campbell, D. J., \& Kemp, B. E. (2010). Whole body deletion of AMP-activated protein kinase $\beta 2$ reduces muscle AMPK activity and exercise capacity. Journal of Biological Chemistry, 285(48), 37198-37209. https://doi.org/10.1074/jbc.M110.102434

Strålfors, P., Björgell, P., \& Belfrage, P. (1984). Hormonal regulation of hormone-sensitive lipase in intact adipocytes: identification of phosphorylated sites and effects on the phosphorylation by lipolytic hormones and insulin. Proceedings of the National Academy of Sciences of the United States of America, 81(11), 3317-3321. https://doi.org/10.1073/pnas.81.11.3317

Sumida, K. D., Arimoto, S. M., Catanzaro, M. J., \& Frisch, F. (2003). Effect of age and endurance training on the capacity for epinephrine-stimulated gluconeogenesis in rat 
hepatocytes. Journal of Applied Physiology, 95(2), 712-719.

https://doi.org/10.1152/japplphysiol.01125.2002

Summermatter, S., Baum, O., Santos, G., Hoppeler, H., \& Handschin, C. (2010). Peroxisome proliferator-activated receptor $\gamma$ coactivator $1 \alpha(\mathrm{PGC}-1 \alpha)$ promotes skeletal muscle lipid refueling in vivo by activating de novo lipogenesis and the pentose phosphate pathway. Journal of Biological Chemistry, 285(43), 32793-32800. https://doi.org/10.1074/jbc.M110.145995

Svensson, M., Rosvall, P., Boza-Serrano, A., Andersson, E., Lexell, J., \& Deierborg, T. (2016). Forced treadmill exercise can induce stress and increase neuronal damage in a mouse model of global cerebral ischemia. Neurobiology of Stress, 5, 8-18. https://doi.org/10.1016/j.ynstr.2016.09.002

Sylow, L., \& Richter, E. A. (2019). Current advances in our understanding of exercise as medicine in metabolic disease. Current Opinion in Physiology, 12, 12-19. https://doi.org/10.1016/j.cophys.2019.04.008

Thirone, A. C. P., Huang, C., \& Klip, A. (2006). Tissue-specific roles of IRS proteins in insulin signaling and glucose transport. Trends in Endocrinology and Metabolism, 17(2), 70-76. https://doi.org/10.1016/j.tem.2006.01.005

Tian, W. N., Duzic, E., Lanier, S. M., \& Deth, R. C. (1994). Determinants of $\alpha 2$-adrenergic receptor activation of $\mathrm{G}$ proteins: Evidence for a precoupled receptor/G protein state. Molecular Pharmacology, 45(3), 524-531. https://www.researchgate.net/publication/15052993

Tiraby, C., Tavernier, G., Lefort, C., Larrouy, D., Bouillaud, F., Ricquier, D., \& Langin, D. (2003). Acquirement of brown fat cell features by human white adipocytes. Journal of Biological Chemistry, 278(35), 33370-33376. https://doi.org/10.1074/jbc.M305235200

Toti, L., Bartalucci, A., Ferrucci, M., Fulceri, F., Lazzeri, G., Lenzi, P., Soldani, P., Gobbi, P., La Torre, A., \& Gesi, M. (2013). High-intensity exercise training induces morphological and biochemical changes in skeletal muscles. Biology of Sport, 30(4), 301-309. https://doi.org/10.5604/20831862.1077557

Townsend, L. K., Medak, K. D., Knuth, C. M., Peppler, W. T., Charron, M. J., \& Wright, D. C. (2019). Loss of glucagon signaling alters white adipose tissue browning. The FASEB Journal, 33. https://doi.org/10.1096/fj.201802048RR

Valet, P., Grujic, D., Wade, J., Ito, M., Zingarettii, M. C., Soloveva, V., Ross, S. R., Graves, R. A., Cinti, S., Lafontan, M., \& Lowell, B. B. (2000). Expression of human $\alpha 2$-adrenergic receptors in adipose tissue of $\beta$-adrenergic receptor-deficient mice promotes diet-induced obesity. Journal of Biological Chemistry, 275(44), 34797-34802. https://doi.org/10.1074/jbc.M005210200 
van Loon, L. J. C., Jeukendrup, A. E., Saris, W. H. M., \& Wagenmakers, A. J. M. (1999). Effect of training status on fuel selection during submaximal exercise with glucose ingestion.

Journal of Applied Physiology, 87(4), 1413-1420.

https://doi.org/10.1152/jappl.1999.87.4.1413

Volianitis, S., Yoshiga, C. C., Nissen, P., \& Secher, N. H. (2004). Effect of fitness on arm vascular and metabolic responses to upper body exercise. American Journal of Physiology Heart and Circulatory Physiology, 286(5 55-5), 1736-1741.

https://doi.org/10.1152/ajpheart.01001.2003

Wahlang, B., McClain, C., Barve, S., \& Gobejishvili, L. (2018). Role of cAMP and phosphodiesterase signaling in liver health and disease. Cellular Signalling. https://doi.org/10.1016/j.cellsig.2018.06.005

Wahrenberg, H., Bolinder, J., \& Arner, P. (1991). Adrenergic regulation of lipolysis in human fat cells during exercise. European Journal of Clinical Investigation, 21(5), 534-541. https://doi.org/10.1111/j.1365-2362.1991.tb01406.x

Wahrenberg, H., Engfeldt, P., Bolinder, J., \& Arner, P. (1987). Acute adaptation in adrenergic control of lipolysis during physical exercise in humans. American Journal of Physiology Endocrinology and Metabolism, 253(4), 383-390.

Wan, Z., Root-Mccaig, J., Castellani, L., Kemp, B. E., Steinberg, G. R., \& Wright, D. C. (2014). Evidence for the role of AMPK in regulating PGC-1 alpha expression and mitochondrial proteins in mouse epididymal adipose tissue. Obesity, 22(3), 730-738. https://doi.org/10.1002/oby.20605

Ward, M. M., Mefford, I. N., Parker, S., Chesney, M. A., Barr Taylor, C., Keegan, D. L., \& Barchas, J. D. (1983). Epinephrine and norepinephrine responses in continuously collected human plasma to a series of stressors. Psychosomatic Medicine, 45(6), 471-486. https://doi.org/10.1097/00006842-198312000-00002

Wasserman, D. (1995). Regulation of Glucose Fluxes During Exercise in the Postabsorptive State. Annual Review of Physiology, 57(1), 191-218. https://doi.org/10.1146/annurev.physiol.57.1.191

Wasserman, D. H., \& Cherrington, A. D. (1991). Hepatic fuel metabolism during muscular work: role and regulation. American Journal of Physiology-Endocrinology and Metabolism. https://doi.org/10.1152/ajpendo.1991.260.6.e811

Wasserman, D. H., Spalding, J. A., Lacy, D. B., Colburn, C. A., Goldstein, R. E., \& Cherrington, A. D. (1989). Glucagon is a primary controller of hepatic glycogenolysis and gluconeogenesis during muscular work. American Journal of Physiology - Endocrinology and Metabolism. https://doi.org/10.1152/ajpendo.1989.257.1.e108

Werle, E. O., Strobel, G., \& Weicker, H. (1990). Decrease in rat cardiac beta1- and beta2- 
adrenoceptors by training and endurance exercise. Life Sciences, 46, 9-17.

Williams, R. S., Caron, M. G., \& Daniel, K. (1984). Skeletal muscle $\beta$-adrenergic receptors: Variations due to fiber type and training. American Journal of Physiology - Endocrinology and Metabolism, 9(2). https://doi.org/10.1152/ajpendo.1984.246.2.e160

Winder, W. W., Hagberg, J. M., Hickson, R. C., Ehsani, A. A., \& McLane, J. A. (1978). Time course of sympathoadrenal adaptation to endurance exercise training in man. Journal of Applied Physiology Respiratory Environmental and Exercise Physiology, 45(3), 370-374. https://doi.org/10.1152/jappl.1978.45.3.370

Winder, W. W., Hickson, R. C., Hagberg, J. M., Ehsani, A. A., \& McLane, J. A. (1979). Training-induced changes in hormonal and metabolic responses to submaximal exercise. Journal of Applied Physiology Respiratory Environmental and Exercise Physiology, 46(4), 766-771.

Xie, W., Ye, Y., Feng, Y., Xu, T., Huang, S., Shen, J., \& Leng, Y. (2018). Linderane Suppresses Hepatic Gluconeogenesis by Inhibiting the cAMP/PKA/CREB Pathway Through Indirect Activation of PDE 3 via ERK/STAT3. Frontiers in Pharmacology, 9, 476. https://doi.org/10.3389/fphar.2018.00476

Zhang, Ying, Shumilina, E., Häring, H. U., Lang, F., \& Ullrich, S. (2009). Epinephrine-induced hyperpolarization of pancreatic islet cells is sensitive to PI3K-PDK1 signaling. FEBS Letters, 583(18), 3101-3106. https://doi.org/10.1016/j.febslet.2009.08.027

Zhang, Yong, Wan, J., Liu, S., Hua, T., \& Sun, Q. (2018). Exercise induced improvements in insulin sensitivity are concurrent with reduced NFE2 / miR-432-5p and increased FAM3A. Life Sciences, 207(May), 23-29. https://doi.org/10.1016/j.lfs.2018.05.040

Zoladz, J. A., Koziel, A., Woyda-Ploszczyca, A., Celichowski, J., \& Jarmuszkiewicz, W. (2016). Endurance training increases the efficiency of rat skeletal muscle mitochondria. Pflugers Archiv European Journal of Physiology, 468(10), 1709-1724. https://doi.org/10.1007/s00424-016-1867-9 